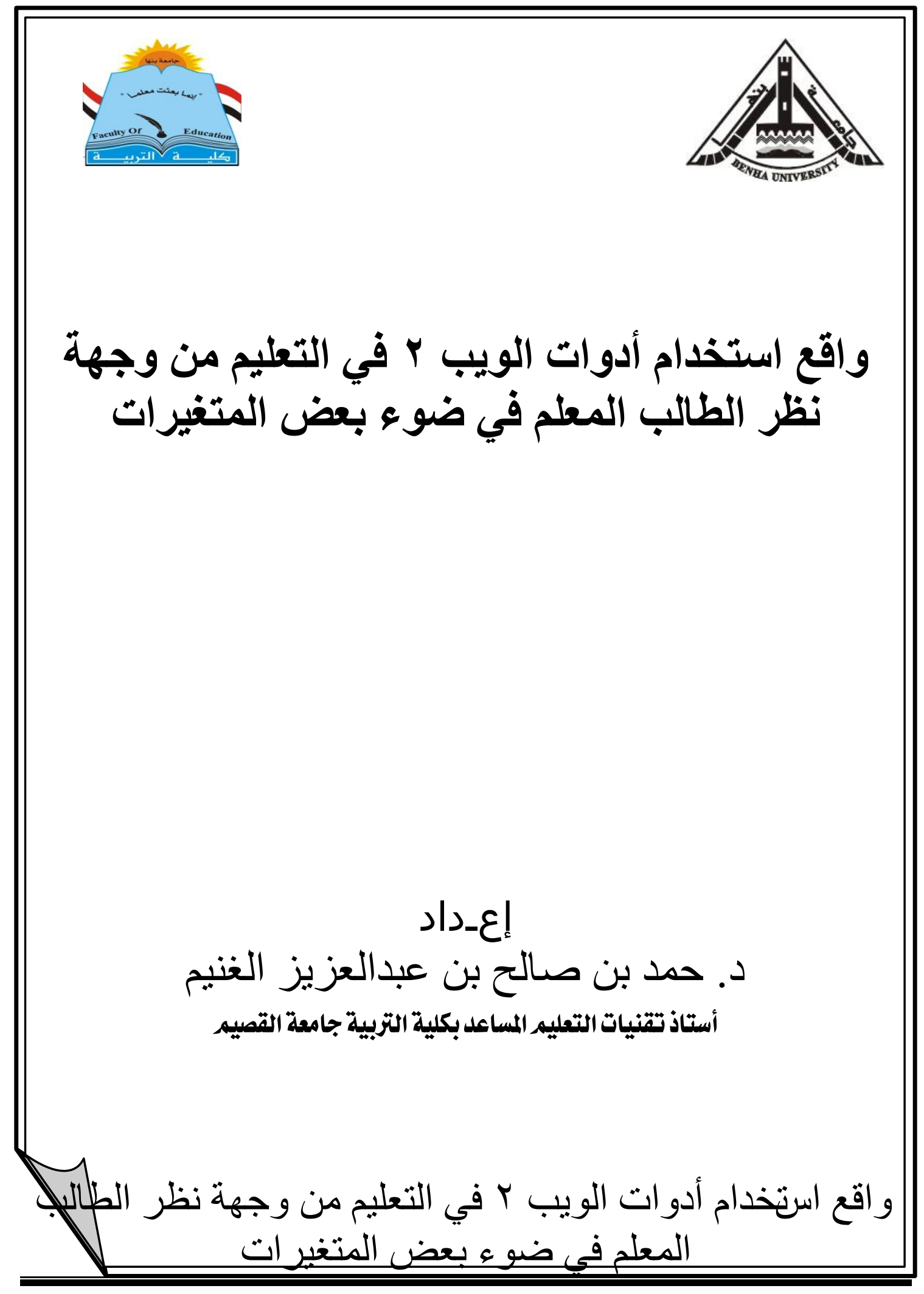




$$
\text { إع-داد }
$$

د. حمد بن صالح بن عبدالعزيز الغنيم

أستاذ تقنيات التعليم المساعد بكلية التربية جامعة القصيه

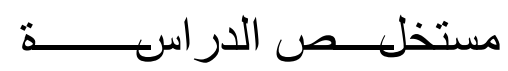

هدفت الدراسة إلى التعرف على واقع استخدام أدوات العيب 2.0 في العملية التعليمية

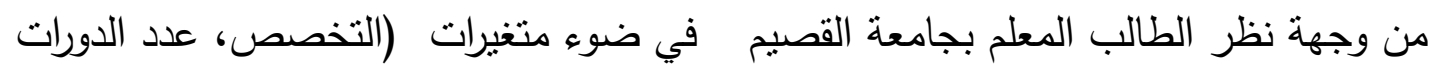

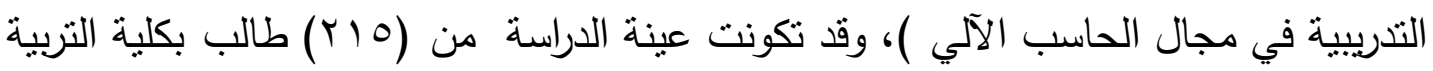

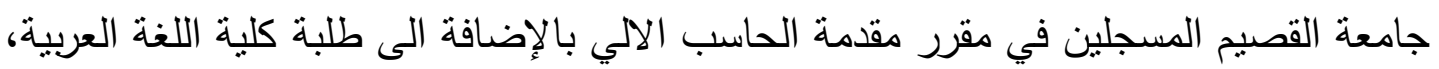

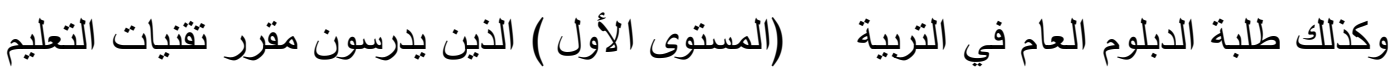

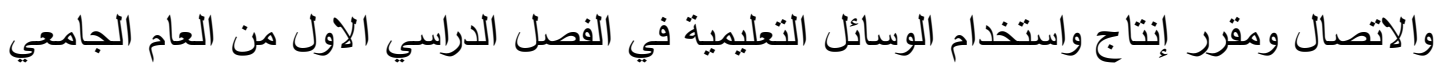

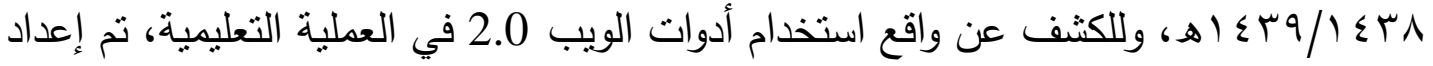
استبانة مكونة من (9) عبارة نوزعت على أربعة محاور الهتخدام محررات الويب التشاركية

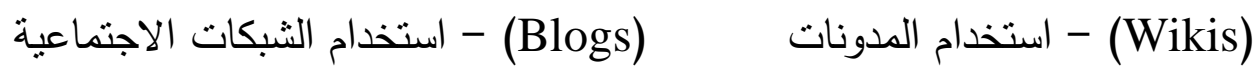

(Social Networks)

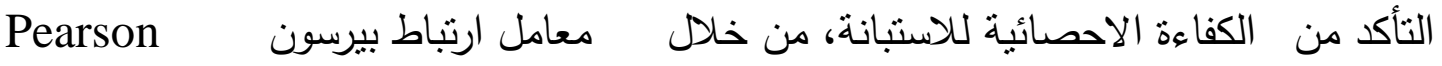

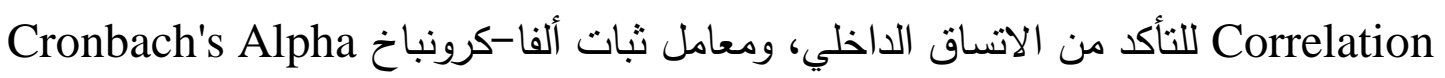

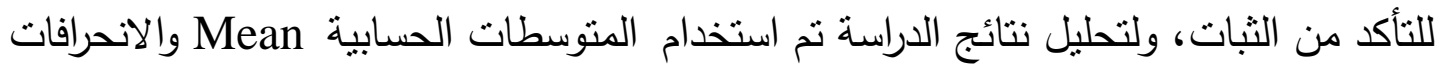
المعيارية Standard Deviations للتعرف على واقع ومعوقات استخدام أدوات الويب 2.0 في العملية التعليمية، كما تم استخدام تحليل التباين أحادي الاتجاه One Way ANOVA في ومعاد الكثف عن دلالة الفروق في استجابات الطلاب حول واقع ومعوقات استخدام أدوات الويب 2.0

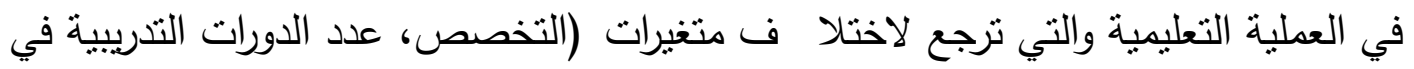

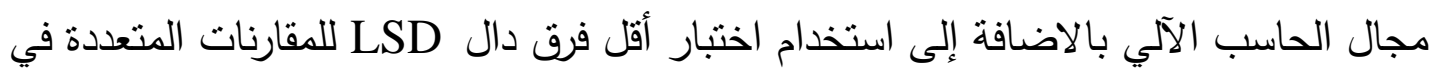
حالة دلالة تحليل التباين أحادي الاتجاه. وقد أظهرت نتائج الدراسة أن واقع استخدام أدوات الويب التهاه 2.0 في العملية التعليمية ككل

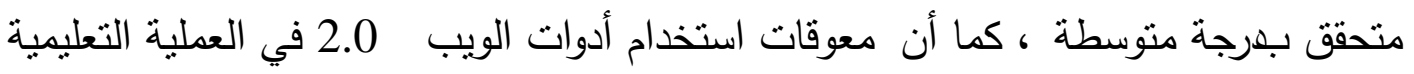
(المعوقات ككل) جاءت بدرجة متوسطة، كما كثفت الدراسة عن وجود فروق دالة احصائياً في 
و اقع استخدام أدوات الويبك في التعليممن وجهة نظر الطالب المعلد في ضوء بعض المتغير ات

استجابات الطلاب حول واقع استخدام الدحررات النتاركية، والددونات ترجع الى اختلاف

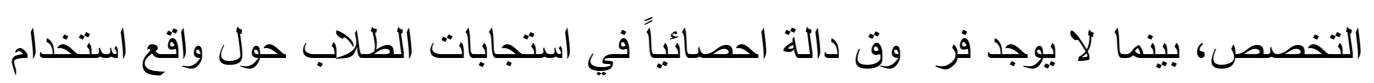

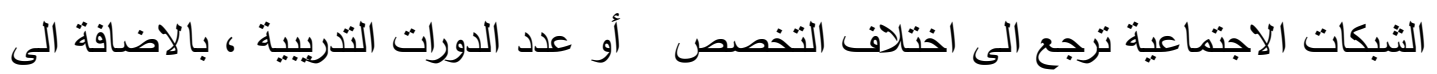

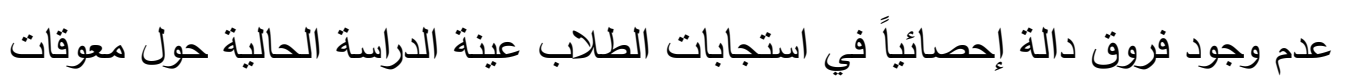

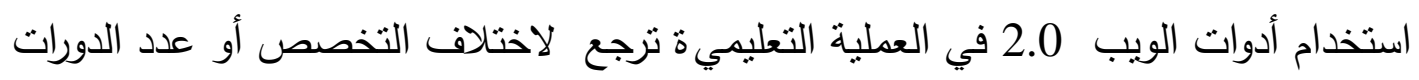
التدريبية في مجال الحاسب الالي. الكلمات الدالة: (الويب 2.0 ، أدوات الويب الإل 2.0). 
تصدرت شبكة الانترنت والويب كل اهتمامات مجتمع اليوم والذي يطلق عليه مجتمع

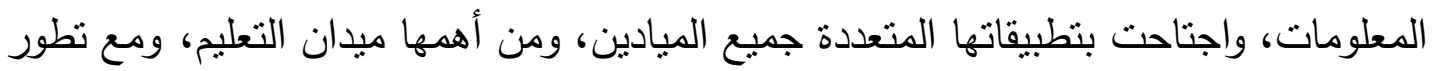
الويب وظهور أجيال جديدة، استحدثت أدوات ذات تطبيقات تثاركية انعكست على أدوار ومهام

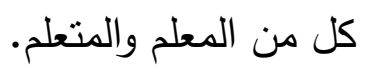
ويمثل الويب 2.0 نقلة نوعية غيرت من سلوك وطبيعة مستخدي الثنبكة الذين كانوا

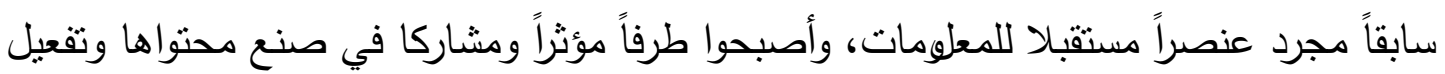
مضنمونها. حيث يشير (Nagy,Bigum,2007) أن الجيل الثاني للويب يمثل تغيير لبيئة الويب، فلم تعد بيئة قراءة فقط بل أصبحت بيئة قراءة وكتابة، مما يتيح الفرصة للطلاب لمشاركة

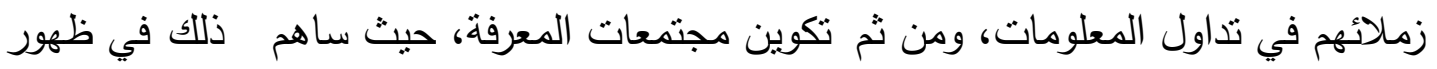

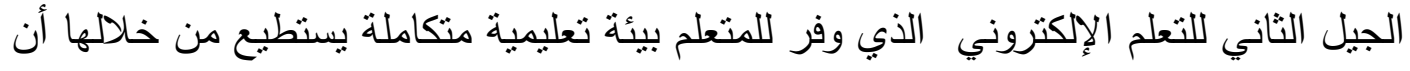
يتفاعل مع رفاقه في بناء المحتوى الالكتروني. وفي ذات السياق يرى (Downes, 2005) أن التطورات التي نتجت عن ظهور الجيل الثاني للويب، والتي انعكست على العملية التعليمية، أدت إلى:

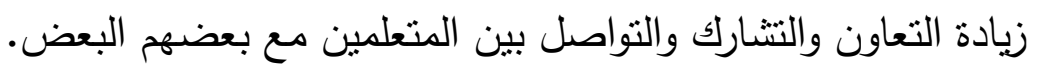

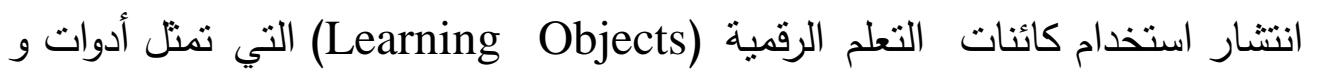
كقوالب لبناء ذللك المحتوي الالكتروني. ه تصميم بيئات التعلم الثخصية للخهلات التعليمية بحيث تتمركز حول المتعلم. زيادة استخدام الثبكات الاجتماعية على الإنترنت. هنح المتعلم حرية اختيار الوسائط المتعدد في المحتوي الالكتروني.

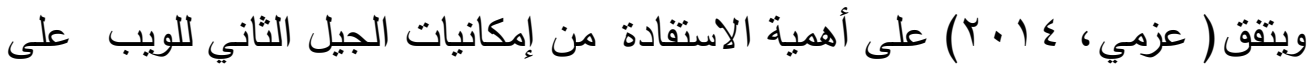

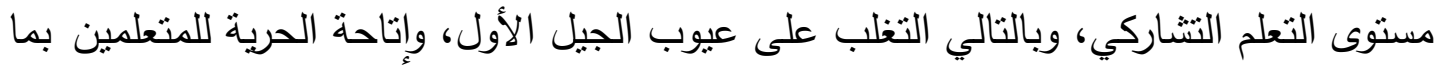

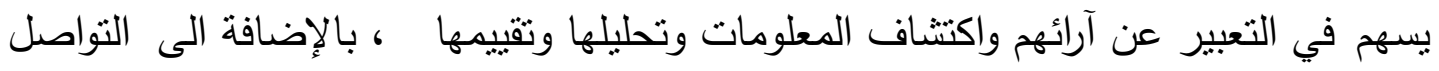
المتزامن وغير متزامن ، حيث يوفر الجيل الثاني للويب تطبيقات و أدوات مثل المنتديات الإلكترونية، وغرف المحادثة، وخاصية التعليق على مساهمة زميل ومحررات الويب النتاركية ، 


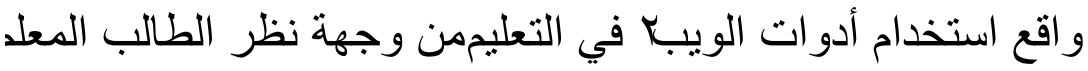
في ضوء بعض المن المتغير ات

وتتيح هذه الأدوات لكل متعلم إمكانية إضافة معلومة ، أو التعليق عليها ، مع إمكانية إضافة

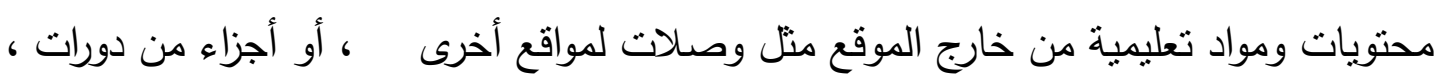

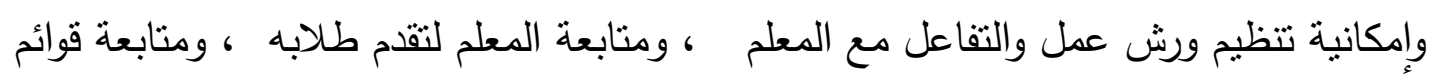
التقديرات من جانب المتعلم لتطوير أدائه، وهذه الخبرات التفاعلية تسهم في تحقيق نتائج تعليمية أكثر فائدة من التعلم التقليدي.

وفي ظل التغير المستمر والتطورات المتعاقبة لتكنولوجيا المعلومات، فلم يعد من

المكن للمتعلمين تجاهل مثل هذا التقام التكنولوجي ، والاستفادة منه وتوظيفه في العملية

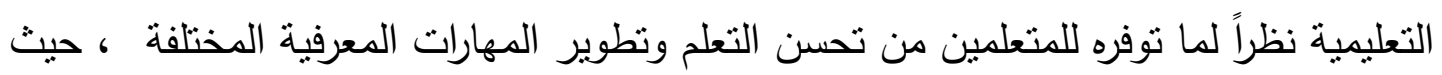

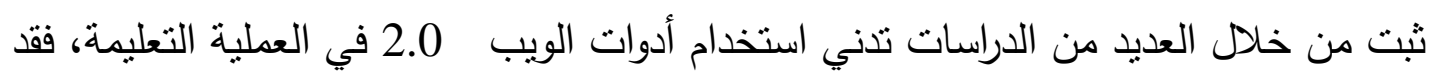

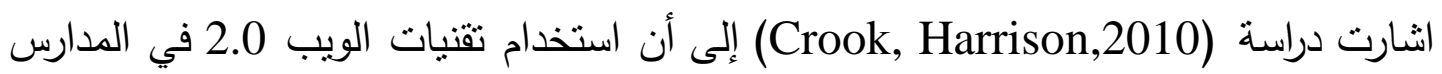

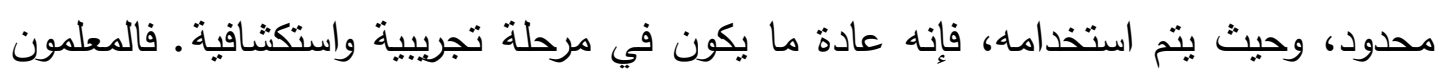

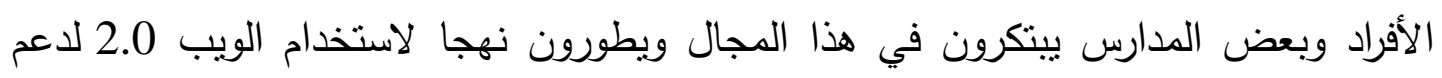

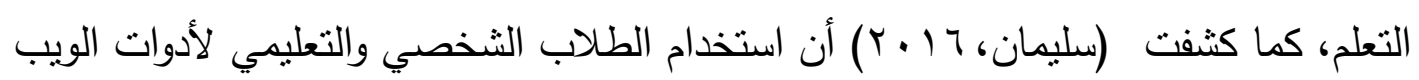

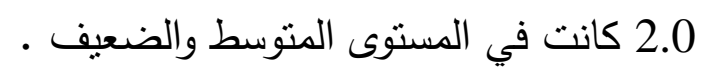

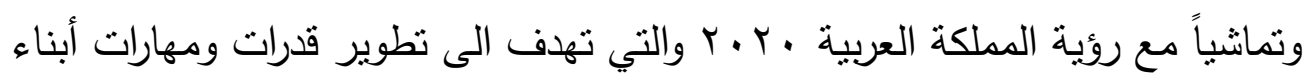

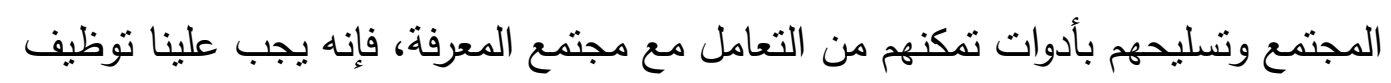

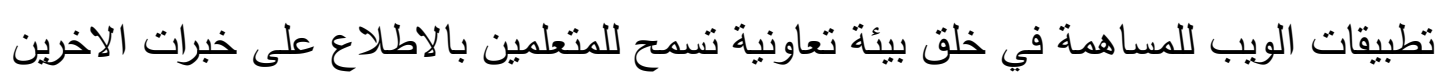

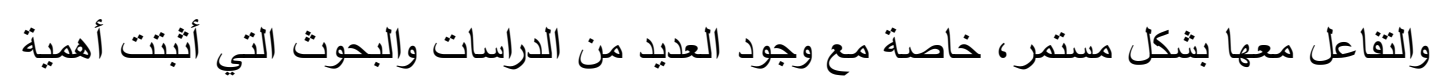

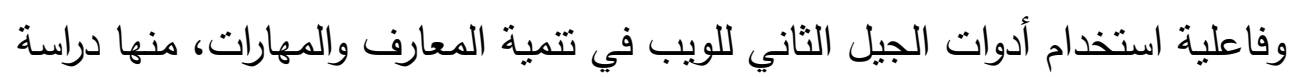

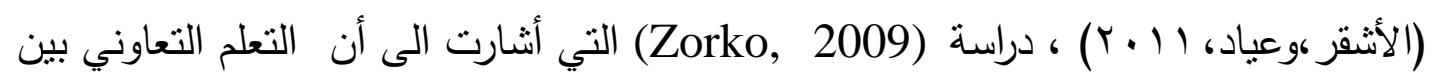

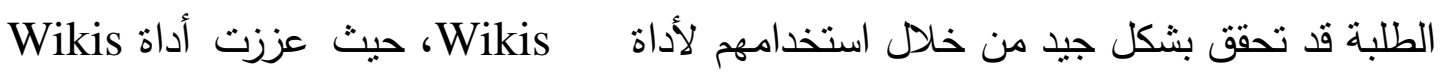

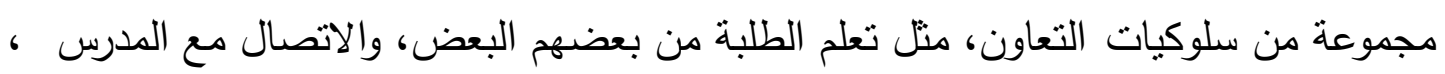

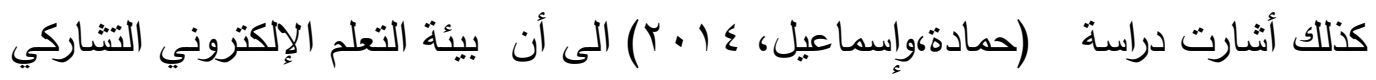

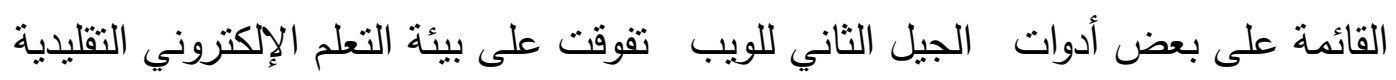

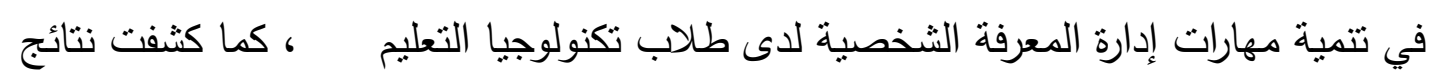

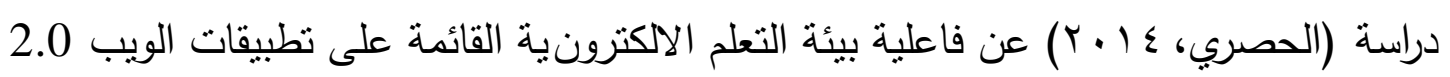




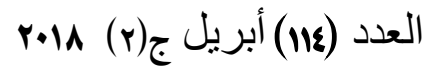

مجلة كلية التربية ببنها

في تتمية الجوانب المعرفية وبعض مهارات توظيفها لدى طلاب شعبة الدراسات الاجتماعية بكلية التربية .

تأسيساً على ما سبق واستتاداً على نتائج الدراسات السابقة، والتي اثبتت ضرورة نوظيف

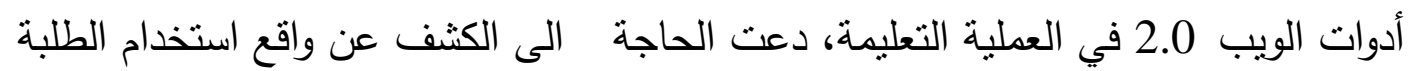
لأدوات الويب 2.0 في العطلية التعليمية، وتحديد أهم العقبات التي تحد من الاستخدام.

مشكلـة الدر اسـة وتساؤ لاتها:

انطلاقاً من توصيات العديد من المؤتمرات منل (المؤتمر العلمي الرابع عثر للجمعية

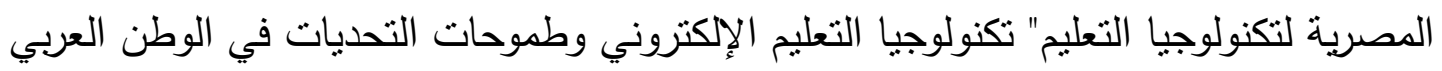

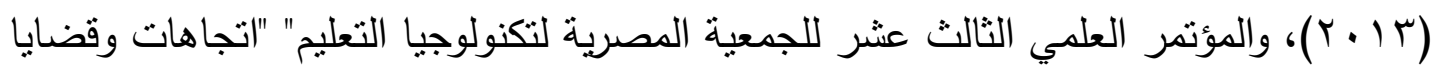

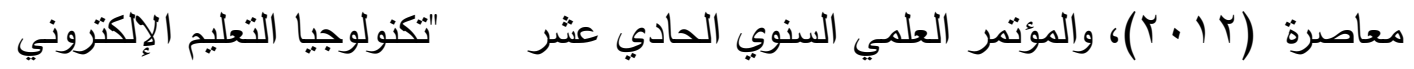

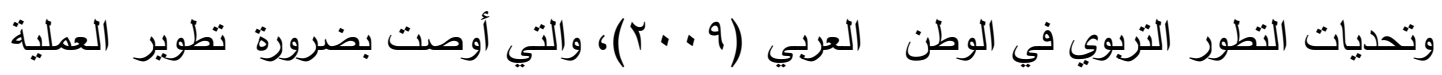

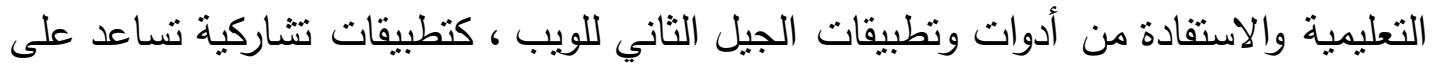
التعلم النشط النتاركي، مما يسهم في تطوير دور كل من المعلم والمتعلم. واستتاداً على نتائج الدراسات التي كثفت عن تدني استخدام الطلاب والمعلمين لأدوات

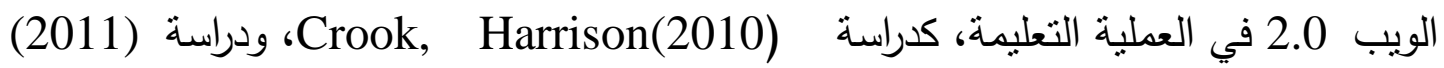

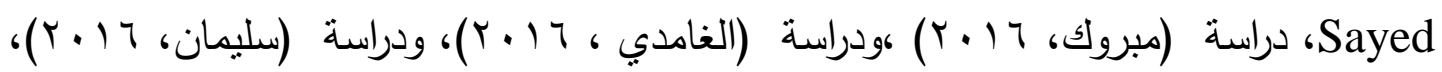

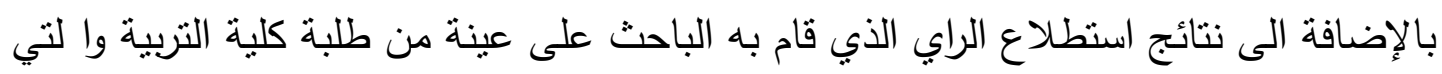

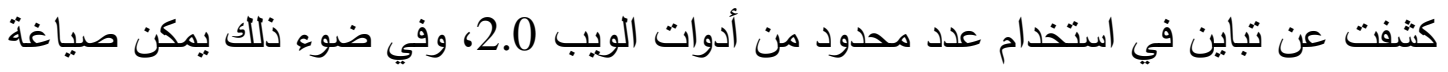
مشكلة الدراسة في التساؤلات التالية: 1 ما واقع استخدام أدوات الويب 2.0 في العملية التعليمية من وجهة نظر الطالب المعلم

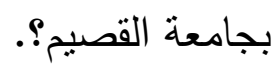
r ما معوقات استخدام أدوات الويب 2.0 في العملية التعليمية من وجهة نظر الطالب

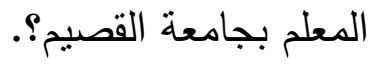
r هل تختلف استجابات الطلاب عينة الدراسة حول واقع استخدام أدوات (التخصص، الدورات

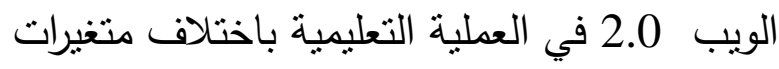

$$
\text { التدريبية في مجال الحاسب الآلي)؟ فئب }
$$




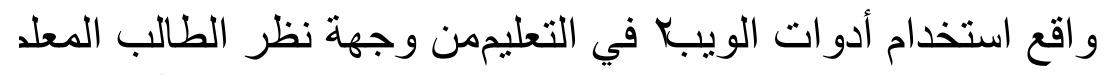

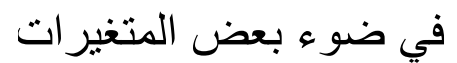

ـ هل تختلف استجابات الطلاب عينة الدراسة حول معو قات استخدام أدوات الويب 2.0 في العملية التعليمية باختلاف متغيرات (التخصص، الدورات التدريبية في مجال

$$
\begin{aligned}
& \text { الحاسب الآلي)؟. } \\
& \text { أه ــــــاف الدراســـــــة }
\end{aligned}
$$

تسعى الدراسة الحالية لتحقيق الأهداف التالية:

" التعرف على واقع استخدام أدوات الويب 2.0 في العطلية التعليمية من وج هة نظر

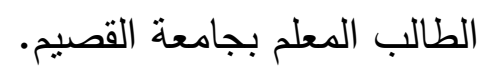

التعرف على المعوقات التي تحد من استخدام أدوات الويب 2.0 في العملية التعليمية من وجهة نظر الطالب المعلم بجامعة القصيم. التعرف على الاختلافات الدالة إحصائيا في استخدام الطلاب عينة الدراسة لأدوات الويب 2.0 في العملية التعليبية والتي تُعزى لمتغيرات (التخصص، الدورات التنريبية

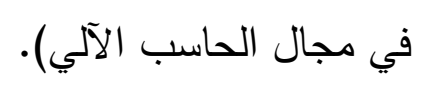
ه التعرف على الاختلافات الدالة إحصائيا في معوقات استخدام الطلاب عينة الدراسة لأدوات الويب 2.0 في العملية التعليمية تُعزى لمتغيرات (التخصص، الدورات التنريبية

$$
\begin{aligned}
& \text { في مجال الحاسب الآلي). } \\
& \text { أهميـــــة الدر اسلـــــة : }
\end{aligned}
$$

قد تسهم الدراسة الحالية في توجيه مصممي البرامج التدريبية نحو احتياجات الطلاب فيما يتعلق بأدوات الويب 2.0 ومن ثم إعداد برامج ندريبية وفق احتباجاتهم. توجيه انتباه أعضاء هيئة التدريس إلى أكثر أدوات الويب 2.0 التي يمكن الاستفادة منها في التدريس والتي يستخدمها الطلبة. توجيه اهتمام الباحثين لإجراء بحوث حول الاستفادة من تقنيات الويب 2.0 في تدريس المقررات المختلفة (مقررات نظرية- مقررات عملية). توجه اصحاب القرار نحو أهم العقبات التي تحد من استخدام الطلبة لأدوات الويب 2.0 ومن ثم وضع الحلول المناسبة لها. 


$$
\text { ح عــدود الدراســـــة }
$$

التزمت الاراسة الحالية بالحدود التالية:

• الحدود البشرية : شملت الدراسة جميع طلبة كلية التربية المسجلين في مقرر مقدمة الحاسب الالي بالإضافة الى طلبة كلية اللغة العربية، وكذللك طلبة الدبلوم العام في التربية الذين يدرسون مقرر تقنيات التعليم والاتصال ومقرر إنتاج واستخدام الوسائل التعليمية، وبلغ عددهم (10) بالب. بالب.

• الحلود الزمنية : تم تطبيق أدوات الدراسة في الفصل الدراسي الأول للعام الجامعي ه) $\leqslant r q / 1 \leqslant r \wedge$ • الحدود الموضوعية : نم النطبيق على أدوات الويب 2.0 النالية : محررات الويب النش اركية (Wikis)، والمدونات (Blogs)، والثبكات الاجتماعية .(SocialNetworks)

$$
\text { أداة الدراســـــة: }
$$

استبانة واقع استخدام أدوات الويب 2.0 من وجهة نظر طلبة جامعة القصيم • (من

$$
\text { عينــــــة الدر اســــــة: }
$$

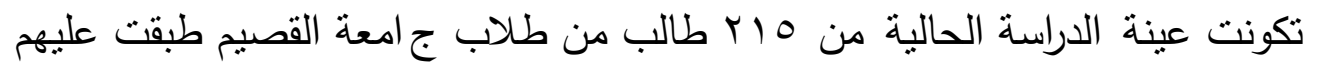

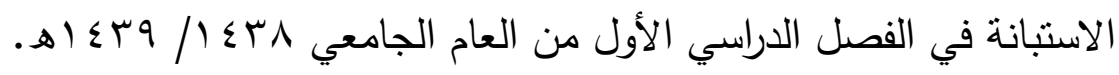

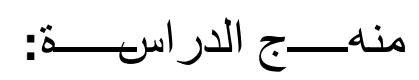

• اتبعت هذه الدراسة المنهج الوصفي التحليلي الذي يختص بوصف ما هو كائن،

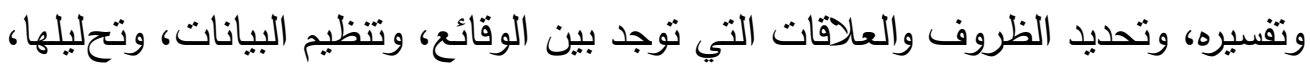

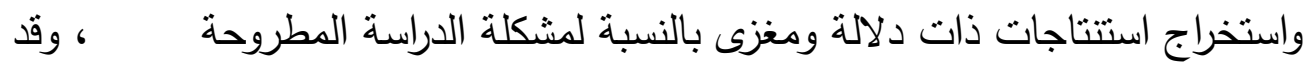

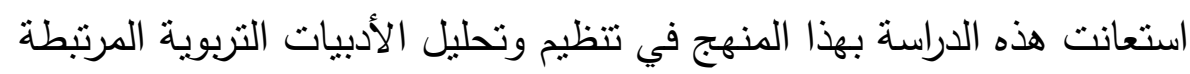
بموضوع الدراسة. 
و اقع استخدام أدوات الويبك في التعليممن وجهة نظر الطالب المعلد في ضوء بعض المتغير ات

مصطلحـــات الدراســــة:

\section{الويـــبـ 2.0}

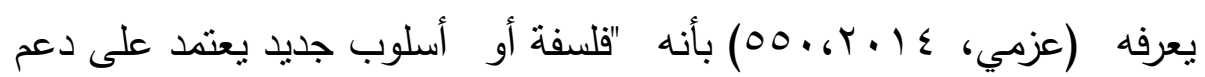

التواصل بين مستخدمي الإنترنت في بناء مجتمعات الكترونية تشاركية وتتعكس تلأك

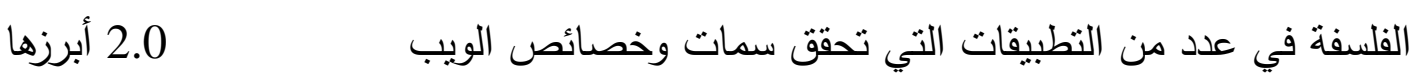

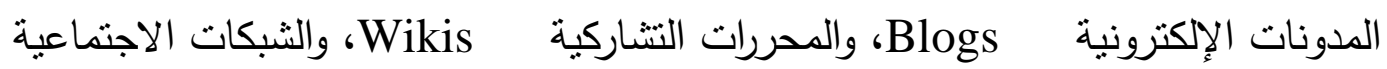
Social Network

كما عرفه (James,Yowell,2009,11) بأنه " التطبيق الذي يستخدم شبكة الإنترنت كبيئة ويسمح بالمشاركة الفعالة والتعاون والتفاعل بين المستخدمين، ويتميز بإنشاء ومثاركة المصادر الفكرية والاجتماعية بين المستخدمين".

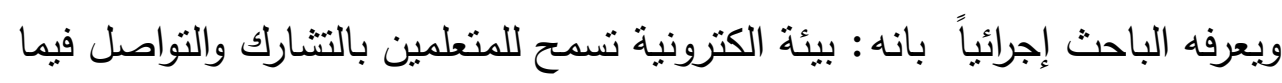
بينهم باستخدام مجموعة من الادوات والتطبيقات من اجل بناء مجتمع المعرفة.

\section{أدوات الويهــبـ}

يعرفها (Downes, 2005) بأنها "مجموعة من الأدوات الني تساعد المتعلم فى المشاركة فى بيئة تتكون من شبكة من الأثخاص والخدمات والموارد".

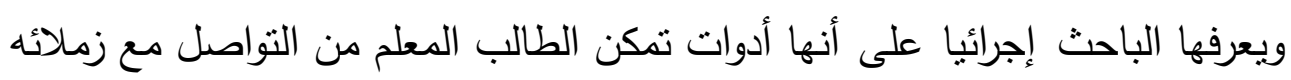

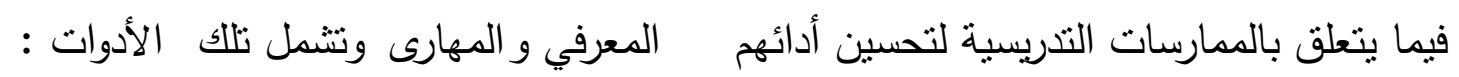
محررات الويب التشاركية (Wikis)، والمدونات (Blogs)، والثبكات الاجتماعية Social) .Networks) 


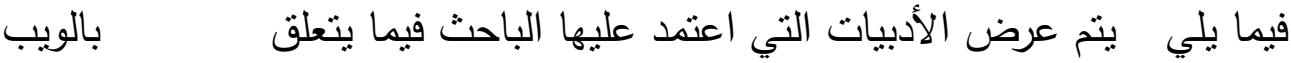
2.0 من حيث التعريف والخصائص بالإضافة إلى أدوات الويب 2.0 من حيث التعريف والأهمية التربوية.

\section{أولاً: الــويب 2.0}

هنالك الكثير من الآراء حول مفهوم الويب 2.0 يمكن ذكر بعضاً منها ومن ثم استخلاص نقاط الاتفاق بينها، حيث يُعرف الويب مغرم الوبل 2.0 بأنه "مجموعة من التقنيات الجديدة

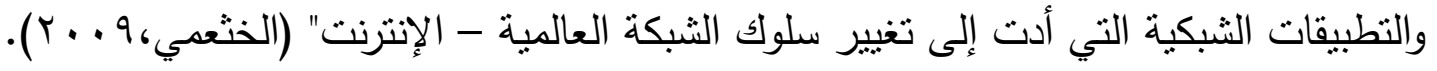

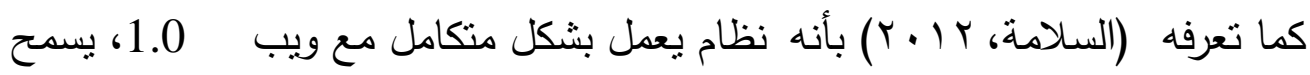

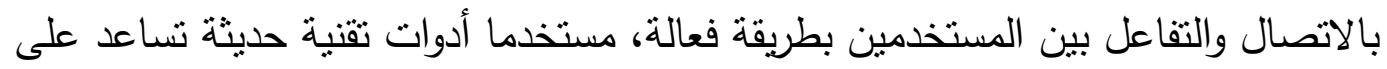
نشر الملفات والأفكار بطريقة سهلة، وبذلك يكون المستخدمون مشتركون في بناء الموقع وليسوا مستخدمين له فقط.

كما يُعرف بأنه "فلسفة أو أسلوب جديد يعتمد على دعم التواصل بين مستخدمي الإنترنت في بناء مجتمعات الكترونية تشاركية ، وتتعكس تلاك الفلسفة في عدد من التطبيقات

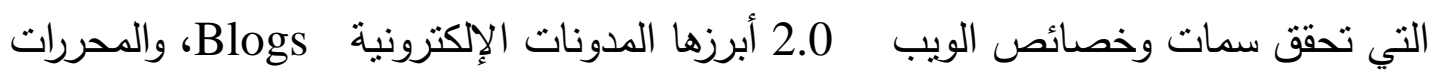
التثاركية Wikis، والثبكات الاجتماعية Social Network، وملخصات المواقع RSS"

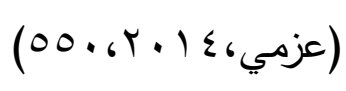

من خلال العرض السابق يمكن للباحث تدديد اهم الخصائص التي يشتمل

$$
\text { عليها الويب } 2.0 \text { : }
$$

• بيئة تسمح بإمكانية التفاعل والمشاركة لمستخدمي الإنترنت بما يسهم في بناء

$$
\text { المجتمعات الالكترونية. }
$$

• بيئة نسمح للمستخدمين بنشر ملفاتهم وأفكارهم على الموقع بسهولة ويسر من خلال

$$
\text { أدوات تقنية حديثة. }
$$

• نظام يمكن المستخدمين من الاتصال والتواصل بطريقة فعالة ، من خلال بيئة عمل

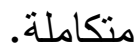




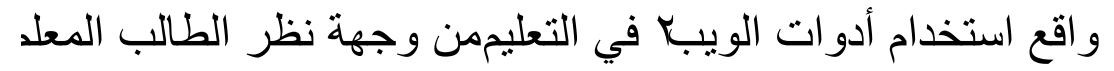
في ضوء بعض المتغير ات

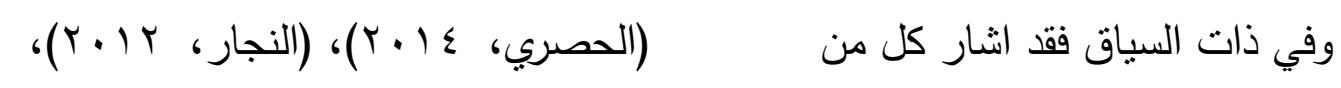

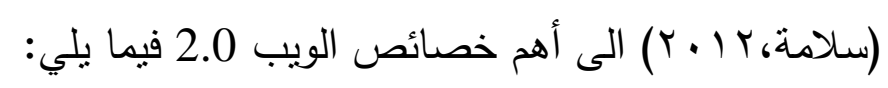

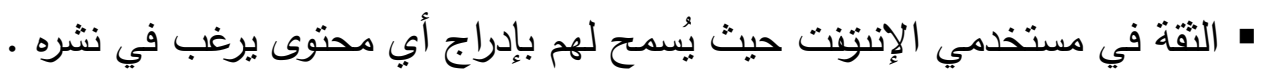

$$
\text { • مشاركة مستخدمي الإنترنت في بناء وتطوير المحتوى. }
$$

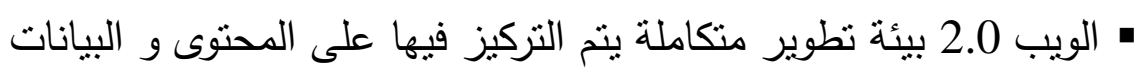

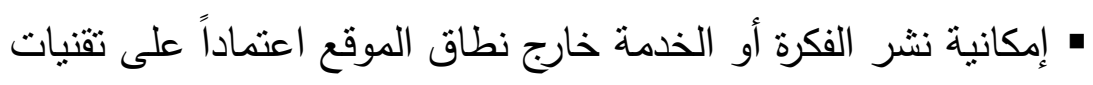

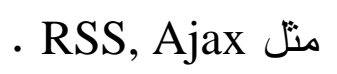

والجدي بالذكر أن هناك اختلافات جوهرية بين خصائص كل من الويب 1.0 والويب

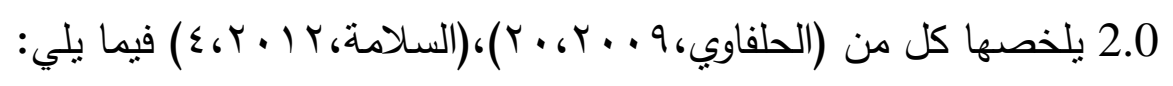

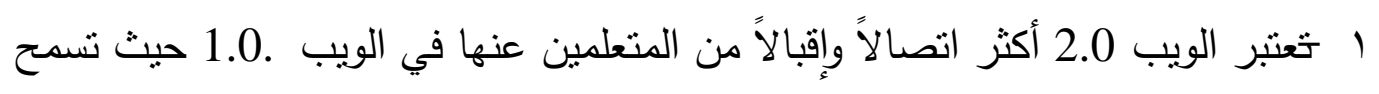

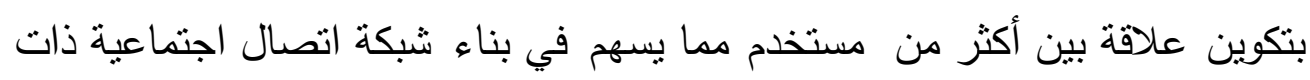

$$
\text { اهتمامات ومصالح مشتركة. }
$$

r تمنح الويب 2.0 الفرصة للمشاركة وإبداء الآراء مما يسمح للمتعلمين بالاندماج في أداء

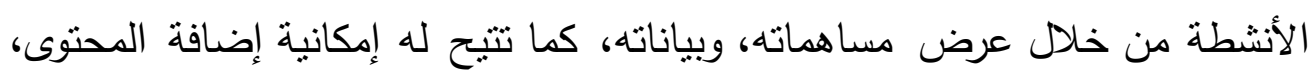
وتعديله، ومراجعته ، على عكس ما تسمح به الويب 1.0 التي تعتبر المستخدم مجرد

$$
\text { قارئ لا يسمح لله بإبداء الرأي. }
$$

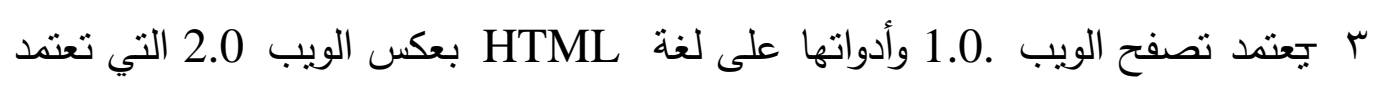

$$
\text { على XML الأكثر تقدماً وسرعة. }
$$

ع تقيح الويب 2.0 للمستخدمين إمكانبة الوصول إلى أي صفحة داخل الموقع بمجرد نقرة

واحدة بعكس الويب .1.0 التي لا تسمح بالوصول الى الصفحات السابقة بشكل دائم. ه تعتدد تطبيقات الويب 2.0 على برمجيات أجاكس AJAX الأقوى والأفضل ديناميكية

$$
\text { من برمجيات J2EE المستخدمة في الويب } 1.0
$$




\section{ثانياً : أدوات/ تطبيقات الويب 2.0}

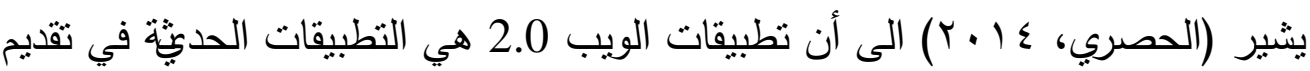

خدمات الإنترنت والتي ظهرت بعد ظهور مصطلح الويب 2.0 حيث تحمل نفس خصائصه، كما انها أظهرت سبل جديدة للتواصل بين مستخدمي الإنترنت.

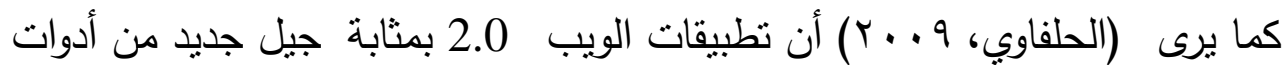

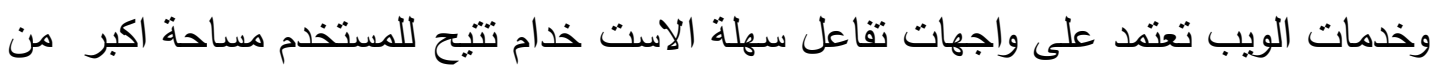

التفاعل والتنشارك والتعاون في بناء وإدارة محتوى تفاعلي في إطار اجتماعي يحافظ على وجود

$$
\text { علاقات إنسانية بين المستخدمين. }
$$

بناءً عليه ظهر العديد من التطبيقات التكنولوجية التي تعتمد في خصائصها على الويب

2.0 والتي يمكن اجمالها في ال جدول التالي : (الحلفاوي، 9. . ب)، (Light,11,2010)

(Crook, Harrison, 10,2010)

\begin{tabular}{|c|c|c|c|}
\hline مثال & التعريف & تطبيقات الويب 2.0 & مـ \\
\hline $\begin{array}{r}\text { http://www.bl } \\
\text { ogger.com }\end{array}$ & 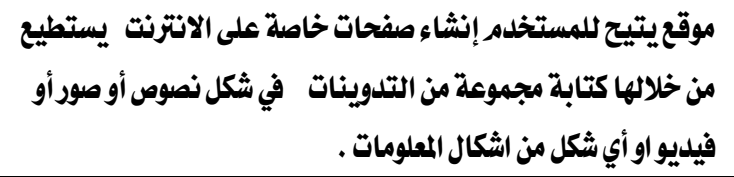 & Blogs المدونات & 1 \\
\hline $\begin{array}{c}\text { http://ar.Wikis } \\
\text { pedia.org }\end{array}$ & مستخدم تلتام لإدارة محتويات المواقع عبر الإنترنت ويتميز بأنه يسمح لأئ & المحرر التشاركي Wikis & r \\
\hline $\begin{array}{l}\text { http://www,T } \\
\text { witter.com }\end{array}$ & 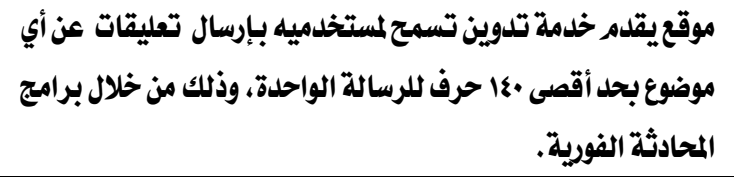 & التدوين المصفر & r \\
\hline $\begin{array}{l}\text { htpp://www.fa } \\
\text { cebook.com }\end{array}$ & موقيسع اجتماعي يساعد المستخدمين في مشاركة المعلومات والأخبار & الشبكات الاجتماعية & $\xi$ \\
\hline $\begin{array}{c}\text { htpp://www,y } \\
\text { outube.com }\end{array}$ & 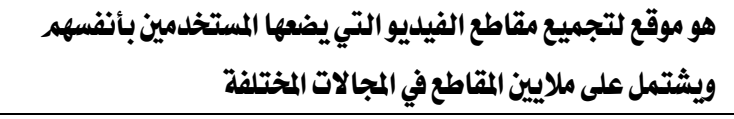 & مشاركة الفيليو & 0 \\
\hline $\begin{array}{c}\text { http://www.fli } \\
\text { ckr.com }\end{array}$ & هو موقح لتجميع الصوريتيح وضع الصور وتبادلها بين المستخدمين. & $\begin{array}{r}\text { مشاركة الصور } \\
\text { Photo Sharing }\end{array}$ & 9 \\
\hline $\begin{array}{l}\text { http://www.se } \\
\text { condlife.com }\end{array}$ & موقع اقتراضي ثلاثي الأبعاد يحاكي المجتمع التقليدي ويستطيع & $\begin{array}{rr}\text { البيئات الاجتماعية الاقتراضية } \\
\text { Social } & \text { Virtual } \\
& \text { Environments } \\
\end{array}$ & v \\
\hline $\begin{array}{r}\text { http://www.sli } \\
\text { de.com }\end{array}$ & تمقديمية يتيح للمستخدم مشاركة زملائه في إنتاجونشر عروض & $\begin{array}{r}\text { مشاركة العروض التقديمية } \\
\text { Presentation Sharing }\end{array}$ & $\wedge$ \\
\hline
\end{tabular}




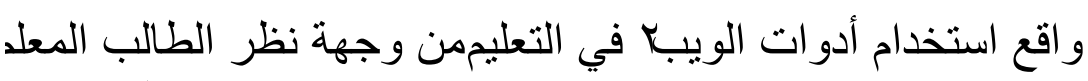

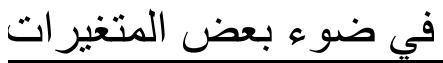

\begin{tabular}{|c|c|c|c|}
\hline مثال & التعريف & تطبيقات الويب 2.0 & مـ \\
\hline $\begin{array}{r}\text { http://www.sk } \\
\text { ype.com }\end{array}$ & وعرض وجهات النظظر & $\begin{array}{c}\text { أدوات المؤتمرات المرئية } \\
\text { Video and } \\
\text { Conferencing Tools }\end{array}$ & 9 \\
\hline $\begin{array}{c}\text { http://deliciou } \\
\text { s.com }\end{array}$ & ملد كبير من المستخدمين للمستخده تخزين الروابطوترتيبها ومشاركاتها بين & $\begin{array}{r}\text { Social المضلاتالاجتماعية } \\
\text { bookmarking } \\
\end{array}$ & 1. \\
\hline Webcasting & 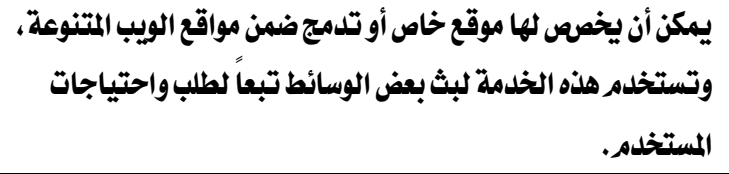 & $\begin{array}{r}\text { Web } \quad \text { أدوات البث المباشر } \\
\quad \text { Casting }\end{array}$ & $"$ \\
\hline خالمواقع عامة بكثير من & 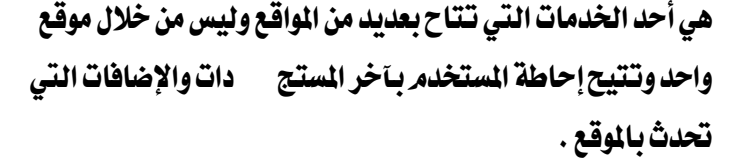 & أدوات قارئ الأخبار الآلي & $\mathbb{I r}$ \\
\hline
\end{tabular}

وفيما يلي يتم عرض التطبيقات التي استخدمت في الاراسة الحالية:

محررات الويب التشاركية (Wikis)

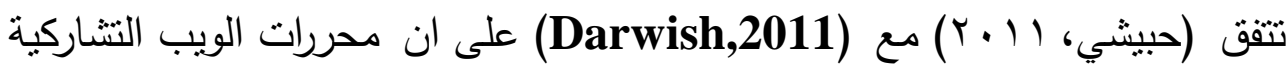

بمثابة قاعدة بيانات قابلة للتوسع وهي ت تعتمد على نظام النص التتعيبي لتخزين وتعديل المعلومات، وتسمح بالتبادل المعرفي بين زوارها وتبادل وجهات النظر المختلفة مما يثرى خبرات

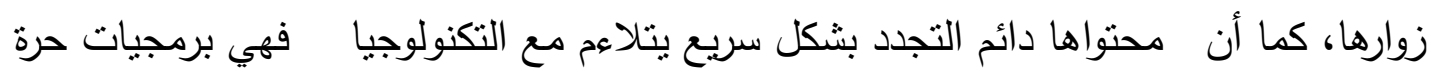
مفتوحة الدصدر ، وتعد تطبيقا هاما لـفهوم التعلم الجماعي المشترك.

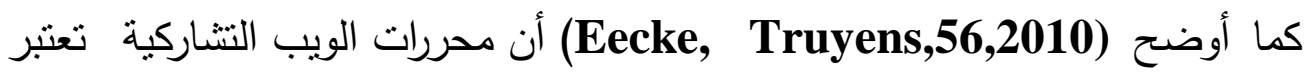
مساحة رقمية يتم وضعها على مزود موقع بحيث يسمح بالمشاركة والتفاعل فى إدراج

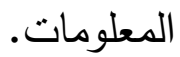

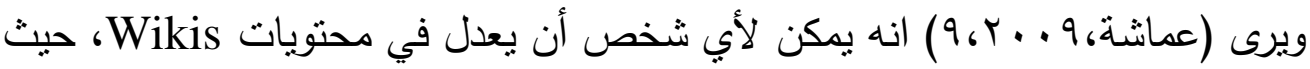

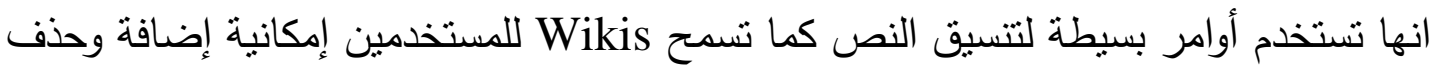
وتعديل وتغيير بعض المحتويات كما تشجع Wikis على تصميم روابط بين الصفحات.

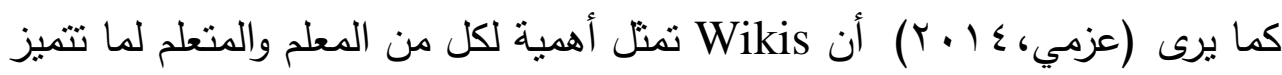
بالكثير من الفوائد التعليمية ، فهي تسهم في تنمية الثعور بالمسئولية ، بالإضافة الى نتمية مهارات التفكير الناقد ، وتطوير المهارات المختلفة المرنبطة بالقراءة والكتابة والفهم للمعلومات ، الإهيه 
كما تساعد المتعلم على نطوير مهارات التعبير والتواصل ، كما تتيح محررات الويب التتاركية للمعلم التواصل الفعال مع المتعلمين مدا يسهم في دعم وتتمية المهارات الثخصية والمهنية تأسيساً على ما سبق فإن Wikis مجموعة من صفحات الويب المترابطة معاً بالاعتماد

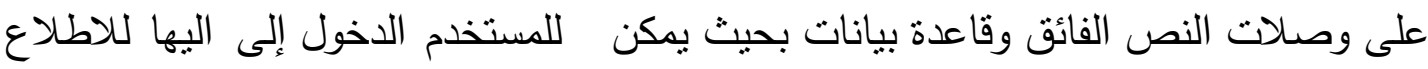

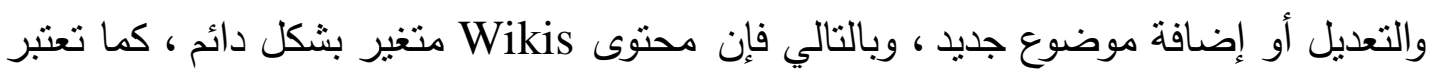

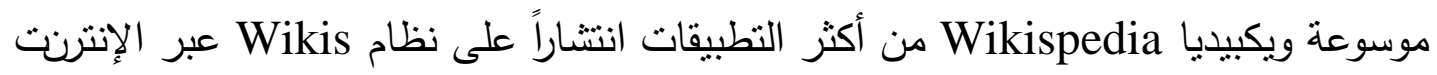

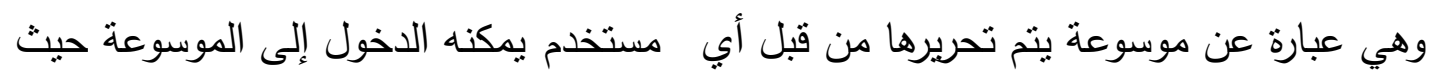

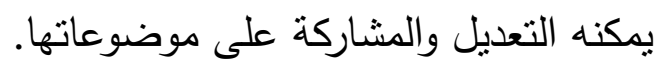

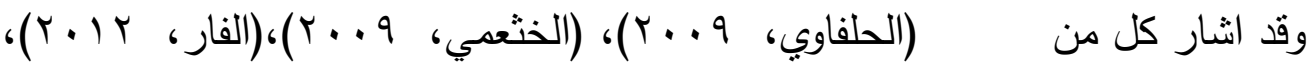

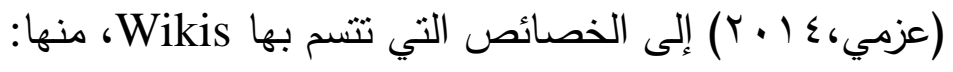
تسمح Wikis بالمشاركة والتعاون فالمتعلمون يعملون معاً من أجل نطوير المعرفة

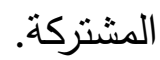
تسمح Wikis بتتوع طرق التعليم من خلاد تبادل الأدوار بين المتعلمين فأحياناً هم

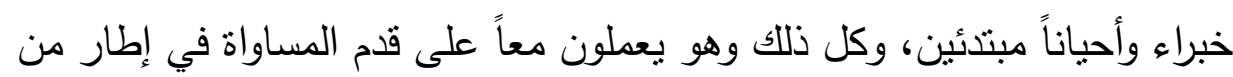

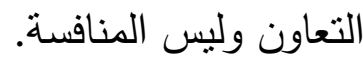
هنمح Wikis للمتعلم رؤية نتائج الأنشطة والمهام التي يقوم بها بشكل مباشر .

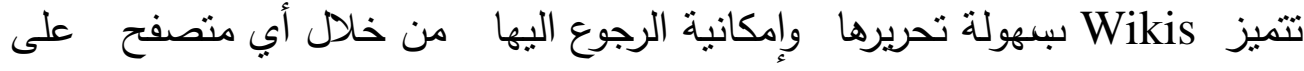
الانتزنت. تأسيساً على ذلك فإن Wikis تدعم التعلم التعاوني، وتسهم في بناء مجتمع المعرفة، كما انها تسمح للمستخدمين إمكانية التعبير عن آرائهم واتجاهاتهم.

المبـدوزنسات (Blogs)

المدونة في أصلها مشتقة من كلمة web log أب سجل الثبكة أو كتاب الثبكة وتعتبر إحدى تطبيقات الويب 2.0 حيث تعمل من خلال نظام لإدارة المحتوى وأهم ما يميز المدونات عن غيرها من صفحات الويب التقليدية الأخرى أنها تسمح للمستخدمين بالمشات الماركة

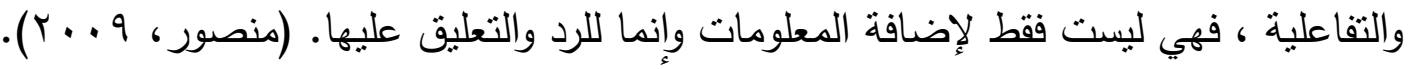




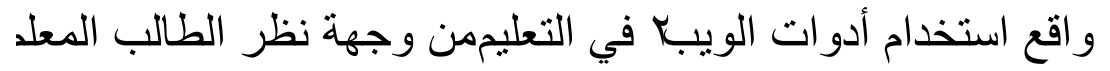
في ضوء بعض المتغير ات

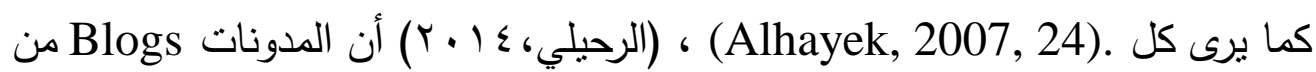

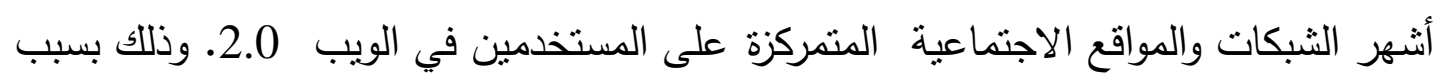

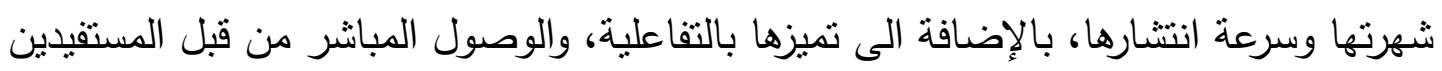

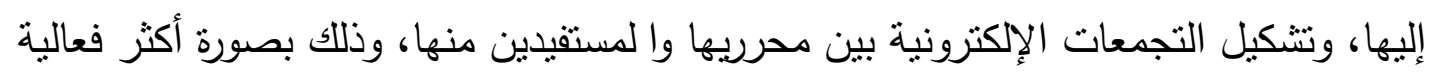

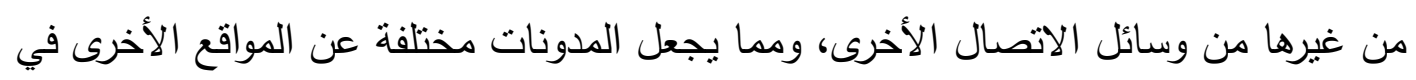

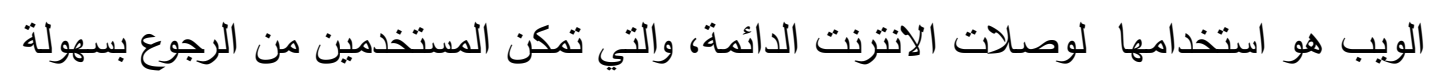

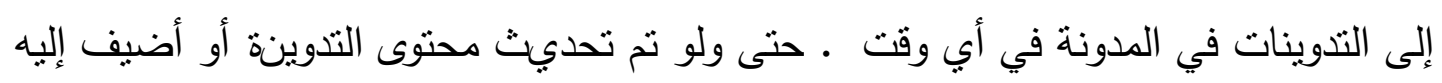

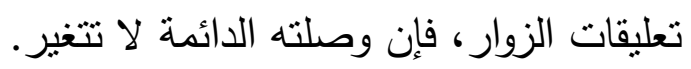

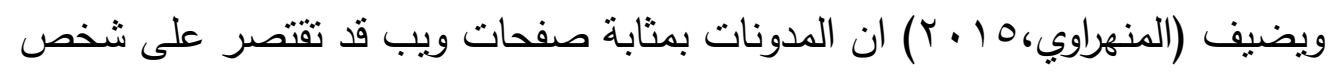

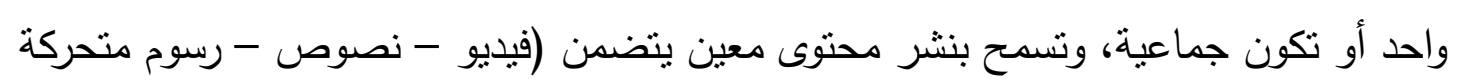

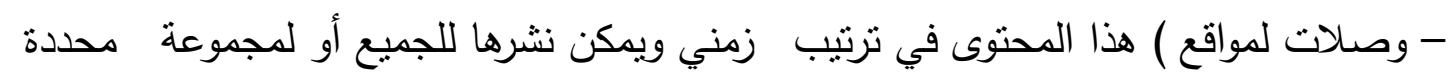
ويتاح للمتصفح التعليق عليها.

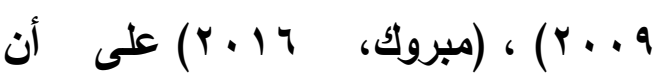
(الخثعمي، وقد اتفق كل من

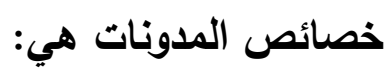
محتوى منظم كمداخل مستقلة يشتمل كل منها على نص أو روابط فائقة، ومتاحة

$$
\text { جميعاً في ترتيب زمني تتازلي ( من الأحدث إلع الأقدم ). }
$$

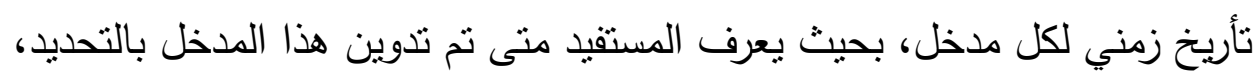
وهذا التاريخ ينت باليوم والثهر والسنة، وأحياناً بالساعة والدقيقة.

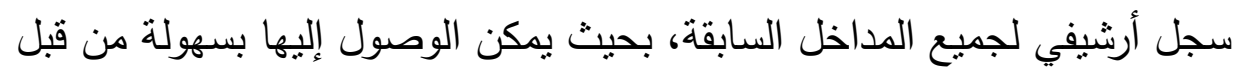
المستخدمين.

\section{الشبكات الإتتماعية Social Networks).}

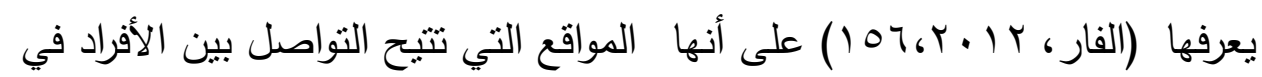

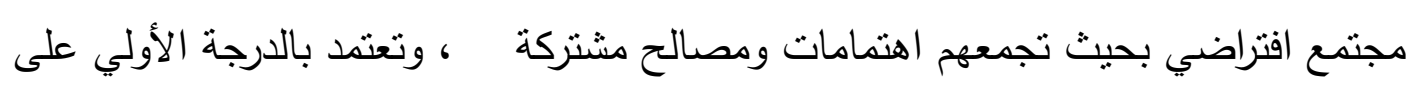
مستخدميها في تغذيتها وتتشليها، وتتتوع تلك الثبكات حسب الأهداف التي أنشئت من أجلها. 
وترى (الختعمي، 9 . . Y، T) أن الثبكات الاجتماعية Social Networking عبارة عن مجموعة من المواقع على شبكة الإنترنت ظهرت مع الجيل الثاني للويب أو ما يعرف باسم الئح

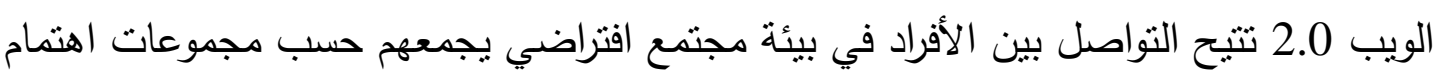

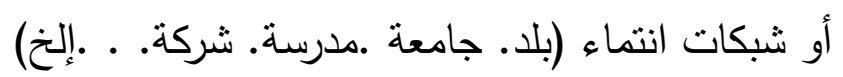

وبالتالي فإن الثبكات الاجتماعية هي مجموعة من المواقع على شبكة الانترنت تتيح

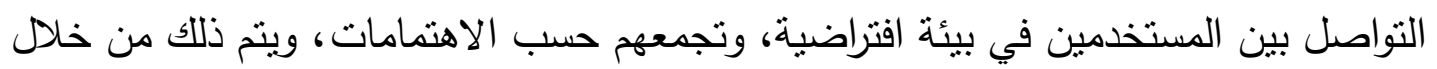
خدمات التواصل المباشر منل إرسال الرسائل أو الاطلاع على الثئل الملفات الثخصية للآخر ين.

(Ellison,2007)

ويوجد نوعان من الثبكات الاجتماعية Social Networking : الثبكات الاجتماعية

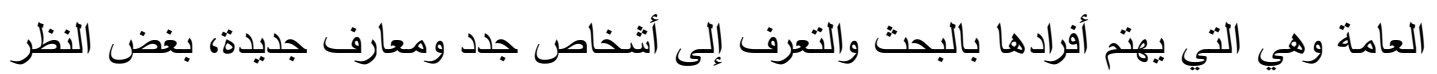

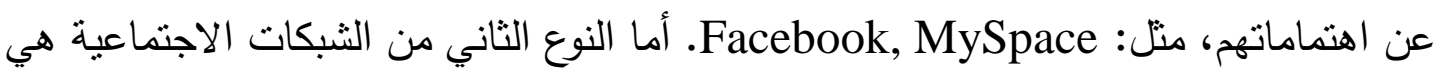

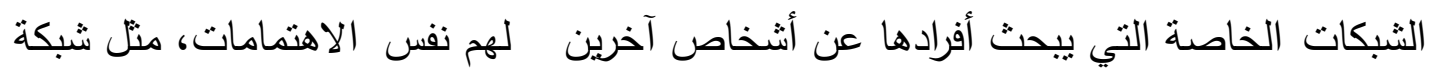
LinkedIn و Flickr

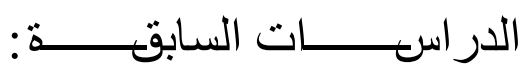

دراسة (حميد،\&/r)

هدفت الدراسة الى الكثف عن واقع استخدام أعضاء هيئة التدريس بجامعة حجة لتطبيقات الويب 2.0 في التعليم بالإضافة الى تحديد المشكلات التي تحول دون استخدام أعضاء هيئة التدريس لنطبيقات الويب 2.0 في التعليم الجامعي، حيث استخدم الباحث المنهج

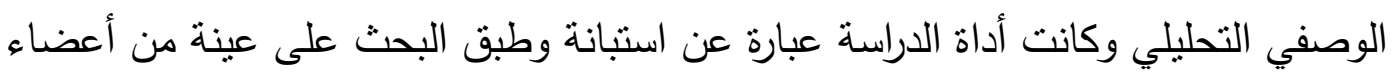

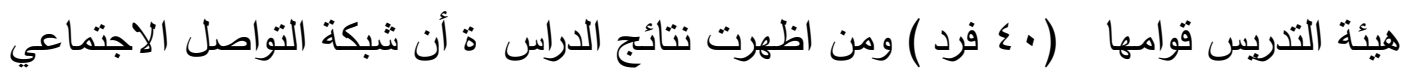
Facebook

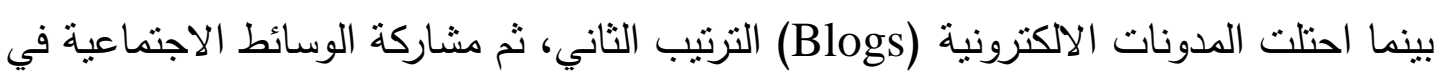
الترتيب الثالث ثم الويكي (Wikis) في الترتيب الرابع ، وكان من أهم المشكلات التي تعيق

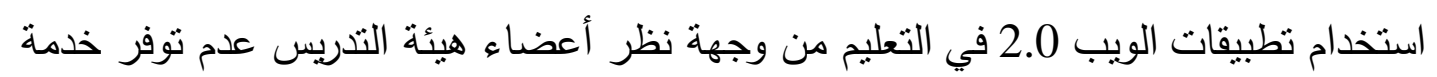

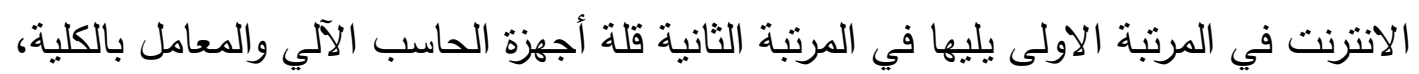
ثم جاء في المرتبة الثالثة ضعف وجود برامج ودورات تدريبية ملاسبة لأعضاء هيئة التدريس. 


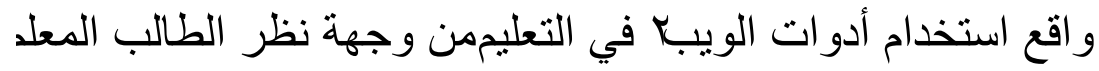
في ضوء بعض نطو المتغير اتل

\section{دراسة (العيسائي والحضرمي،و.•r)}

هدفت الدراسة إلى معرفة واقع استخدام تطبيقات الويب المعلومات بالمكتبات الأكاديمية بجامعة السلطان قابوس في عصر الرقمنة والانفجار

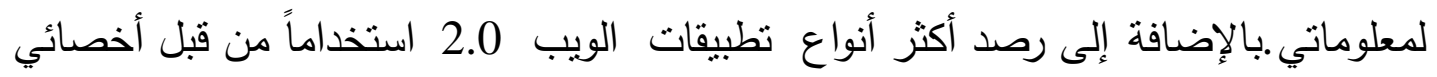

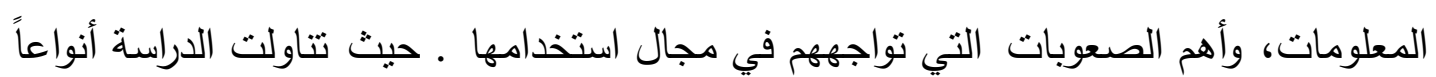
مختلفة من تطبيقات الويب 2.0 منل (خدمة الملخص الوافي، والمدونات، والثبكات الاجتماعية،

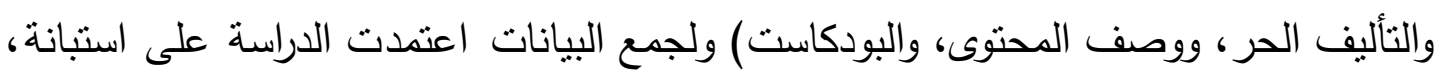

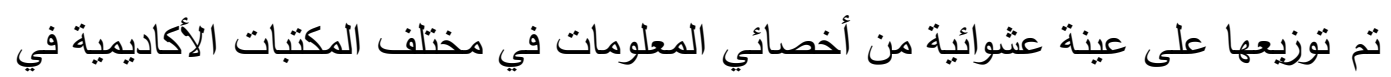

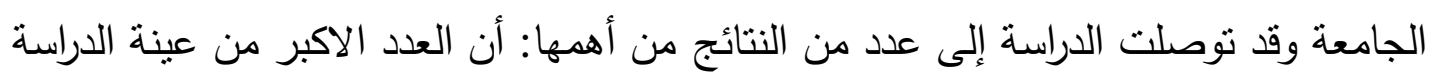

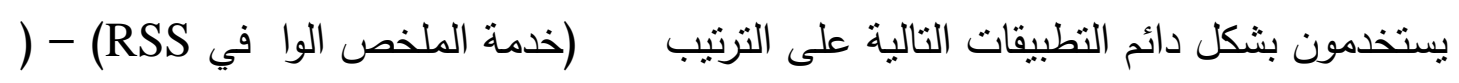

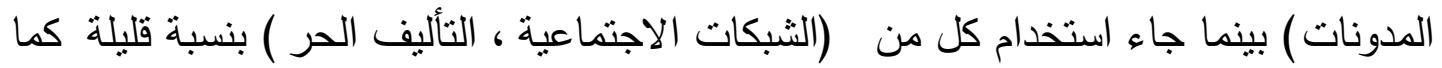

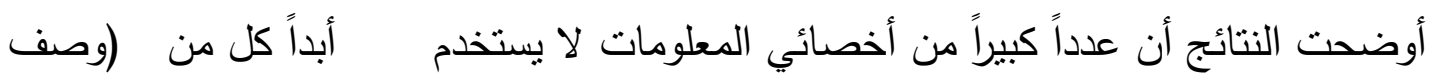

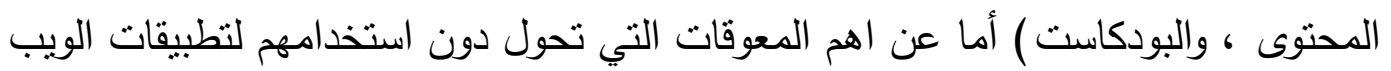

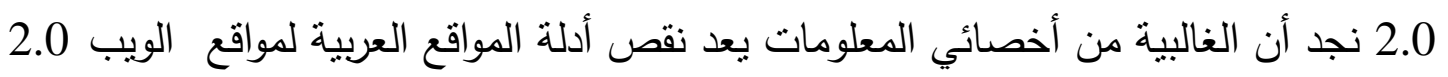

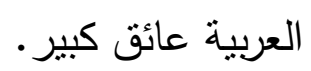

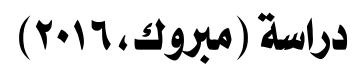

هدفت الدراسة إلى تحديد واقع استخدام تطبيقات الويب 2.0 في التدريس من قبل أعضاء هيئة التدريس والطالبات بقسم الاقتصاد المنزلي التربوي ، وتحديد المشكلات المرتبطة

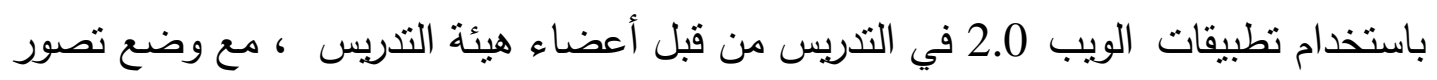

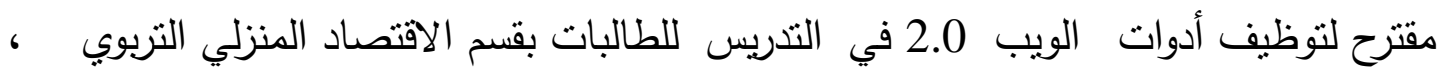

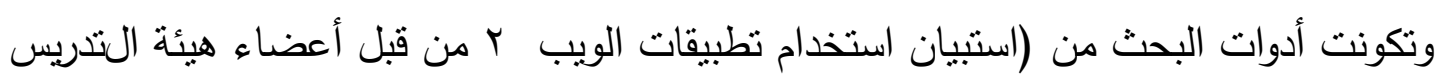

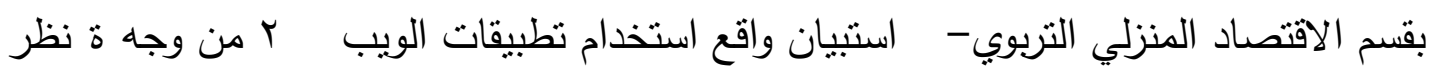

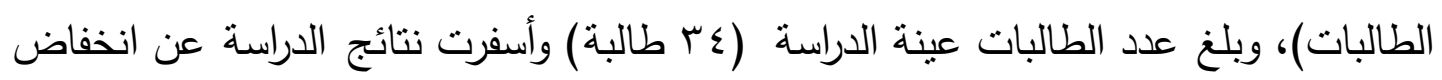
استخدام أعضاء هيئة التدريس للمدونات الإككترونية التعليمية ، وعدم الاستفادة من تطبيقات التهات

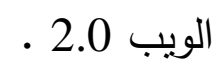


هدفت الدراسة إلى التعرف على مدى استخدام معلمات المواد الدراسية بالمرحلة

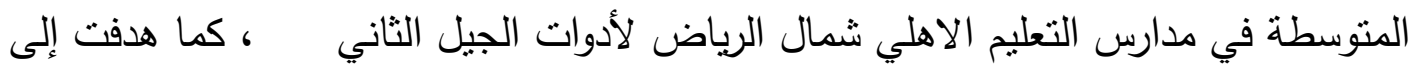

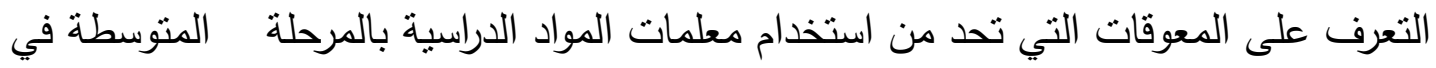

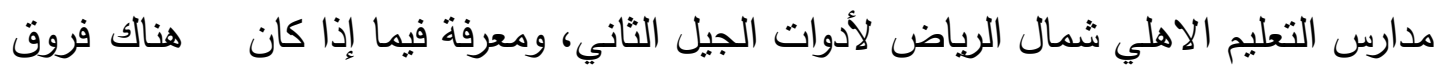

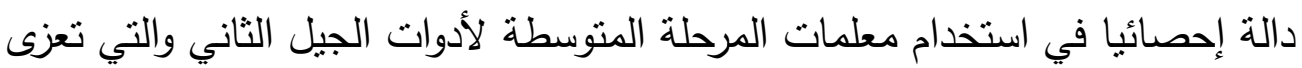

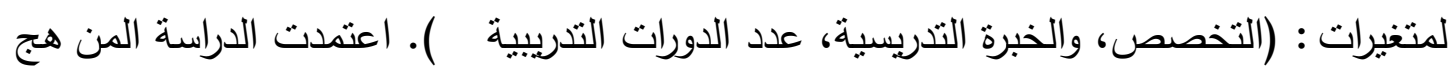
الوصفي المسحي. وتضمنت عينة الدراسة (· V) معلمة من معلمات المرحلة المتوسطة للتعليم

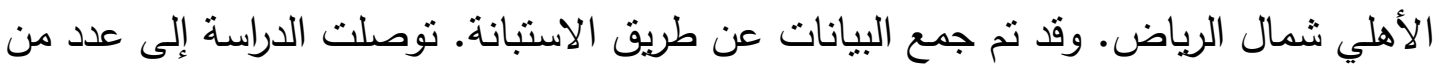

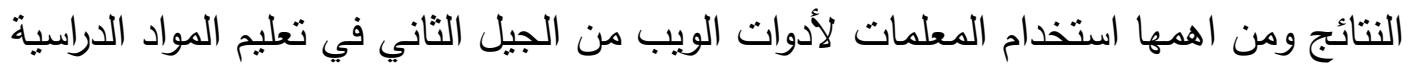

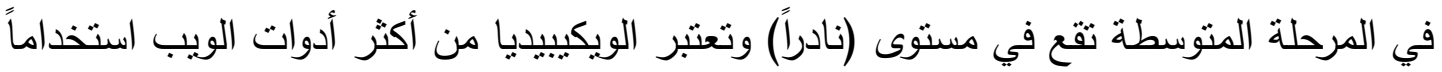

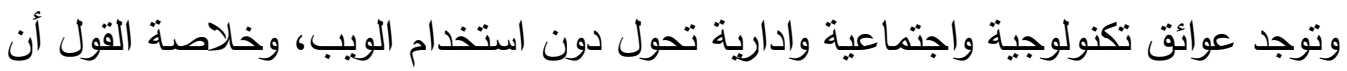
المعلمات في المدرسة المذكورة لا تستخدم أدوات الويب في تدريس المواد بشكل كاف نتئنة

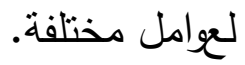

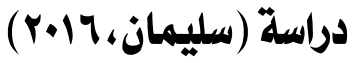

هدفت الدراسة إلى التعرف على واقع الاستخدام الثخصي والتعليمي لأدوات الويب 2.0

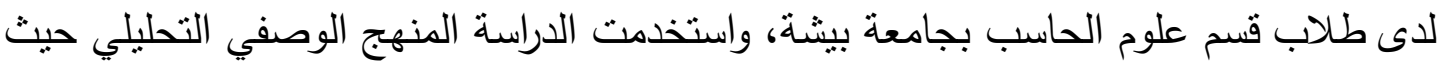

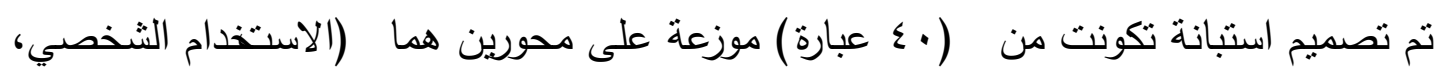

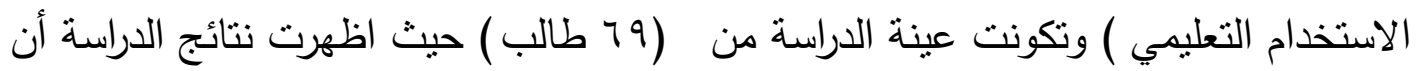

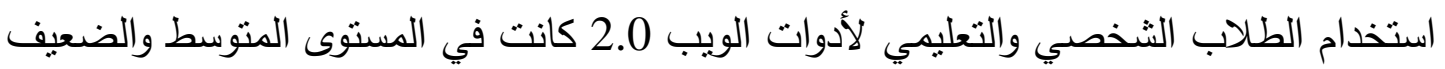
كما جاء استخدام (WhatsApp) أعلى استخدام على المستوى الثخصي والتعليمي لعينة

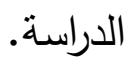

\section{Chiang,Liu, Chen,Shih (2011) دراسة}

هدفت الدراسة إلى الكثف عن استخدامات طلبة جامعة نايوان لأدوات الويب 2.0

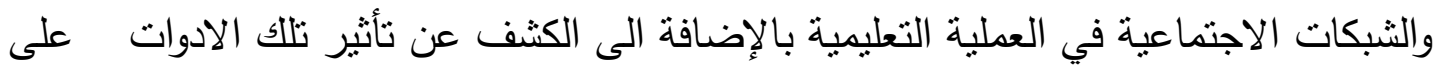




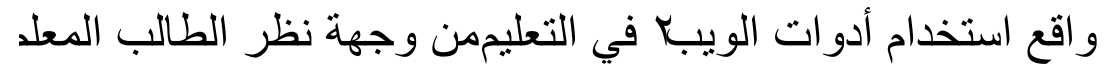
في ضوء بعض المتغير ات

سلوكياتهم ، حيث شملت عينة الدراسة (79 ب طالب). وأظهرت النتائج أن أدوات الويب 2.0

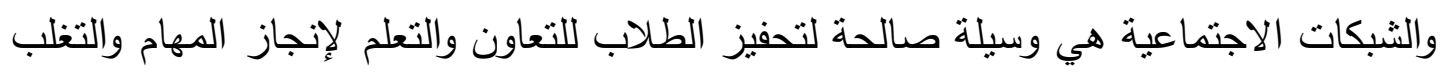

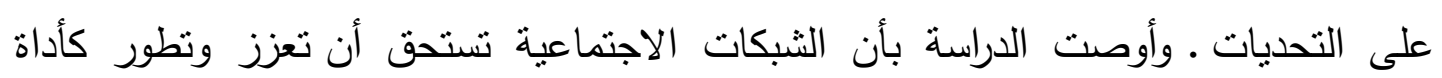
تعليمية يمكن استخدامها داخل الجامعة.

\section{An,Y., Ballard,G. \& Williams,K. دراسة (2011)}

الغرض من هذه الدراسة هو استكثاف أفضل الممارسات في التدريس باستخدام تقنيات

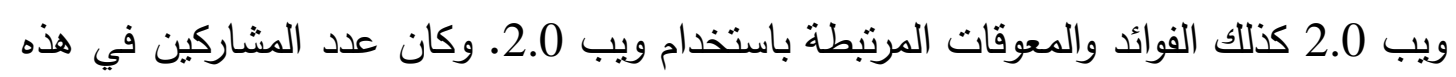

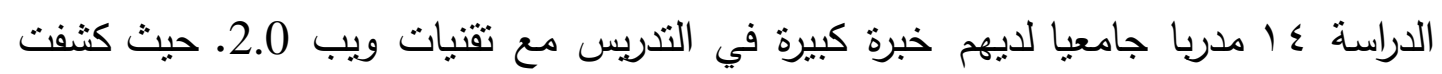
الدراسة إلى أن الفوائد الرئيسية لاستخدام تقنيات ويب 2.0 في التشريس تشمل تتمية مهارات

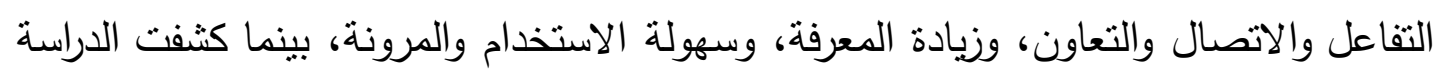
أن من أهم عقبات استخدام أدوات الويب 2.0 هي المشاكل التكنولوجية المتعلقة بالاستخدام.

\section{Sayed (2011) دراسة}

هدفت الدراسة إلى الكثف عن استخدامات المعلمين في جامعة إفل لتقنيات الويب 2.0

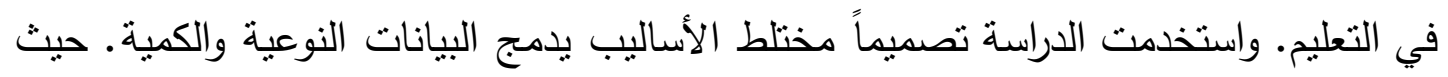
طبقت استبانة على عينة قوامها سبعة وعشرون مدرسا من معلمي اللغة الإنجليزية كلغة أجنبية

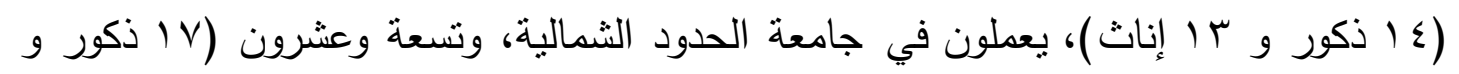

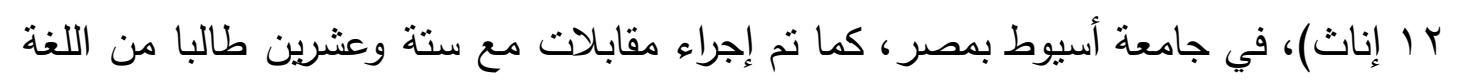
الإنجليزية كلغة أجنبية (إفل) من كلا الجامعتين وتسعة من معلمي اللغة الإنجليزية كلغة أجنبية

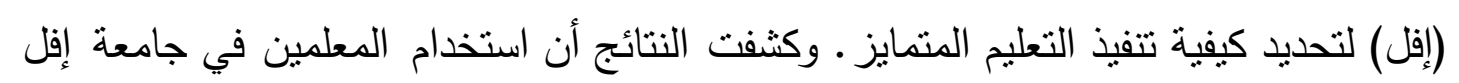

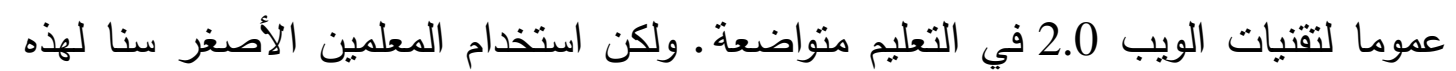

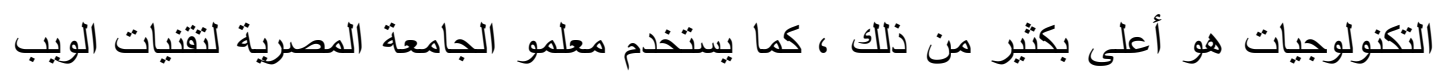
2.0 أكثز من نظرائهم السعوديين. وشملت التوصيات إجراء بحوث تحدد الأسباب الحقيقية وراء امتتاع المعلمين عن استخدام تقنيات الويب 2.0 في تدريس اللغة الإنجليزية كلغة أجنبية. 


\section{Ali (2014) دراسة (2014)}

هالدت الدراسة الى الكثف عن استخدام أدوات الويب 2.0 (Blogs, Wikis, RSS) من قبل المتخصصين بالمكتبة الاكاديمية بجامعة الكويت، حيث تم إعداد استبانة مكونة من

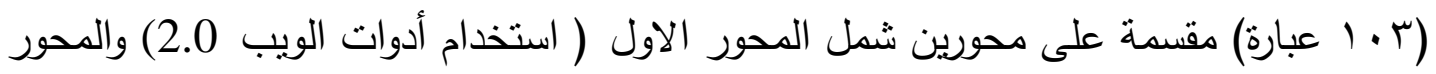

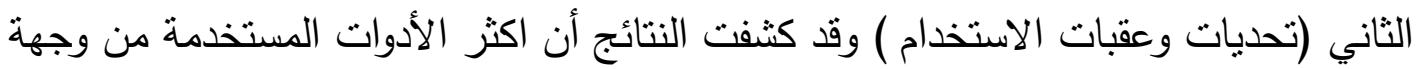

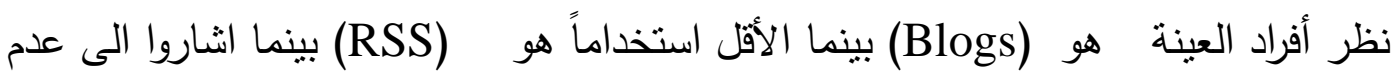
استخدامهم لتقنية (Wikis) لأنها تحتاج الى خبرة في التعامل معها.

\section{التعقيب على الدراسات السابقة:}

• من حيث الهدف من الدراسة : هناك دراسات هدفت إلى الكثف عن مدى استخدام أدوات

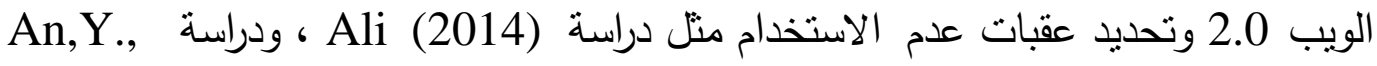
، Ballard,G. \& Williams,K.(2011) تأثثرات استخدام أدوات الويب

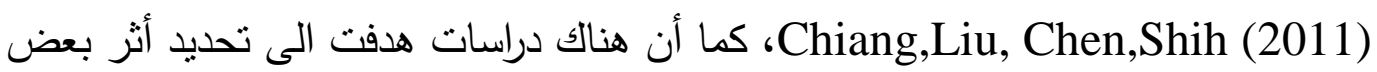
المتغيرات على استخدام أدوات الويب 2.0 متل التخصص، والخبرة التدريسية، عدد الدورات

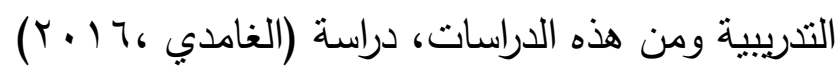
من حيث أدوات جمع البيانات : معظم الدراسات السابقة استخدمت الاستبانة كأداة لجمع داني البيانات، من حيث نوع التطبيق الذي استخدم في الدراسة : هناك دراسات استخدمت تطبيقات الويب ، دابي

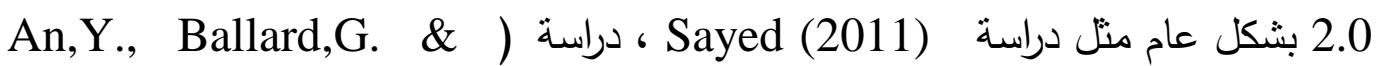

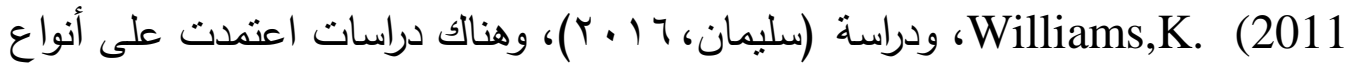

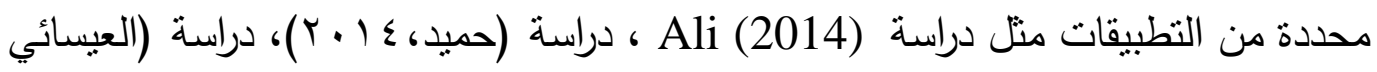

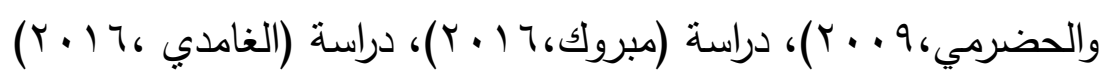

• من حيث النتائج : فقد كثفت بعض الدراسات عن تقوق استخدام شبكات التواصل

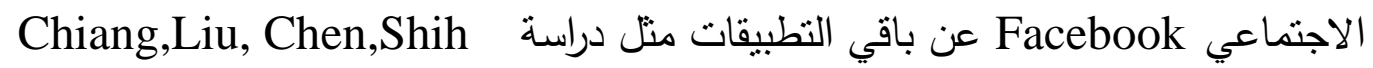

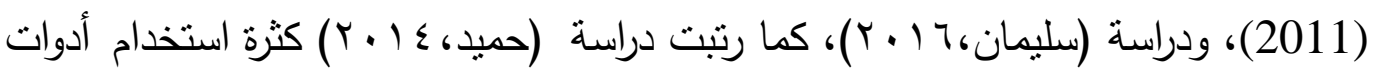
الويب 2.0 حيث جاء Facebook في المرتبة الاولى يليه المدونات في المرتبة الثانية ثم 


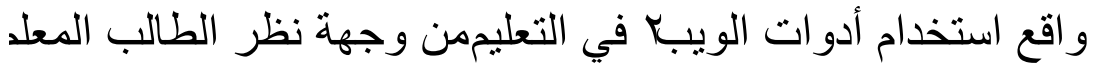
في ضوء بعض المتغير الطالب المطات

محررات الويب التثاركي، بينما اظهرت دراسات أخرى أن الدحررات النتاركية هي الأكثر

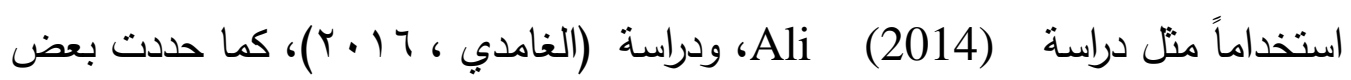
الدراسات نوعية العقبا ت التي تحول دون استخدام ادوات الويب

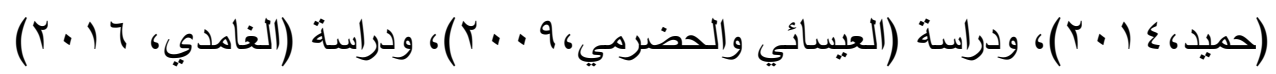
فــــروض الــدر اسبـــــة

ا لا توجد فروق دالة إحصائياً في استجابات الطلاب عينة الدراسة حول واقع استخدام

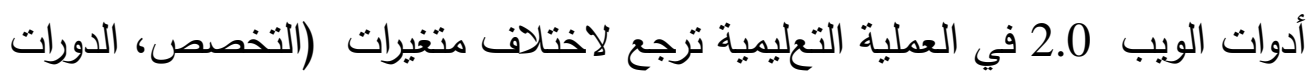
التدريبية في مجال الحاسب الآلي). r r لا توجد فروق دالة إحصائياً في استجابات الطلاب عينة الدراسة حول معوقات استخدام

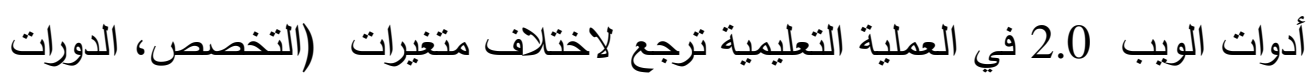

$$
\text { التدريبية في مجال الحاسب الآلي). }
$$

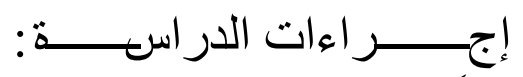

أولاً : منهج الدراسة: اتبعت هذه الدراسة المنهج الوصفي التحليلي الذي يختص بوصف ما هو

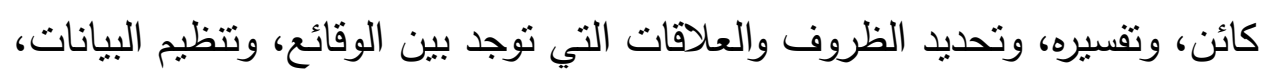

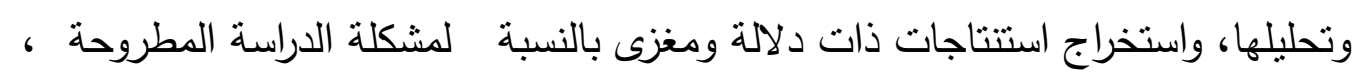

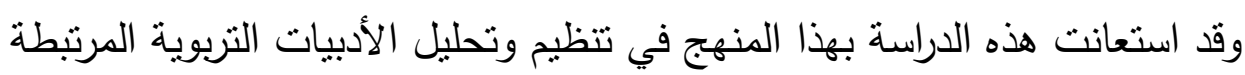
بموضوع الدراسة.

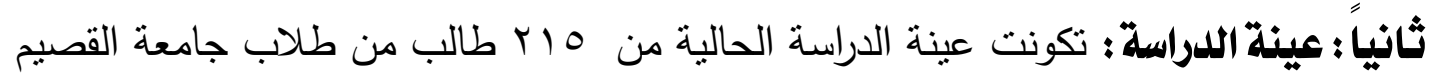

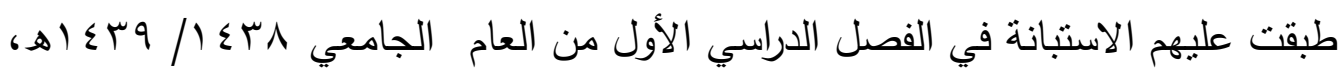

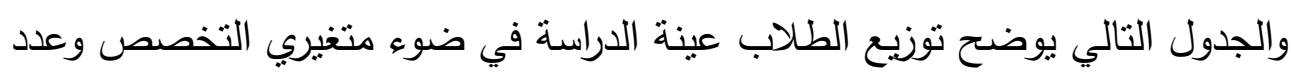

$$
\text { الدورات في مجال الحاسب الآلي: }
$$

\begin{tabular}{|c|c|c|}
\hline \multicolumn{3}{|c|}{ التخصص } \\
\hline النسبة & العدد & الفئة \\
\hline$\% 11,7$ & ro & شريعة ودراسات إسلامية \\
\hline
\end{tabular}

جدول (1) : توزيع الطلاب عينة الدراسة في ضوء متفير التخصص 


\begin{tabular}{|c|c|c|}
\hline$\% \wedge, \xi$ & M & لغة عربية \\
\hline$\% r \wedge, \xi$ & 71 & تربية بلدنية \\
\hline$\% 19,0$ & SY & لفة إنجليزية \\
\hline$\% 17,1$ & rq & كيمياء \\
\hline$\% \vee, q$ & iv & فيزياء \\
\hline$\% \vee, \varepsilon$ & 17 & حاسب آلي \\
\hline
\end{tabular}

جدول (ץ) : توزيع الطلاب عينة الدراسة في ضوء متفير عدد الدورات التدريبية

\begin{tabular}{|c|c|c|}
\hline \multicolumn{3}{|c|}{ عدد الدورات التدريبية في مجال الحاسب الآلي } \\
\hline$\% 7 \cdot, 9$ & $|r|$ & لايوجد \\
\hline$\%$ rq, & 07 & من ا-ب دورات \\
\hline$\% 1 r$, & ru & أكثر من ب دورات \\
\hline
\end{tabular}

يتضح من الجدول السابق أن أعلى نسبة من طلاب عينة الدراسة من تخصص التربية

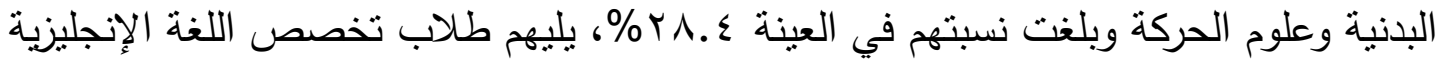

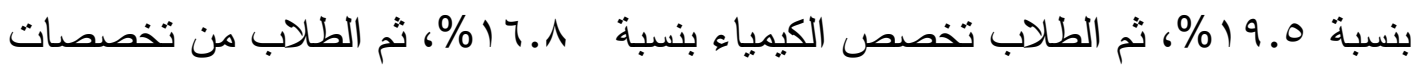

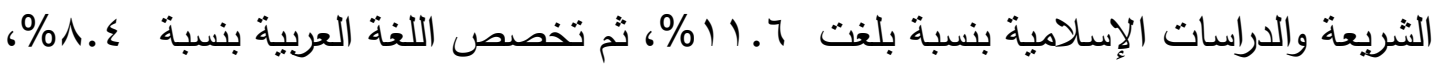
فطلاب تخصص الفيزياء بنسبة و.9\%، وأخيراً الطلاب تخصص الحساسب الآلي بنسبة

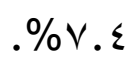

كذللك يتضح من الجدول السابق أن النسبة الأكبر من الطلاب لم يحضروا أب دورات تدريبية

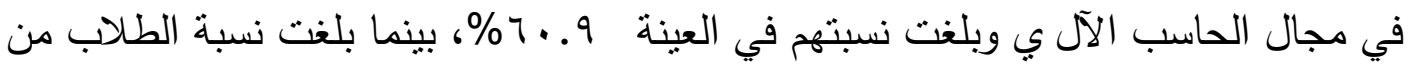

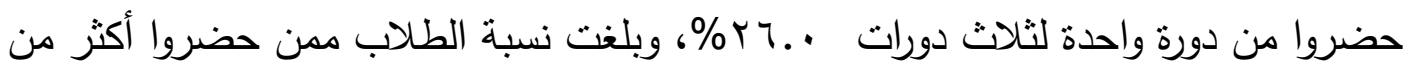

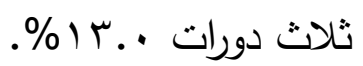
ثالثاً : أدوات الدراسة : تمنلت اداة الدراسة في استبانة واقع استخدام أدوات الويب 2.0 في

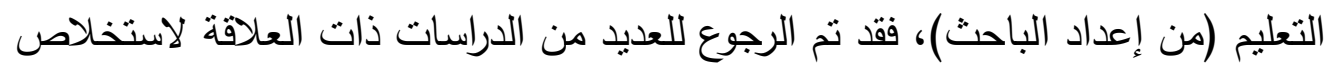

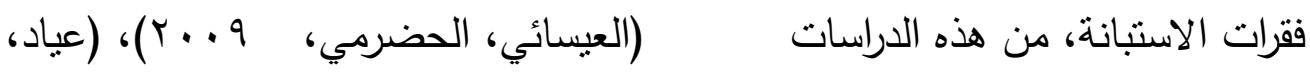

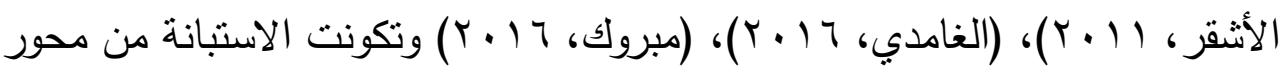




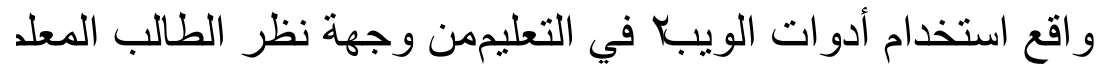
في ضوء بعض المتنغير ات التطل

رئيسي يشمل البيانات الاساسية للطالب (يذكر فيها الطالب تخصصه وعدد الدروات التي حصل عليها في مجال الحاسب الالي )، ثم أربعة محاور وزعت عليهم فقرات الاستبانة

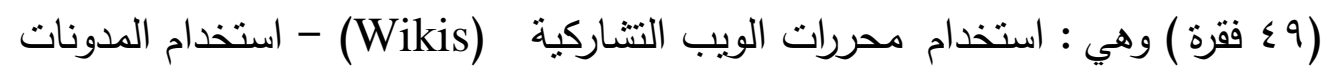
(Blogs) - استخدام الثبكات الاجتماعية (Social Networks)- معوقات الغنات استخدام أدوات الويب 2.0 في العطلية التعليمية. رابعاً : الكفاءة الإحصائية للاستبانة (الصلدق، الثبات) : للتأكد من الكفاءة الإحصائية للاستبانة

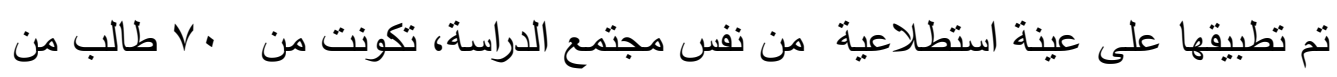

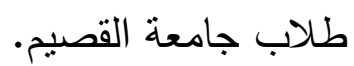

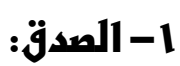

تم الاعتماد على الصدق الظاهري Face Validity)، وصدق الاتساق الداخلي في التحقق من صدق الاستبانة الحالية وهو ما يتضح في النالي: (Internal Consistency)

• الصدق الظاهري:

حيث تم عرض الاستبانة في صورتها المبدئية على عدد من المحكمين الخبراء

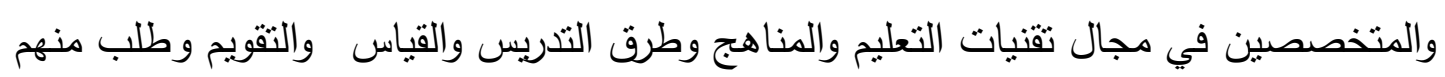

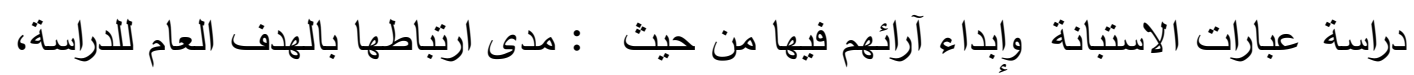

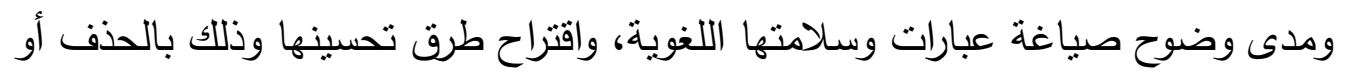

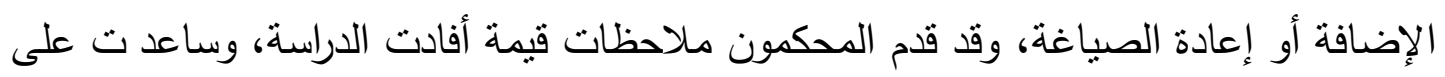
إخراج الاستبانة بصورة جيدة.

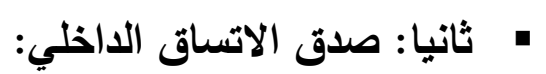

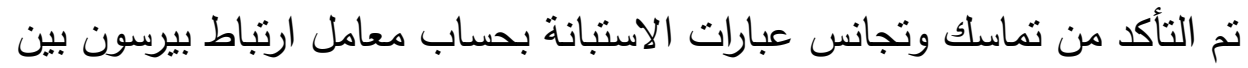

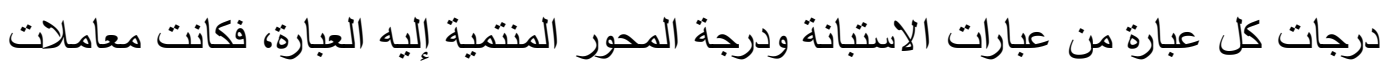

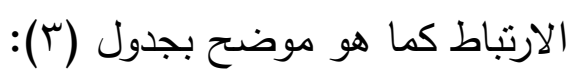

جدول رقم (ץ) معاملات ارتباط بيرسون بين درجات عبارات الاستبانة والدرجة الكلية للمحور

\begin{tabular}{|c|c|c|c|c|c|}
\hline معامل الارتباط & s & | معامل الارتباط & $A$ & معامل الارتباط & A \\
\hline \multicolumn{2}{|c|}{ استخاه الشبكات الاجتماعية Networks) } & \multicolumn{2}{|c|}{ استخلاه الملدونات التليمية العملية ) في } & \multicolumn{2}{|c|}{ استخداه المحرراتية التثاركية (Wikis) في } \\
\hline
\end{tabular}




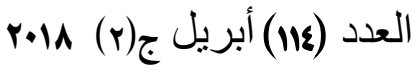

مجلة كلية التربية بينها

\begin{tabular}{|c|c|c|c|c|c|}
\hline معامل الارتباط & 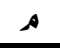 & معامل الارتباط & 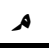 & معامل الارتباط & م \\
\hline$* * \bullet, r r \cdot$ & 19 & $* * \cdot, 7 \mid V$ & 9 & $* * \bullet, 0 \wedge \uparrow$ & 1 \\
\hline$* *,\{O Y$ & r. & ***, OV乏 & 1. & $* * *, 01$ & $r$ \\
\hline$* * \bullet, \S \mid r$ & rI & $* * \cdot, Y \xi Y$ & 11 & ***,, $71 V$ & $r$ \\
\hline$* * \bullet, 09 r$ & $r r$ & $* * \bullet, 0 \wedge 7$ & ir & $* * *, 7 \leqslant \Lambda$ & $\xi$ \\
\hline$* * \bullet, 7 r$ & rr & $* * \bullet$, OrV & ir & \multirow{2}{*}{$* * \bullet, 7 \mid r$} & \multirow{2}{*}{0} \\
\hline$* * \bullet, 099$ & rz & $* * \bullet, 09$. & 18 & & \\
\hline$* * \cdot, 8 Y q$ & ro & $* * \cdot, Y \xi Y$ & 10 & \multirow{2}{*}{$* * *, V Y r$} & \multirow{2}{*}{7} \\
\hline$* *, V I r$ & rq & $* * \bullet, 79 \vee$ & 17 & & \\
\hline$* * \bullet$, Orr & rV & \multirow{2}{*}{$* * \bullet, Y \cdot Y$} & \multirow{2}{*}{ iv } & \multirow{2}{*}{$* * \cdot, 09 r$} & \multirow{2}{*}{ v } \\
\hline$* *$, rar & $r \wedge$ & & & & \\
\hline$* * \bullet, 091$ & $r q$ & \multirow{2}{*}{$* * \bullet, 07 \mathrm{r}$} & \multirow{2}{*}{11} & \multirow{2}{*}{$* * *, 0 \cdot 1$} & \multirow{2}{*}{$\wedge$} \\
\hline$* * *, 0.0$ & $r \cdot$ & & & & \\
\hline \multicolumn{6}{|c|}{ معوقات استخدام أدوات الويب2.0 في العملية التعليمية } \\
\hline$* * \bullet$, OAV & 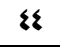 & $* * \bullet, \Sigma\rceil$ \ & rA & $* * \bullet, r v \cdot$ & rI \\
\hline$* * \cdot$, rVo & §o & $* * \bullet,\{\wedge \vee$ & rq & $* *$, rVY & rr \\
\hline$* * \bullet, r \mid \Lambda$ & $\{\eta$ & $* *,\{7 \uparrow$ & ६• & $* * \bullet,\{0 \Lambda$ & rr \\
\hline$* * \bullet$, rАๆ & \&Y & $* * \bullet, \Delta 9 \mathrm{Y}$ & $\$ 1$ & $* * *, \mathrm{rrI}$ & r乏 \\
\hline$* *,, r 90$ & $\S \Lambda$ & $* * \bullet, r q \Lambda$ & $\varepsilon r$ & $* * \bullet$, or. & ro \\
\hline \multirow{2}{*}{$* * \bullet,\{\wedge\}$} & \multirow{2}{*}{$\$ 9$} & \multirow{2}{*}{$* * \bullet, r 99$} & \multirow{2}{*}{$r$} & ***, rAV & rq \\
\hline & & & & $* * \bullet, r \leqslant 1$ & rv \\
\hline
\end{tabular}

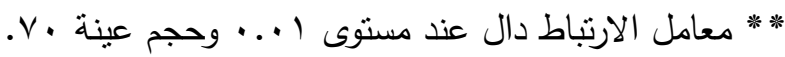

يلاحظ من الجدول (ب) أن معاملات ارتباط درجات كل عبارة م ن عبارات الاستبانة والدرجة الكلية للمحور المنتمية إليه العبارة معاملات ارتباط موجبة ودالة إحصائياً عند مستوى دلالة ( ( . .)، مما يدل على تجانس عبارات الاستبانة في كل محور فيما بينها وتماسكها مع بعضها البعض.

كذلك تم التحقق من الصدق البنائي للجزء الأول من الاس تبانة والخاص بالواقع عن

طريق صدق تجانس واتساق محاور الجزء الأول للاستبانة مع بعضها البعض بحساب

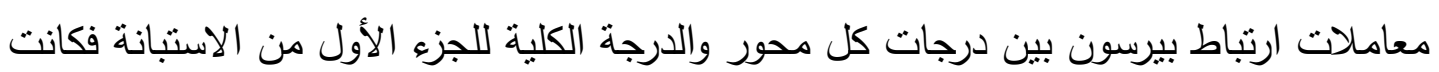
كما هي موضحة بالجدول التالي:

جلول رقم (飞) معاملات الارتباط بين محاور الاستبلة المتعلقة بالواقع والدرجة الكلية للجزء الأول

\begin{tabular}{|c|c|c|}
\hline استخدام الشبكات الاجتماعية Social في العملية التعليمية & استخلام الملدونات (Blogs) في العملية التعليمية & 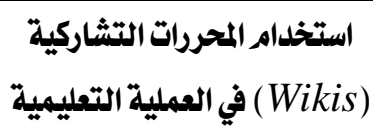 \\
\hline$* * \bullet, O \Lambda \Lambda$ & $* * \bullet, \vee \wedge \bullet$ & $* * \bullet, V \cdots$ \\
\hline
\end{tabular}




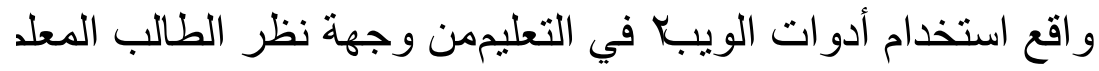

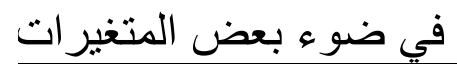

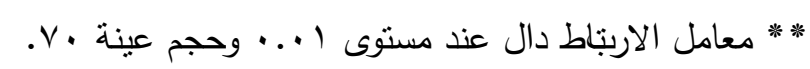

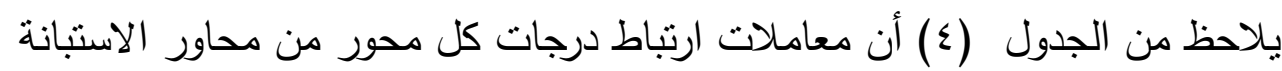

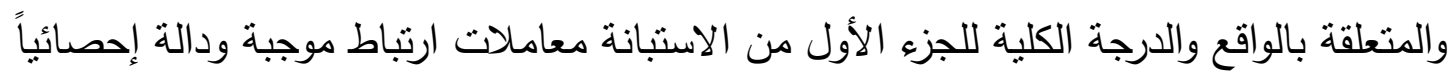
عند مستوى دلالة ( (...)، مما يدل على تجانس محاور الاستبانة المتعلقة بالواقع فيما بينها وتماسكها مع بعضها البعض.

$$
\text { : }
$$

تم التأكد من ثبات الاستبانة المستخدمة في الدراسة الحالية باستخدام معاملات ثبات

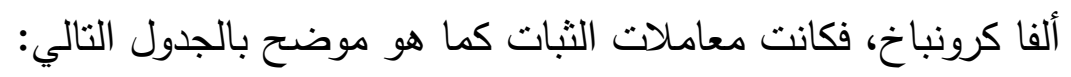

\begin{tabular}{|c|c|c|c|}
\hline معوقات استخداه أدوات 2.0 في العملية & $\begin{array}{c}\text { التعلخدام الشبكات الاجتماعية (Social Networks) } \\
\text { في العملية } \\
\text { التعليمية }\end{array}$ & 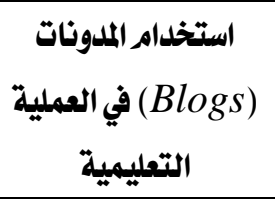 & 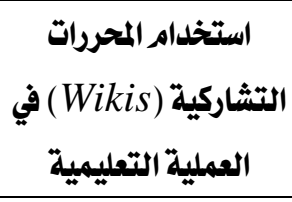 \\
\hline & A & •,AH & - $\mathrm{VA}$. \\
\hline FYY, & \multicolumn{3}{|c|}{ •, } \\
\hline
\end{tabular}

\section{جدول رقم (0) معاملاتثبات ألفا كرونباخ للاستبانة ومحاورها الفرعية}

يتضح من الجدول السابق أن لاستبانة واقع استخدام أدوات الويب $\quad 2.0$ في التعليم

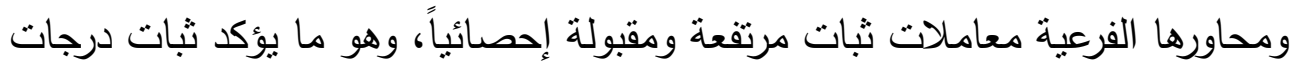

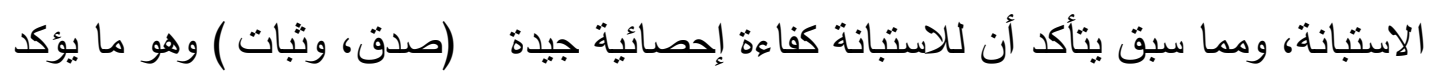
صلاحية استخدامها في البحث الحالي. خامساً: الأساليب الإحصائية المستخلمة : بناءً على طبيعة الدراسة الحالية والأهداف التي تسعى إلى تحقيقها، نم تحليل البيانات

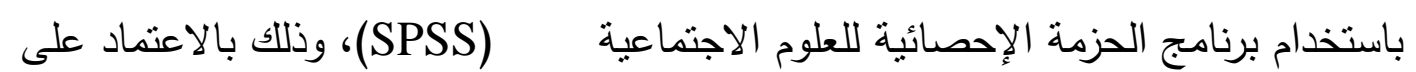

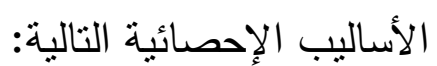

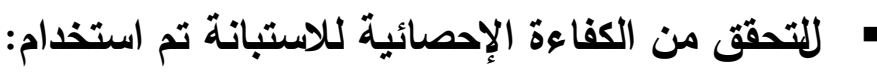
ا ب معامل ارتباط بيرسون Pearson Correlation: للتأكد من الاتساق الداخلي. r كعامل ثبات ألفا-كرونباخ Cronbach's Alpha: للتأكد من الثبات. ثانياً: للإجابة عن أسئلة الدراسة تم استخدام: 
المتوسطات الحسابية Mean والانحرافات المعيارية Standard Deviation: في التعرف على واقع ومعوقات استخدام أدوات الويب 2.0 في العملية التعليمية من وجهة نظر

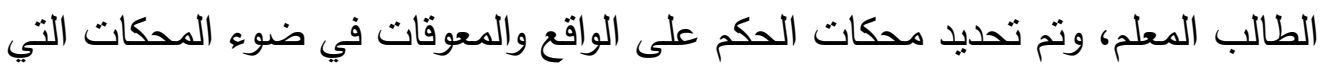

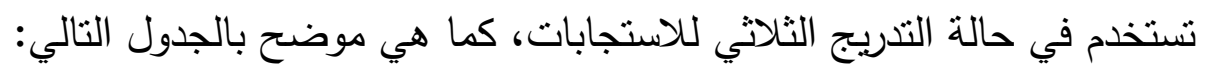

جلول (1) : محكات الحكم على واقع ومعوقات استخدام أدوات الويب 2.0 في العملية التعليمية

\begin{tabular}{|c|c|}
\hline درجة التحقق & متوسط درجات العبارة أو المتوسط الموزون للمحور \\
\hline منخفضة & 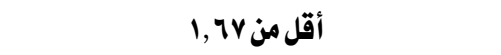 \\
\hline متوسطة & 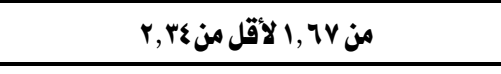 \\
\hline مرتفعة & من عاب, ف فاكثر \\
\hline
\end{tabular}

I تحليل التباين أحادي الاتجاه One Way ANOVA في الكثف عن دلالة الفروق في استجابات الطلاب حول واقع ومعوقات استخدام أدوات الويب العملية التعليمية والتي ترجع لاختلاف متغيرات (التخصص، عدد الدورات التدريبية في مجال الحاسب الآلي). r r بتنبار أقل فرق دال LSD للمقارنات المتعددة في حالة دلالة تحليل التباين أحادي الاتجاه .One Way ANOVA

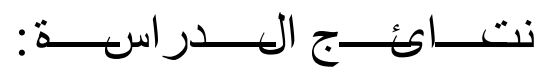

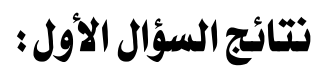

ينص السؤال الأول للاراسة الحالية على "ما واقع استخدام أدوات الويب 2.0 في العطلية التعليمية من وجهة نظر الطالب المعلم بجامعة القصيم؟". للإجابة عن هذا السؤال تم حساب المتوسطات الحسابية والانحرافات المعيارية للدرجات

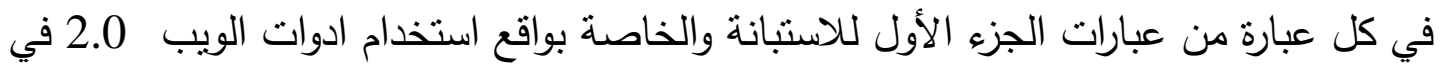
العملية التعليمية، وذللك للتعرف على درجة ومدى تحقق كل عبارة من العبارات، ثم تم حساب المتوسط الموزون والانحراف المعي اري للارجات الكلية في كل محور من محاور الاستبانة والدرجة الكلية ككل، فكانت النتائج كما هي موضحة لعي في التالي: 


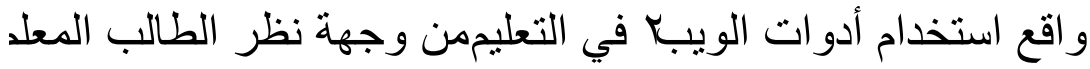

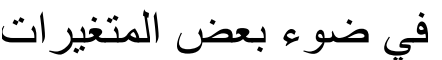

أولاً : فيما يتعلقة باستخدامم مهررات الويب النشاركية (Wikis) في العملية التعليمية:

جدول (V) : المتوسطات والانحرافات الميارية لاستجابات الطلاب حول عبارات

استخداه المحررات التشاركية (Wikis) في العملية التعليمية

\begin{tabular}{|c|c|c|c|c|c|c|}
\hline التزتيب & التحقق & نسبة & الانحراف & 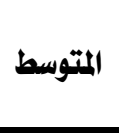 & 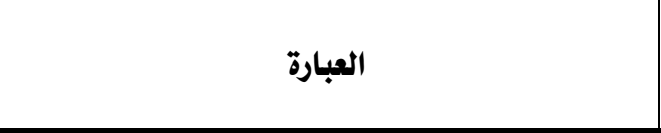 & هـ \\
\hline$r$ & 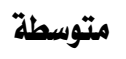 & $\%$ \% , YAr & $\cdot, \vee \vee 乏$ & r, $\cdot$ ฯ. & للحصول على معلومات وفيرة عن المقرر & 1 \\
\hline$\varepsilon$ & متوسطة & $\% 70,117$ & . & 1,904 & لسهولة إعداد أنشطة المادة العلمية المرتبطة بالمقرر & r \\
\hline 0 & 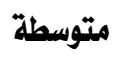 & $\% \neg r, 7 r q$ & $\cdot, \wedge 11$ & I,AYq & لحداثة المعلومات التي تشتمل عليها Wikis & $r$ \\
\hline 1 & 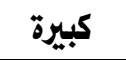 & $\% \wedge 1, r \leqslant$. & $\cdot, \mathrm{YAA}$ & r,\{rr & لسرعة الوصول للمعلومات & \{ \\
\hline$\checkmark$ & ضعيفة & $\%$ \% , \&พ६ & $\cdot, A \cdot r$ & 1,794 & لمشاركة المعلومات مع زملائي في القاعة & ○ \\
\hline r & متوسطة & $\%$ \%,ATV & $\cdot$, Arr & $r, \cdot 90$ & ل لسهولة الاطلاع على خبرات الآخرين & 9 \\
\hline 1 & متوسطة & $\% 71,00$ & $\cdot, \wedge \cdot 9$ & $1, \wedge \leqslant Y$ & $\begin{array}{r}\text { أتلقي المعلومات المتنوعة المرتبطة بالمادة العلمية عبر } \\
\text { Wikis }\end{array}$ & v \\
\hline$\wedge$ & ضميفة & $\% 00,19 \xi$ & •, VHr & 1,707 & ترتبط بمجال تخصصي باستمرار على المقالات المختلفة في Wikis والتي & $\wedge$ \\
\hline \multicolumn{2}{|c|}{ متوسطة } & $\% १\{, 971$ & $\cdot, 01 \varepsilon$ & $1,9 \leqslant 9$ & \multicolumn{2}{|l|}{ العملية التعليمية (المحور الأول ككل) المحردات التشا ركية (Wikis) في } \\
\hline
\end{tabular}

يتضح من الجدول السابق أن : استخدام المحررات النتاركية (Wikis) في العملية

التعليمية (المحور الأول ككل ) متحقق بدرجة متوسطة، حيث بلغ المتوسط الوزني للارجات

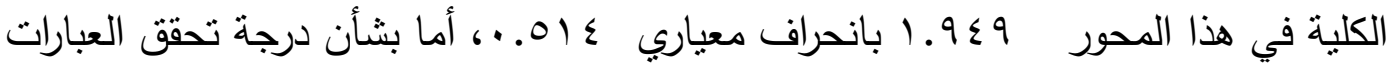
الفرعية في هذا المحور فيلاحظ أن عبارة واحدة متحققة بدرجة كبيرة و عبارتين متحققتان بدرجة ضعيفة وباقي العبارات متحققة بدرجة منوسطة، وهو ما يتضح من التارة والتالي:

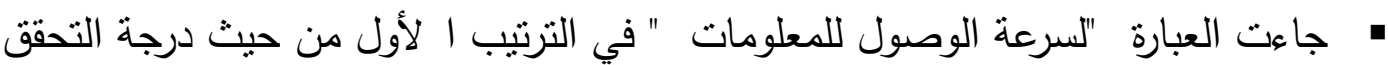

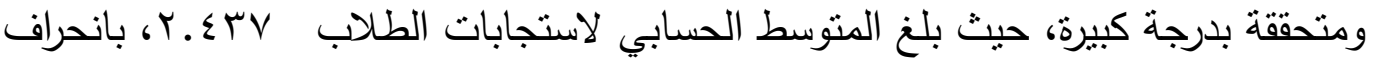

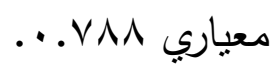

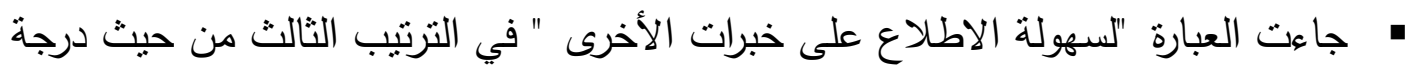

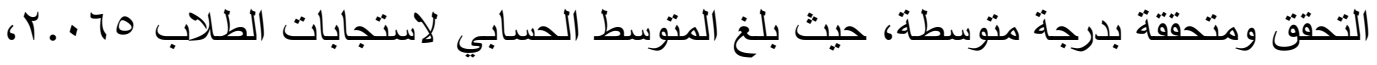




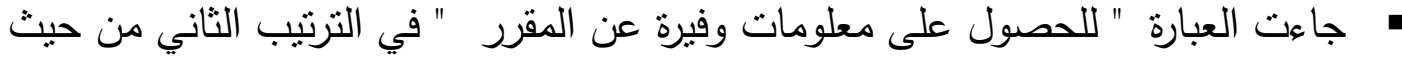
درجة التحقق ومتحققة بدرجة منوسطة، حيث بلغ المتوسط الحسابي لاستجابات الطلاب

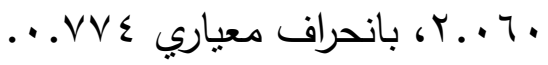
• جاءت العبارة "لسهولة إعداد أنشطة المادة العلمية المرتبطة بالمقرر " في الترتيب الرابع من

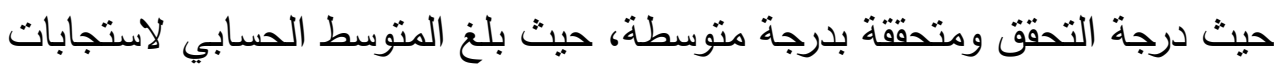

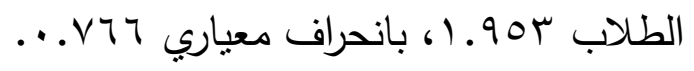
• جاءت العبارة " لحداثة المعلومات التي تنتمل عليها Wikis " في الترتيب الخامس من حيث درجة التحقق ومتحققة بدرجة متوسطة، حيث بلغ المتوسط الحسابي لاستجابات

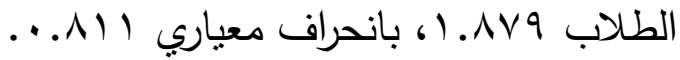

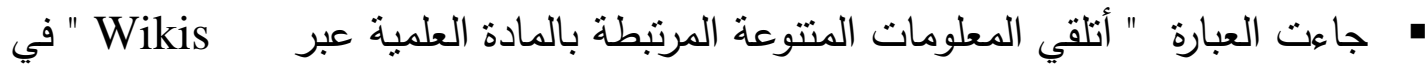

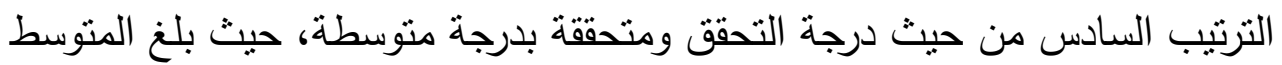

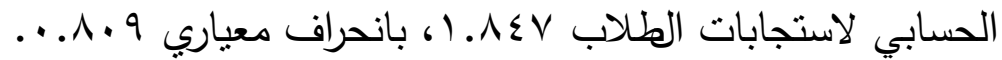

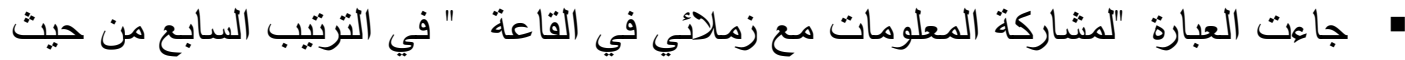

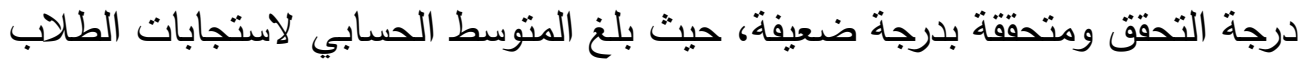

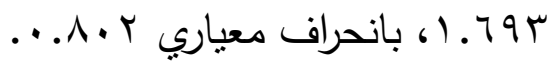

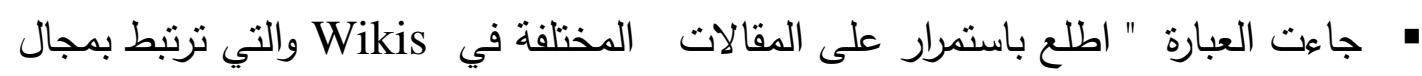
تخصصي" في النرتيب الثامن والأخير من حيث درجة التحقق ومتحققة بدرجة ضعيفة،

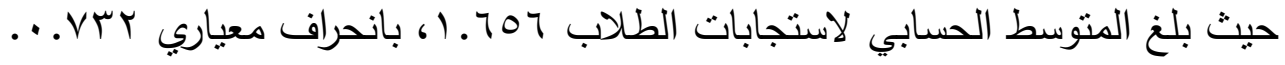
ثانياً: فيما يتعللة باستندام المدونات (Blogs) في العملية التعليمية:

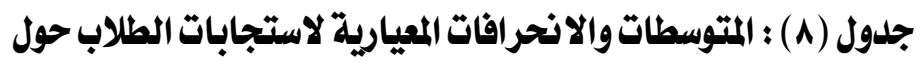
عبارات استخدام المدونات (Blogs) في العملية التعليمية

\begin{tabular}{|c|c|c|c|c|c|c|}
\hline الترتيب & 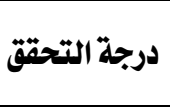 & التحقق & 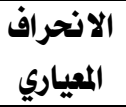 & 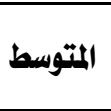 & العبـــــــــــــارة & مر \\
\hline 0 & متوسطة & $\% \uparrow,, \cdots$ & $\cdot, \mathrm{V} \leqslant \varepsilon$ & $1, \wedge \cdot \cdot$ & لاشتمال المدونات على معلومات حليثة & 9 \\
\hline$r$ & متوسطة & $\% 9 r, 19$ & $\cdot, \lambda \cdot r$ & $1,19$. & للحصول على معلومات أكثر تفصيلا & 1. \\
\hline$\varepsilon$ & متوسطة & $\% 71,00$ & •, rr. & $1, \wedge \leqslant V$ & ألخرى اشتمال المدونات على معلومات غير موجودة بمصادر & 11 \\
\hline$r$ & متوسطة & $\% 01,910$ & •, $\mathrm{AAI}$ & I,V V V & لدقة المعلومات المتاحة بالمدونات. & ir \\
\hline$r$ & متوسطة & $\% 7 \xi, 701$ & $\cdot, 170$ & 1,9६. & لسهولة الوصول للمعلومة بالمدونة & It \\
\hline 1 & متوسطة & $\% 9 \xi, \wedge \cdot \eta$ & •, AOr & $1,9 \leq \xi$ & لحرية التعبير عن الرأي والاطلاع على الآراء المختلفة & 18 \\
\hline$\wedge$ & متوسطة & $\%$ or, r.q & $\cdot, A \cdot A$ & I, & استخلدم المدونة كحقيبة الكترونيه لحفظ اعمالي & 10 \\
\hline
\end{tabular}




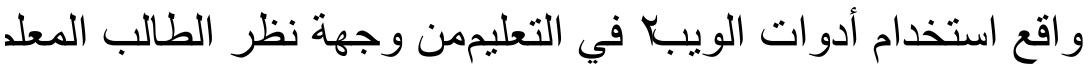

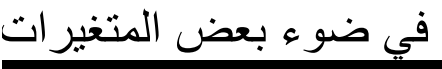

\begin{tabular}{|c|c|c|c|c|c|c|}
\hline الترتيب & درجة التحقق & التحقبة & 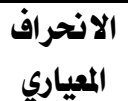 & المتوسط & العبـــــــــــارة & هـ \\
\hline & & & & & وملفات الانجاز & \\
\hline 7 & متوسطة & $\%$ \% , rro & • $\vee \wedge A$ & 1, YvY & 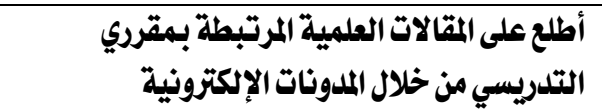 & 17 \\
\hline 9 & ضعيفة & $\% \cdot 0 \cdot, \Delta 0 \%$ & •, $\vee \wedge \varepsilon$ & $1,0 \mathrm{rq}$ & 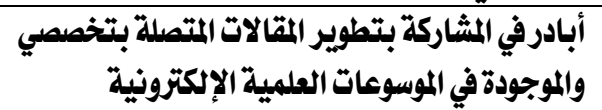 & iv \\
\hline 1. & ضعيفة & $\% \varepsilon q, 1 \leqslant \vee$ & •, 977 & $1, \xi \vee \xi$ & قدرست بإنشاء مدونة ترتبط موضوعها بالمقررات التي & in \\
\hline \multicolumn{2}{|c|}{ متوسطة } & $\% \Delta \Lambda, \Lambda T Y$ & •, §१६ & $1, \times 70$ & 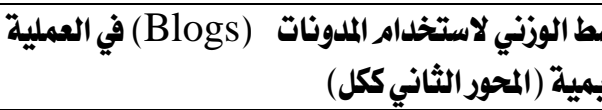 & \\
\hline
\end{tabular}

$$
\text { يتضح من الجدول السابق أن: النئية }
$$

استخدام المدونات (Blogs) في العملية التعليمية (المحور الثاني ككل ) متحقق بدرجة

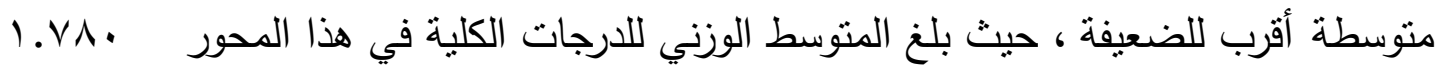

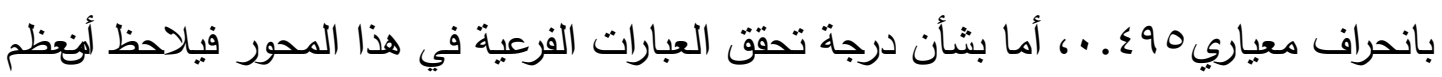

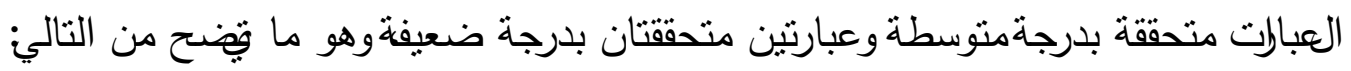

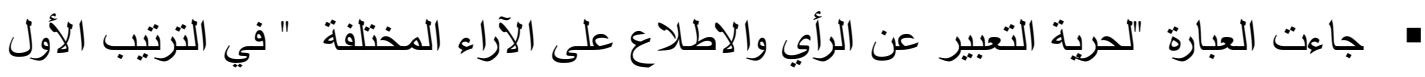

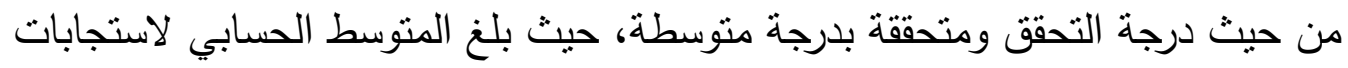

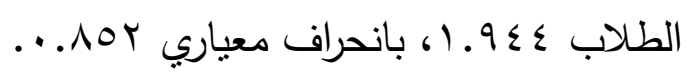

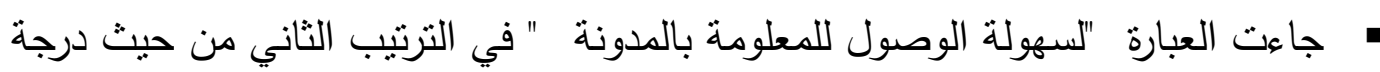

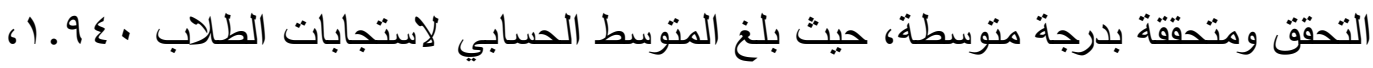

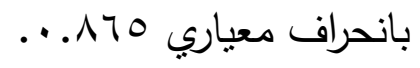

• جاءت العبارة "للحصول على معلومات أكثر تفصيلا " في الترتيب الثالث من حيث درجة التحقق ومتحققة بدرجة منوسطة، حيث بلغ المتوسط الحسابي لاستجابات الطلاب ـ ـ1. 1،

$$
\text { بانحراف معياري r.A. ب... }
$$

• جاءت العبارة "لاشتمال المدونات على معلومات غير موجودة بمصادر أخرى " في الترتيب

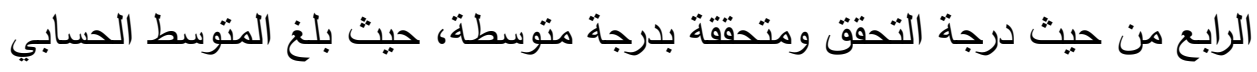

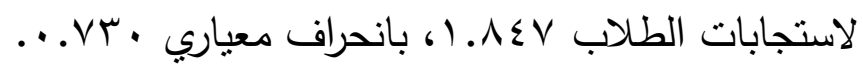




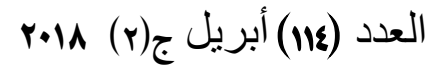

مجلة كلية التربية ببنها

• جاءت العبارة "لاشتمال المدونات على معلومات حديثة " في الترتيب الخامس من حيث

درجة التحقق ومتحققة بدرجة متوسطة، حيث بلغ المتوسط الحسابي لاستجابات الطلاب

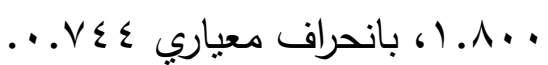

• جاءت العبارة "أطلع على المقالات العلمية المرتبطة بمقرري التدريسي من خلال المدونات الإلكتونية" في الترتيب السادس من حيث درجة التحقق ومتحققة بدرجة متوسطة، حيث بلغ

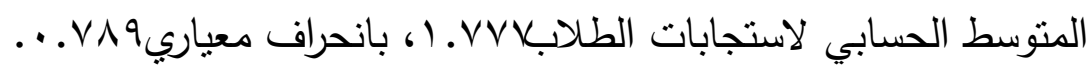

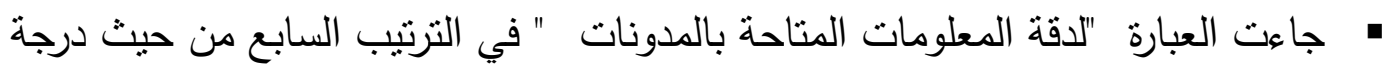

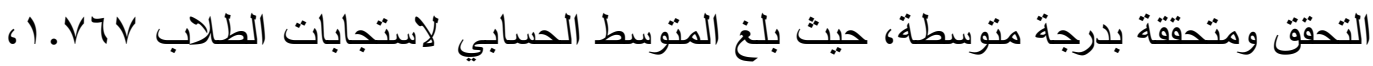

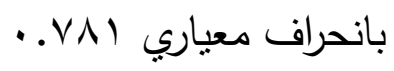

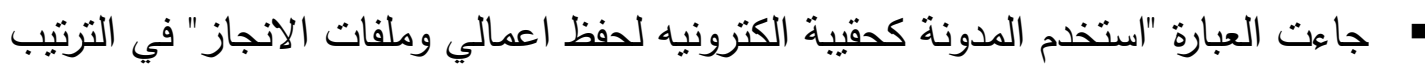
الثامن من حيث درجة التحقق ومتحققة بدرجة منوسطة، حيث بلغ المتوسط الحسابي

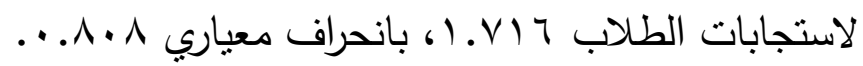

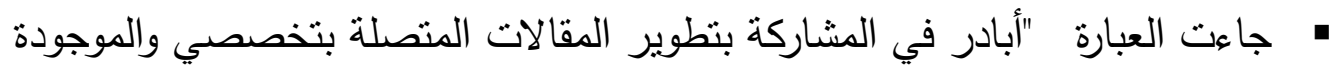

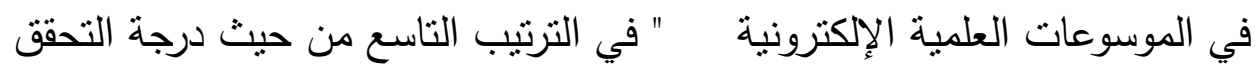

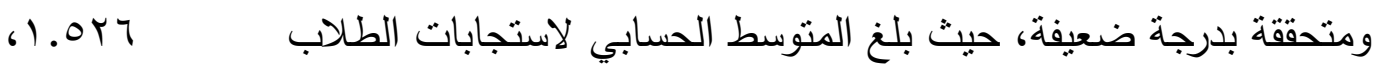

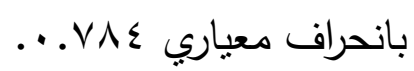
• جاءت العبارة "قمت بإنثاء مدونة ترتبط موضوعها بالمقررات التي ادرسها " في الترتيب

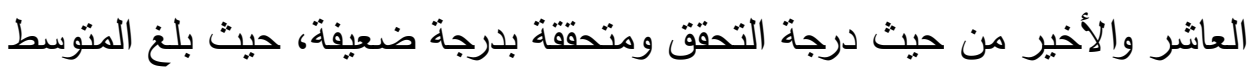

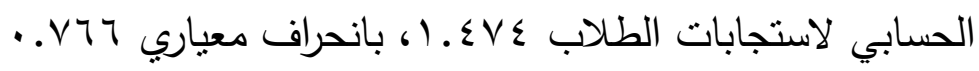

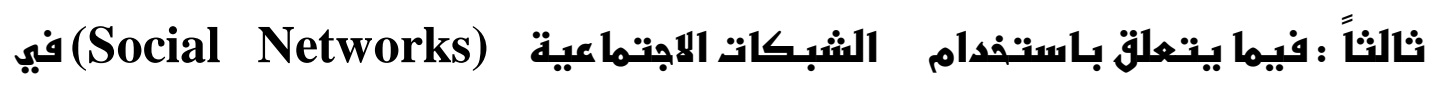
العملية التنعليمية:

جلدول (9) : المتوسطات والانحرافات المعيارية لاستجابات الطلاب حول عبارات استخدام الشبكات الاجتماعية (Social Networks) في العملية التعليمية

\begin{tabular}{|c|c|c|c|c|c|c|c|}
\hline الترتيب & التحقة & التحبة & الالانحراف & 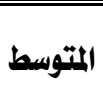 & & 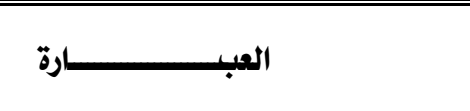 & هـ \\
\hline$r$ & كبيرة & $\% \wedge \xi, 1 \wedge \uparrow$ & $\cdot, \mathrm{Vq}$. & r,orT & 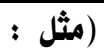 & امتلك ح ساب على الشبكات الاجتماعية & 19 \\
\hline
\end{tabular}

1.0 
و اقع استخدام أدوات الويبً في التعليمن وجهة نظر الطالب المعلد في ضوء بعض ونه المتغير ات

\begin{tabular}{|c|c|c|c|c|c|c|}
\hline الترتيب & التحقق & نسبة & الانحراف - المياري & المتوسط & 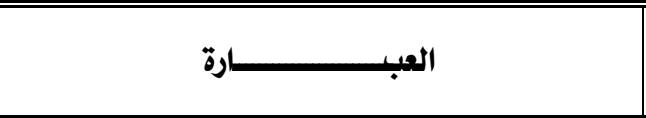 & هـ \\
\hline & & & & & اليوتيوب الفيس بولك، سكاي بي وغيرها) & \\
\hline r & 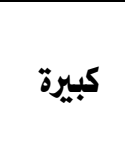 & \%Ar,rrY & $\cdot, r \cdot 9$ & $r,\{r$. & 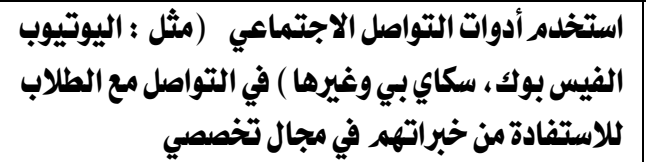 & r. \\
\hline 1 & متوسطة & $\% \vee \&, \& 19$ & •, rro & r,YrT & 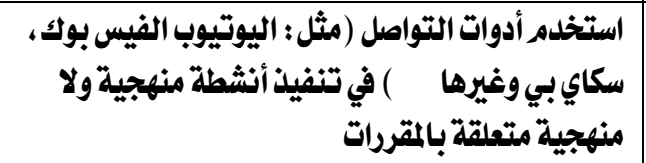 & r \\
\hline 0 & متوسطة & $\%$ \%,$\cdot \vee q$ & $\cdot$, Y07 & r, rol & 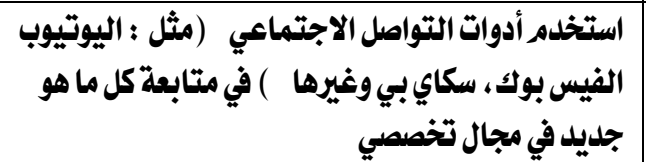 & rr \\
\hline 9 & متوسطة & $\% 77,77 \vee$ & $\cdot, \Lambda \cdot r$ & $r, \cdots$ & 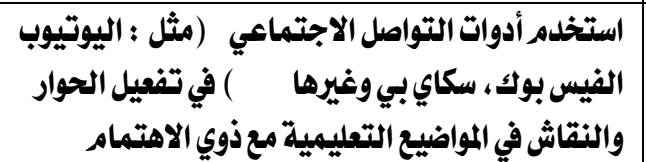 & r \\
\hline$\wedge$ & متوسطة & $\%$ \%, Arv & $\cdot, \mathrm{v90}$ & $r, \cdot 90$ & 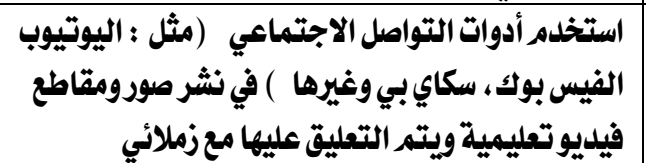 & rq \\
\hline$\xi$ & كبيرة & $\% A r,|Y|$ & •, Yor & $r, \$ 70$ & استخلدم أدوات التواصل الاجتماعي لقلة تكلفتها & ro \\
\hline 1 & 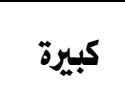 & $\% \wedge 9,71 \%$ & $\cdot, 097$ & r, ११^ & إلى المعلومة أدوات التواصل الاجتماعي لسرعة الوصول & rq \\
\hline$\checkmark$ & متوسطة & $\% 79,1 \xi Y$ & $\cdot$, ArA & $r, \bullet \vee \xi$ & 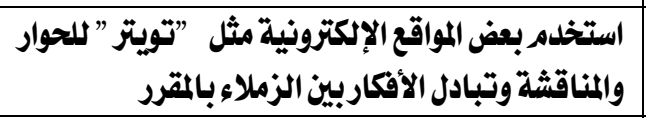 & rr \\
\hline 11 & متوسطة & $\% 7$. . vrvo & $\cdot, \wedge 71$ & 1,AYT & 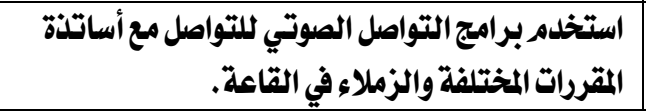 & YA \\
\hline 1. & متوسطة & $\% \eta 1, \wedge \uparrow$. & •, var & 1,107 & 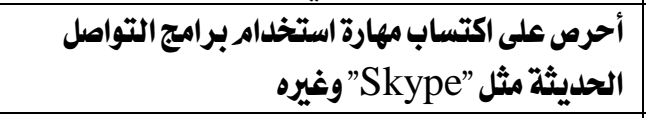 & $r q$ \\
\hline ir & متوسطة & $\% 7,100$ & , AT. & $1,1 \cdot 0$ & 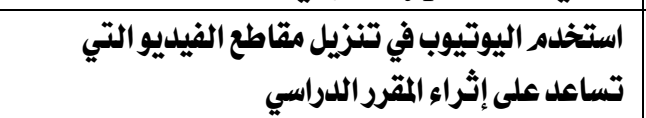 & $r$. \\
\hline \multicolumn{2}{|c|}{ متوسطة } & \% Vr,QYT & r & $r, 1 A \Lambda$ & \multicolumn{2}{|l|}{ 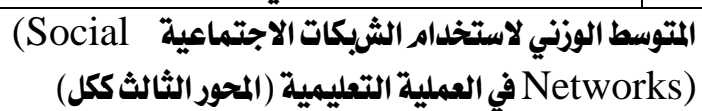 } \\
\hline
\end{tabular}

استخدام الثبكات الاجتماعية (Social Networks) في العطلية التعليمية (المحور

الثالث ككل) متحقق بدرجة منوسطة، حيث بلغ المتوسط الوزني للارجات الكلية في هذا المحور

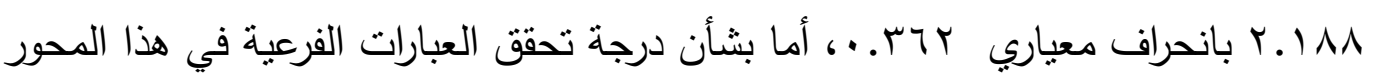




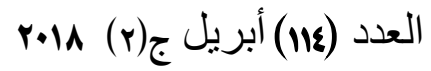

مجلة كلية التربية ببنها

فيلاحظ أن من هذه العبارات ما تحقق بدرجة كبيرة (ع عبارات) ومنها ما تحقق بدرجة متوسطة

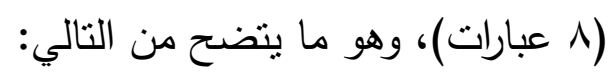

• جاءت العبارة "استخدم أدوات التواصل الاجتماعي لسرعة الوصول إلى المعلومة" في الترتيب

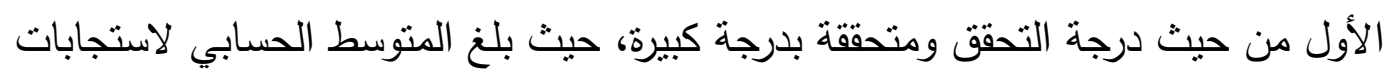

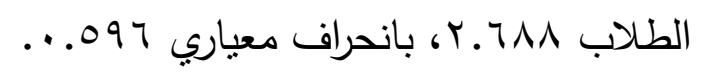

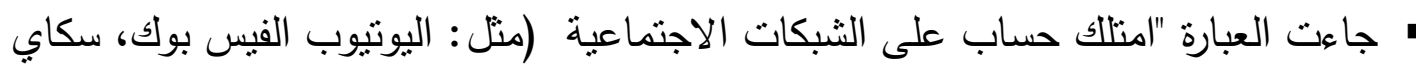

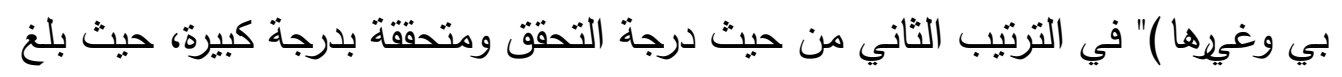

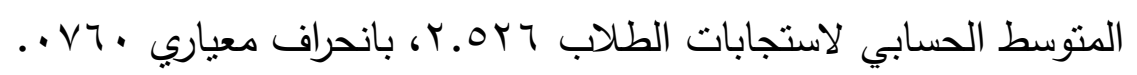

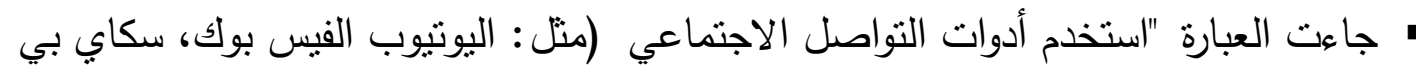
وغيرها) في التواصل مع الطلاب للاستفادة من خبراتهم في مجال تخصصي " في الترتيب

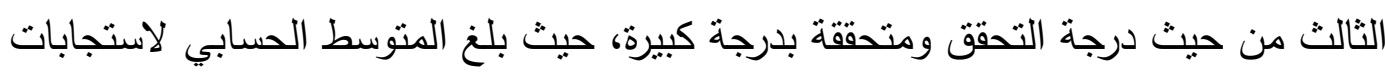

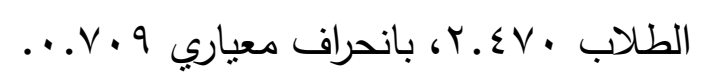
• جاءت العبارة "استخدم أدوات التواصل الاجتماعي لقلة تكلفتها " في التزتيب الرابع من حيث

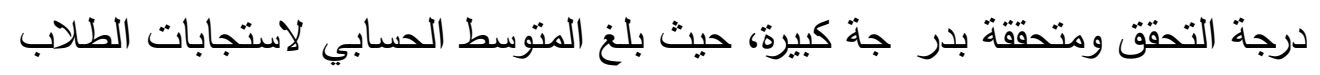

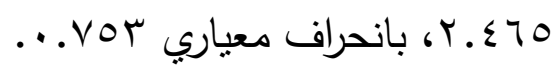

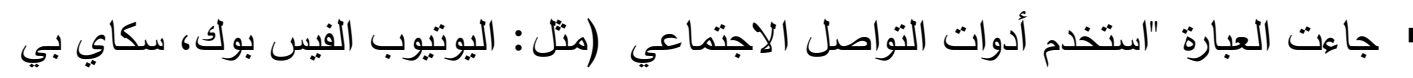

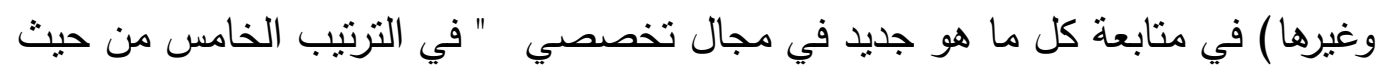

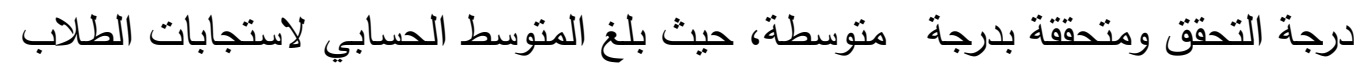

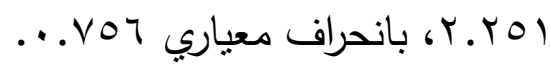
" جاءت العبارة "استخدم أدوات التواصل (متل : اليوتيوب الفيس بوك، سكاي بي وغيرها ) في

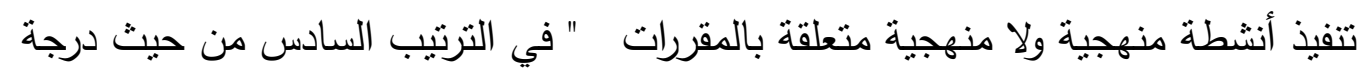

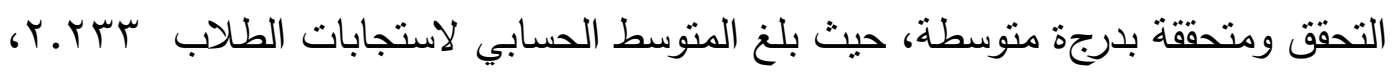

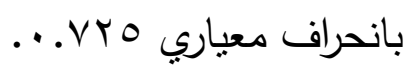




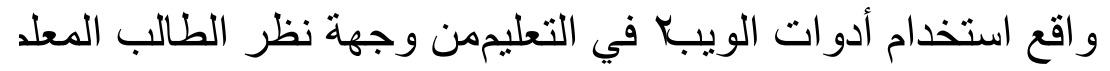
في ضوء بعض المتغير ات

• جاءت العبارة "استخدم بعض المواقع الإلكترونية منل "تويتر" للحوار والمناقثة وتبادل الأفكار

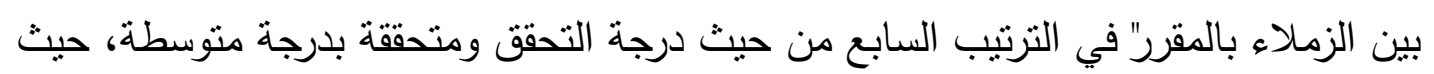

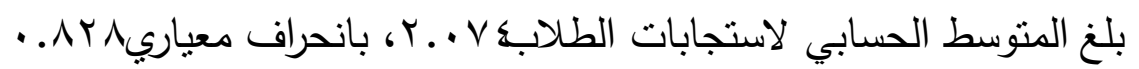

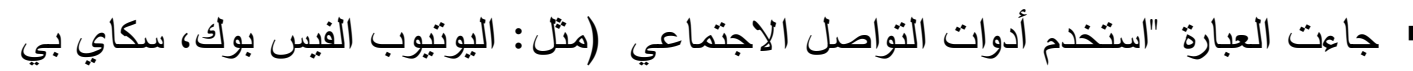

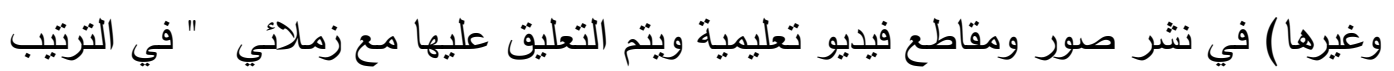

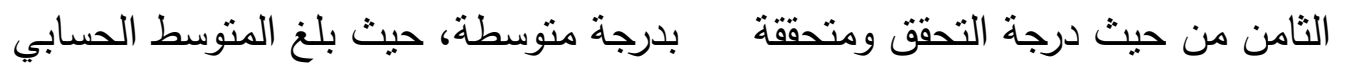

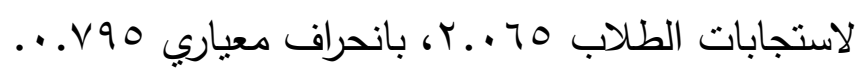

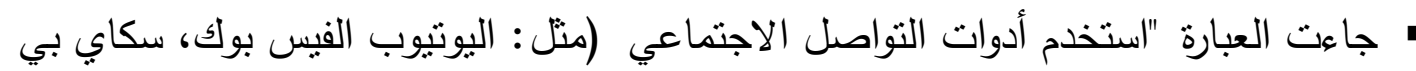

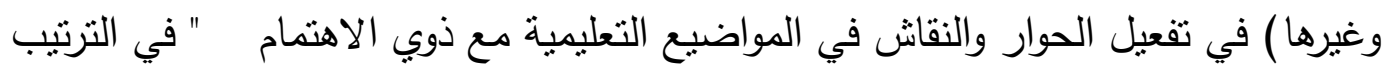

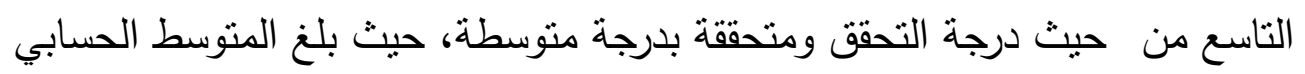

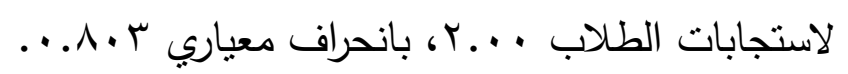

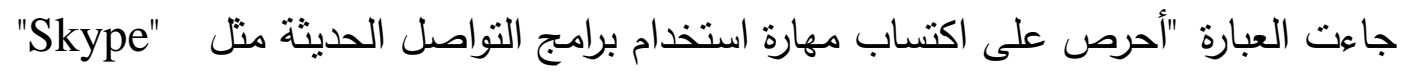

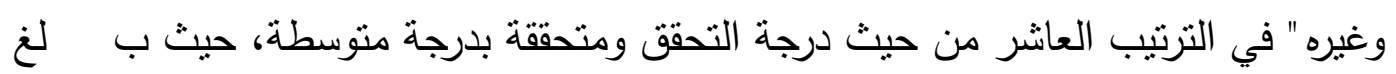

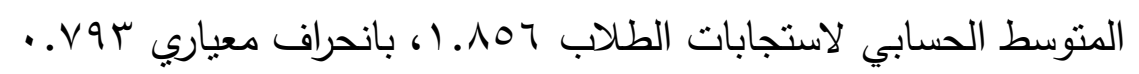

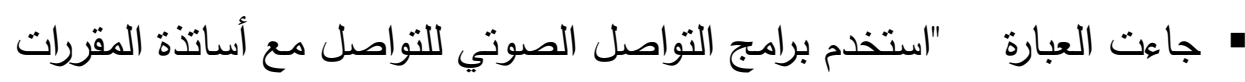

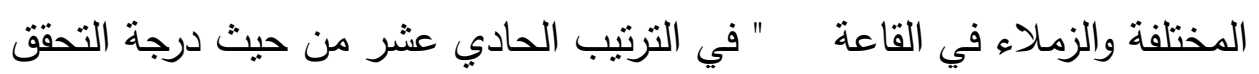

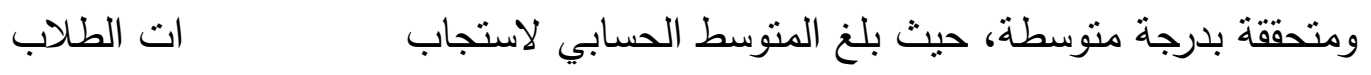

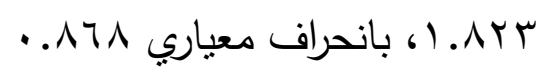

• جاءت العبارة "استخدم اليوتيوب في تنزيل مقاطع الفيديو التي تساعد على إثراء المقرر

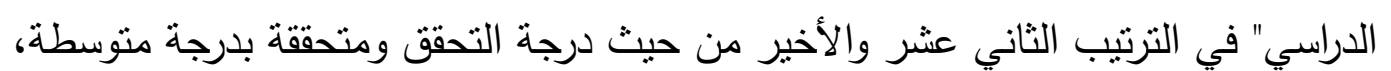

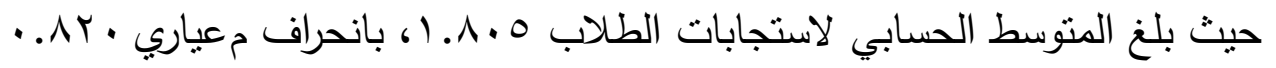
ويمكن تلخيص النتائج السابقة والمتعلقة بواقع استخدام ادوات الويب 2.0 في العملية التعليمية من وجهة نظر الطالب المعلم في الجدول التالي: 


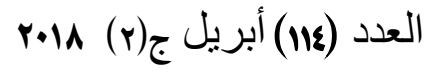

مجلة كلية التربية ببنها

جدول (•1) : واقع استخلام ادوات الويب 2.0 في العملية التعليمية منوجهة نظر الطالب المعله

\begin{tabular}{|c|c|c|c|c|c|c|}
\hline الترتيب & التحقق & التحقق & المياري - المراف & 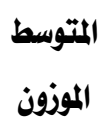 & ب في العملية & التعليمية استخداه أدوات الوي \\
\hline r & متوسطة & $\% १ \xi, q 71$ & •, 018 & $1,9 \& 9$ & \multicolumn{2}{|c|}{ التعليمية المحررات التشاركية (Wikis) في العملية } \\
\hline$r$ & متوسطة & $\% \Delta \Lambda, A T Y$ & •, $\{9 \xi$ & $1, \times 90$ & \multicolumn{2}{|c|}{ استخذام المدونات (Blogs) في العملية التعليمية } \\
\hline 1 & متوسطة & $\%$ \% ,qRr & זעז, & $r, 1 \wedge A$ & \multicolumn{2}{|c|}{ Networks) } \\
\hline & & $\% 70$,orA & •, \&OY & $1,97 \mathrm{~V}$ & 2.0 2.0 في العملية & واقتع استخلام أدوات الويب \\
\hline
\end{tabular}

يتضح من الجدول السابق أن واقع استخدام أدوات الويب 2.0 في العملية التعليمية

ككل متحقق بدرجة منوسطة حيث كان المنوسط الحسابي للارجات الكلية على الجزء الاول من

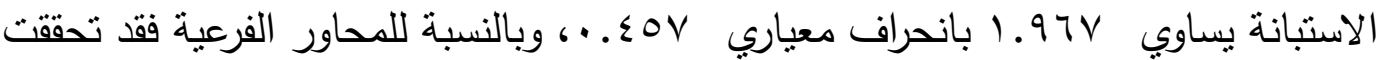
جميعها بدرجة متوسطة، وجاء في الترتيب الأول استخدام الثبكات الاجتماعية Social)

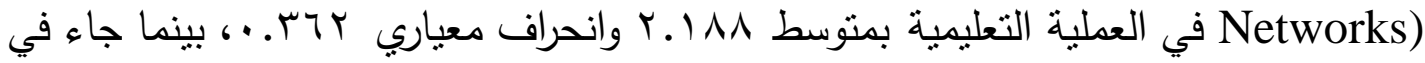

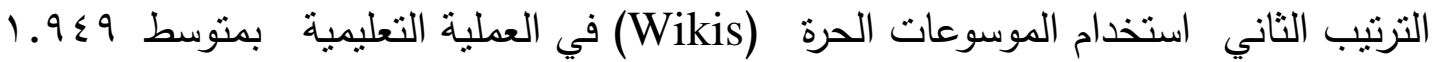
وانحراف معياري ؛ ا0. ،، وفي الترتيب الأخير جاء استخدام المدونات (Blogs) في العطلية

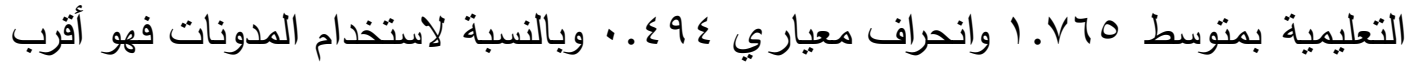
للضعيف.

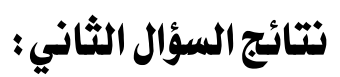

ينص السؤال الثاني للبحث الحالي على "ما معوقات استخدام أدوات الويب 2.0 في العطلية التعليمية من وجهة نظر الطالب المعلم بجامعة القصيج؟". للإجابة عن هذا السؤال تم حساب المتوسطات الحسابية والانحرافات المعيارية للارجات في كل عبارة من عبارات الجزء الثاني للاستبانة والخاصة بمعوقات استخدام ادوات الويب 2.0 في العملية التعليمية، وذللك للتعرف على درجة ومدى تحقق كل معوق من هذه المعوقات، ثم ثم حساب المتوسط الموزون والاتحراف المعياري للارجات الكلية للمعوقات، فكانت النتائج كما هي موضحة في التالي: 
و اقع استخدام أدوات الويبً في التعليمن وجهة نظر الطالب المعلد

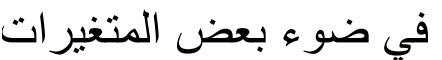

جدول (11) : المتوسطات والانحرافات المعيارية لاستجابات الطلاب

حول معوقات استخلام ادوات الويب 2.0 في العملية التعليمية

\begin{tabular}{|c|c|c|c|c|c|c|}
\hline 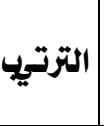 & دالموقة & نسبة & الانحراف & | المتوسط & كــــارة & \\
\hline iv & 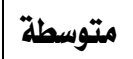 & $\%$ $\%$, ^₹० & •, YAr & 1,190 & | علدم معرفتي بكيفية التسجيل او التعامل مع أدوات الويب 2.0 & \\
\hline 11 & 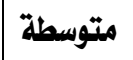 & $\% .07,1 \% \varepsilon$ & $\cdot$, rro & $1,7 \wedge \varepsilon$ & |صعوبة توافر الوقت اللازم للتعامل مع أدوات الويب0.2. & \\
\hline 17 & 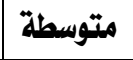 & $\% 71, \% 90$ & $\cdot$, rro & $1, \wedge \leqslant Y$ & |عدم ثقتي بالمعلومات المتاحة على وسائل التواصل الاجتماعي. & \\
\hline 19 & 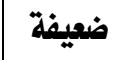 & $\%$ ०६, ov₹ & $\cdot, r \cdot 9$ & $1,7 r v$ & |عدم قناعتي بأهميتها في العملية التعليمية. & \\
\hline ir & 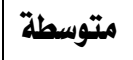 & $\% \vee \cdot, \cdot \vee \wedge$ & $\cdot, \mathrm{VIT}$ & $r, 1 \cdot r$ & معظم المعلومات الواردة بها عبارة عن آراء شخصية تعبر عن وجهات نث & \\
\hline 1. & متوسطة & $\%$ VI, VAr & $\cdot, \Lambda \cdot r$ & r, 10r & | علدم حرص أصحاب المدونات على تحلديث المعلومات بها. & \\
\hline r & 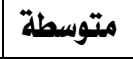 & $\% \vee \vee, r \cdot q$ & $\cdot$, YAV & r, riq & كثرة الإعلانات المزعجة بمواقع التواصل الاجتماعي. & \\
\hline$\checkmark$ & 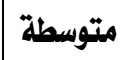 & $\%$ \%r, $\cdot r r$ & $\cdot$, YYY & $r, 191$ & علدم دقة المعلومات الواردة بهمواقع التواصل الاجتماعي. & \\
\hline 10 & 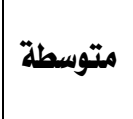 & $\% q r,|v|$ & $\cdot$, ४^9 & $1 / 170$ & | أدوات الويب 2.0 عدافر الأجزة والبرمجيات التي تساعدني على استخدام & \\
\hline ir & متوسطة & $\% 70,117$ & $\cdot, \mathrm{\vee A}$ & 1,904 & |رتفاع التكلفة المادية لاقتناء الأجهزة والبرمجيات. & \\
\hline $1 \varepsilon$ & متوسطة & $\%$ \%r,VYI & $\cdot, \mathrm{V} \leqslant \mathrm{V}$ & $1,91 \mathrm{r}$ & | صعوبة مواكبة التطور السريع لتطبيقات الويب & \\
\hline$\wedge$ & متوسطة & $\% V r, \cdot r r$ & $\cdot, \vee \wedge 9$ & $r, 191$ & | قلقة الادلة باللفة العربية لمواقع الويب 2.0 & \\
\hline 11 & 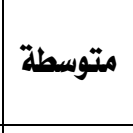 & $\% \vee 1, \cdots 1$ & $\cdot$, YrY & $r, i r \cdot$ & | قلقة وجود دورات وورش تلدريبية حول توظيف أدوات الويب 2.0 في & \\
\hline 0 & 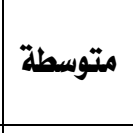 & $\%$ ४ $\leqslant, 1 \cdot 9$ & $\cdot, 790$ & r,rrr & | العملية التعليمية. & \\
\hline 9 & 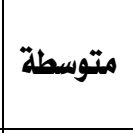 & $\%$ \%r,VIr & • & $r,|\wedge|$ & | التواصل الاجتماعي. & \\
\hline 7 & متوسطة & $\% \vee r, \vee \vee A \mid$ & $\cdot, 7 \wedge \varepsilon$ & r,Yls & | التعليمية اعتماد المقررات على توظيف أدوات الويب 2.0 في العملية & \\
\hline 1 & 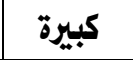 & $\% \wedge 1, r \cdot 0$ & $\cdot, 790$ & r,§ol & نقص الأنثطة التعليمية التي تتطلب استخدام أدوات الويب2.0 & \\
\hline r & كبيرة & $\%$ \% 1, r90 & $\cdot, \mathrm{Yl \varepsilon}$ & 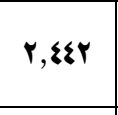 & | التعليمية. & \\
\hline$\xi$ & 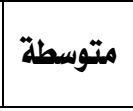 & $\% \vee \vee, 0 \wedge 9$ & $\cdot, \mathrm{V} \leqslant \mathrm{Y}$ & $r, r q \Lambda$ & | العملية التعليمية. & \\
\hline \multicolumn{2}{|c|}{ متوسطة } & $\% .79,\{81$ & •,rr. & $r, \bullet A r$ & المتوسط الوزني لمعوقات استخدام أدوات الويب 2.0 في العملية & \\
\hline
\end{tabular}


يتضح من الجدول السابق أن معوقات استخدام أدوات الويب 2.0 في العملية التعليمية

(المعوقات ككل ) جاءت بدرجة منوسطة، حيث بلغ المتوسط الوزني للارجات الكلية في هذا

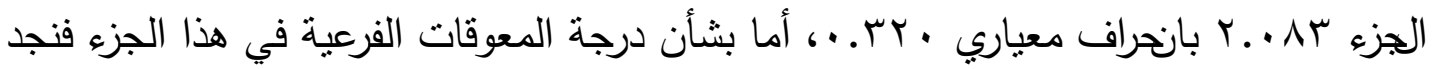
أن بعض المعوقات متحقق بدرجة كبيرة ومنها ما هو متحقق بدرجة منوسطة ومنها ما هو

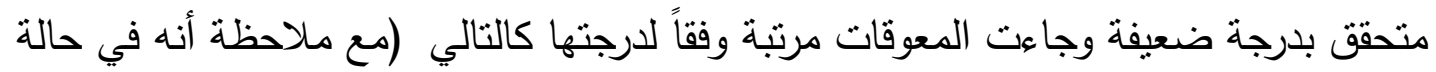
تساوي المتوسطات للعبارات تلك ون الأولوية في الترتيب للعبارة ذات الانحراف المعياري الأقل والذي يدل على تجانس واتفاق أكثر): • جاءت العبارة "نقص الأنثطة التعليمية التي تتطلب استخدام أدوات الويب 2.0" في

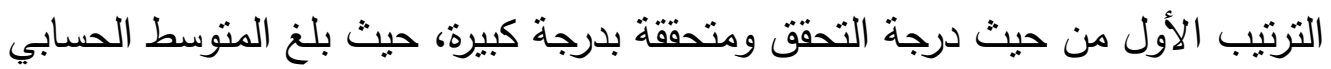

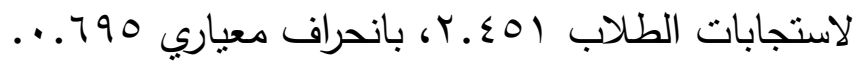

" جاءت العبارة "نقص الوعي لدى المعلمين بأهمية أدوات الويب 2.0 في العملية التعليمية "

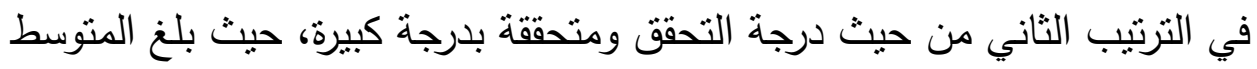

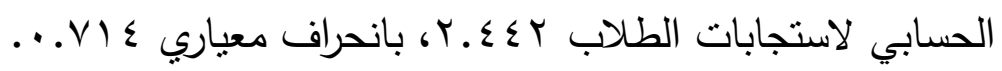

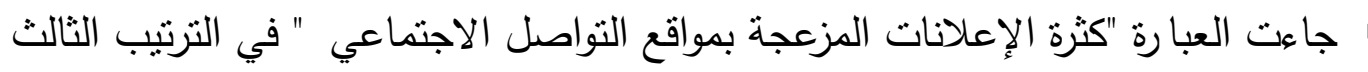
من حيث درجة التحقق ومتحققة بدرجة متوسطة، حيث بلغ المتوسط الحسابي لاستجابات

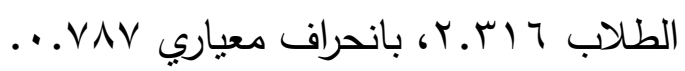
جاءت العبارة "نقص المهارات اللازمة لدى الأساتذة لاستخدام أدوات الويب العملية التعليمية " في الترتيب الرابع من حيث درجة التحقق ومتحققة بدرجة متوسطة، لهنه

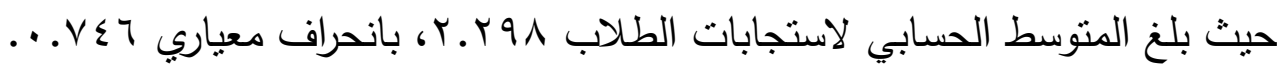
" جاءت العبارة "نقص التتجيع من قبل المعلم لاستخدام أدوات الويب 2.0 في العملية

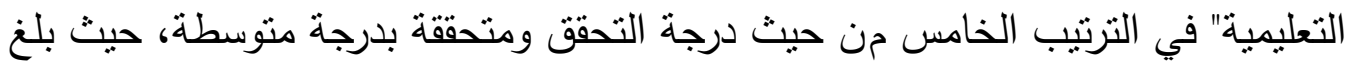
المتوسط الحسابي لاستجابات الطلاب بr.Y.T، بانحراف معياري 790. ...

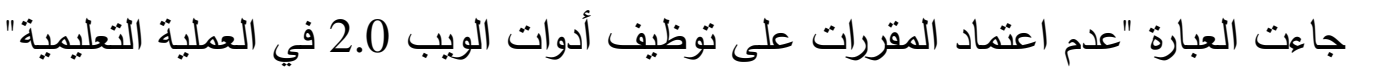
في الترتيب السادس من حيث درجة التحقق ومتحققة بدرجة منوسطة، حيث بلغ المتوسط

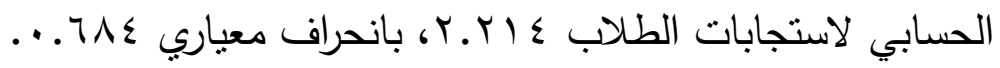




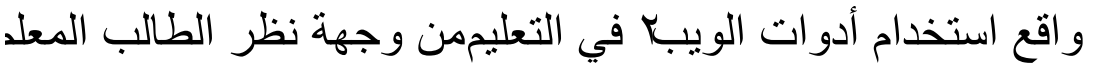
في ضوء بعض المن المتغير ات

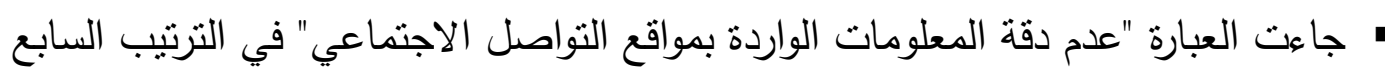

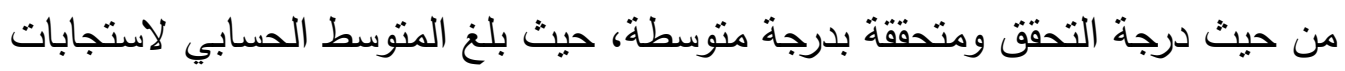

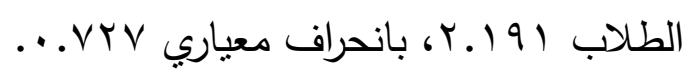

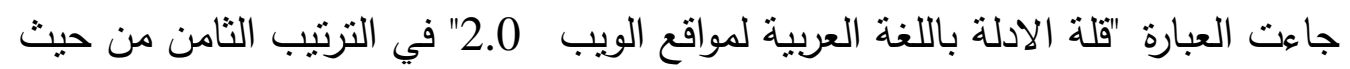

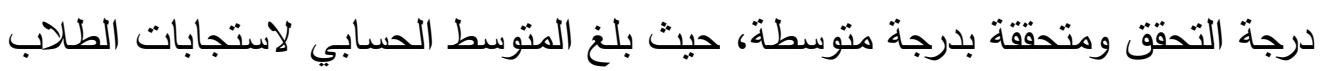

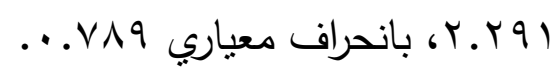

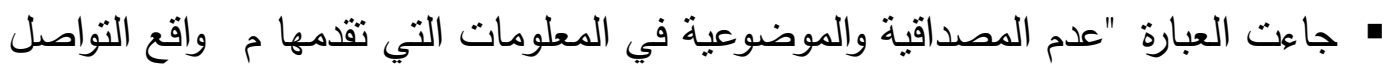
الاجتماعي" في الترتيب التاسع من حيث درجة التحقق ومتحققة بدرجة منوسطة، حيث

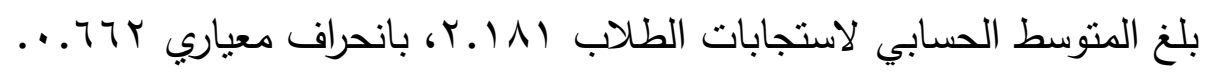

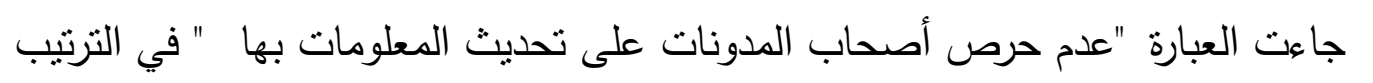
العاشر من حيث درجة التحقق ومتح ققة بدرجة متوسطة، حيث بلغ المتوسط الحسابي

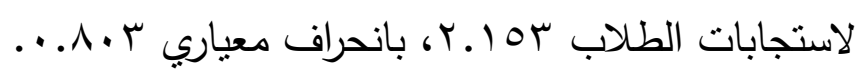

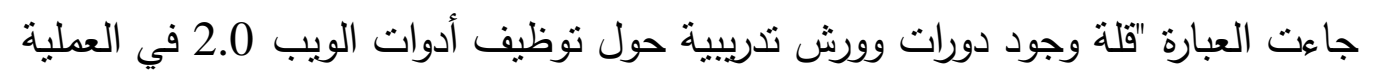

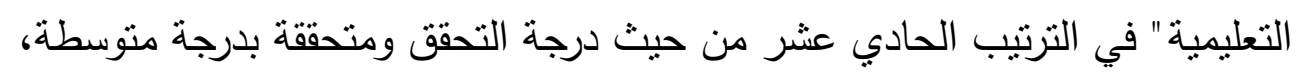

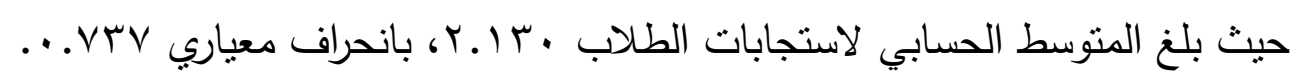

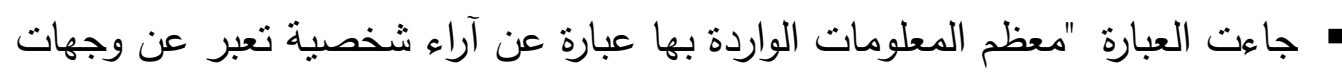

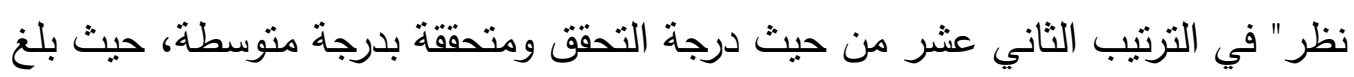

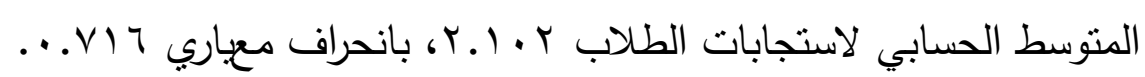

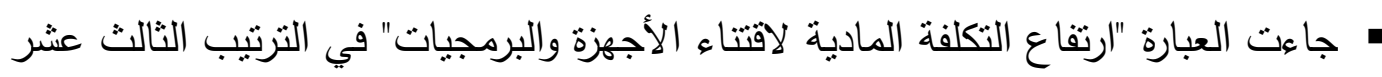

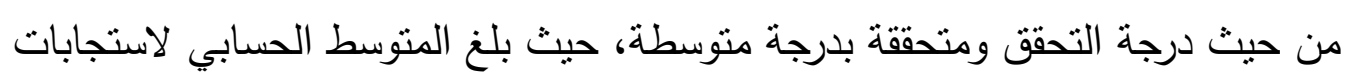

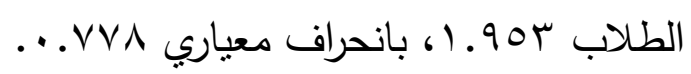

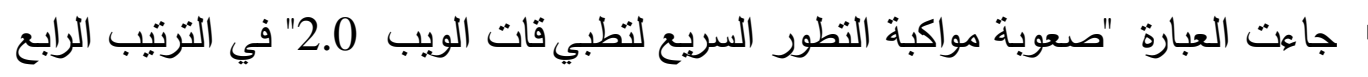

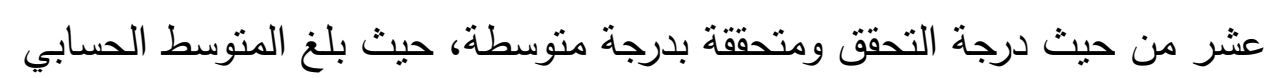

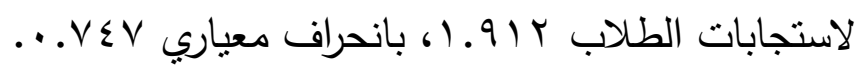


• جاءت العبارة "عدم توافر الأجهزة والبرمجيات التي نساعدني على استخدام أدوات الويب

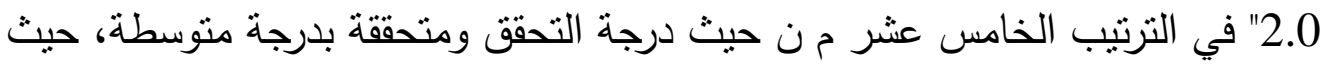

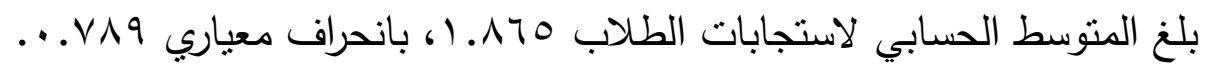

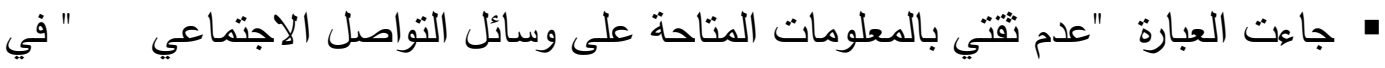
الترتيب السادس عشر من حيث درجة التحقق ومتحققة بدرجة متوسطة، حيث بلغ

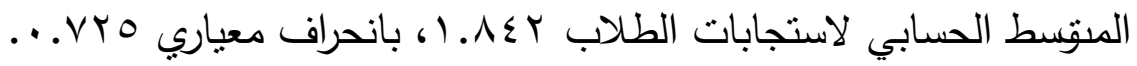
جاءت العبارة "عدم معرفتي بكيفية التسجيل او التعامل مع أدوات الويب 2.0" في الترتيب السابع عشر من حيث درجة التحقق ومتحققة بدرجة منوسطة، حيث بلغ المتوسط

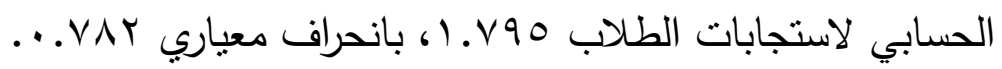

• جاءت العبارة "صعوبة نوافر الوقت اللازم للتعامل مع أدوات الويب 2.0" في الترتيب الثامن عشر من حيث درجة التحقق ومتحققة بدرجة منوسطة، حيث بلغ المتوسط

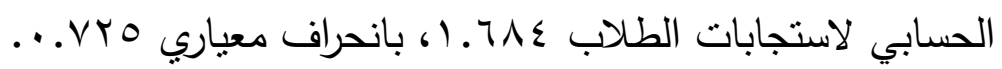

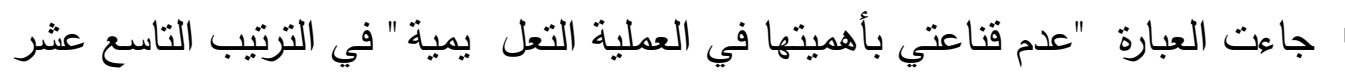
والأخير من حيث درجة التحقق ومتحققة بدرجة ضعيفة، حيث بلغ المتوسط الحسابي

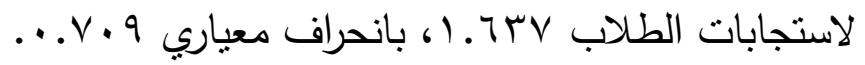

\section{ثالثاً : نتائج السؤال الثالث:}

ينص السؤال الثالث للاراسة الحالية على "هل تختلف استجابات الطلاب عينة الدراسة حول واقع استخدام أدوات الويب 2.0 في العملية التعليمية باختلاف متغيرات (التخصص،

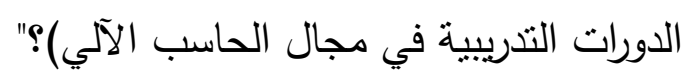

\section{1- 1- بالنسبة لانتخصص:}

تم استخدام تحليل التباين أحادي الاتجاه One Way ANOVA في الكثف عن دلالة الفروق في استجابات الطلاب عينة الدراسة حول واقع استخدام أدوات الويب 2.0 في 


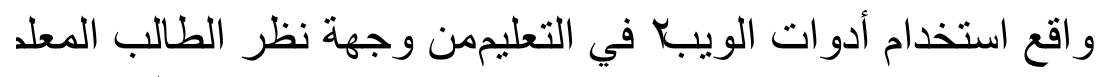
في ضوء بعض المتغير ات الترل

د. حمد بنصالحبن عبدالعزيز

العملية التعليمية والتي ترجع لاختلاف التخصص (نريعة، لغة عربية، تربية بدنية، لغة إنجليزية، كيمياء، فيزياء، حاسب آلى)، فكانت النتائج كما هي موضحة في التالي: 


\section{جدول (ri) : المتوسطات الحسابية والانحرافات المعيارية لاستجابات الطلاب حول}

واقع استخذام أدوات الويب 2.0 في العملية التعليمية في ضوء التخصص

\begin{tabular}{|c|c|c|c|c|c|c|c|c|c|}
\hline \multicolumn{2}{|c|}{ الويتخل 2.0 ككل أدوات } & \multicolumn{2}{|c|}{ استخداه الشبكات الاجتماعية } & \multicolumn{2}{|c|}{$\begin{array}{l}\text { استخدام الملدونات } \\
\text { (Blogs })\end{array}$} & \multicolumn{2}{|c|}{$\begin{array}{c}\text { استخلاه المحررات } \\
\text { التشاركية } \\
\text { (Wikis) }\end{array}$} & \multirow[t]{2}{*}{ العدد } & \multirow[t]{2}{*}{ التخصص } \\
\hline انحراف & متوسط & انحراف معياري & متوسط & انحراف & متوسط & انحراف & متوسط & & \\
\hline Q,YYI & or,ar. & $\xi, 97 \mathrm{~V}$ & $r q, r \cdots$ & $0, \cdot \leq \varepsilon$ & IV,VY. & r,YaI & 17,97 . & ro & شريعة \\
\hline q,ovo & $7 \varepsilon, 17 V$ & $\varepsilon, \eta I V$ & $Y 7,007$ & $\boldsymbol{\xi}$, YAr & $r \cdot, \cdot 07$ & r,Yvq & $1 V, 007$ & 11 & عربية \\
\hline$v, \vee \vee A$ & Tr,AYY & r,AYr & $r q, 7 r r$ & $\xi, r+1$ & 19,81 . & $r, 700$ & $17, \Lambda \cdot r$ & 71 & تربية \\
\hline$\Lambda, I Y V$ & or, हrq & $\xi, r \xi Y$ & rq, rI. & ร,A & 17,090 & 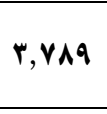 & $1 \xi, O Y \xi$ & $\xi r$ & إنجليزية \\
\hline $1 \cdot, \mathrm{M} 19$ & 07,711 & $0, \cdot v r$ & $r 0, r q 1$ & צ,9Y1 & 10,Arr & $\varepsilon, \wedge \leqslant \wedge$ & $10,\{1 V$ & rq & كيمياء \\
\hline$v, \wedge \cdot 1$ & $\Delta \Lambda, \wedge \Lambda Y$ & $\boldsymbol{\varepsilon}, \boldsymbol{r A} \cdot$ & $r q, ৭ \Sigma 1$ & ร, $\vee 79$ & $17,7 \leqslant V$ & r,YAV & 10, Y9\& & IV & فيزيّاء \\
\hline$\wedge, \xi \cdot\rceil$ & $07,07 r$ & r,§qr & ro, Yo. & 0,0 YY & $17, \cdots$ & $\xi, \wedge \leqslant V$ & $|\varepsilon, \wedge| r$ & 17 & حاسب آلى \\
\hline $9, \cdot 90$ & $09, ₹ 91$ & $\varepsilon, r \leqslant q$ & ry, roY & ร,9rq & 18,701 & $\xi, 11 \xi$ & 10,091 & r10 & ككل العينة \\
\hline
\end{tabular}

جدول (rا ) : دلالة الفروق في استجابات الطلاب حول واقع استخدام

أدوات الويب 2.0 في العملية التعليمية في ضوء التخصص

\begin{tabular}{|c|c|c|c|c|c|c|}
\hline مستول & قفيمة & المربعات & الحرية & المربعموع & مصدر التباين & 2.0 في العتلية الدواتليمية الويب \\
\hline \multirow{3}{*}{$\cdot, \cdot 1$} & \multirow{3}{*}{$r, 979$} & $\xi Y, T Y \xi$ & 7 & $r \wedge \Delta, Y \leqslant 0$ & بين المجموعات & \multirow{3}{*}{ التشاركية (Wikis) المحرات } \\
\hline & & $17, \& 9$ & $r \cdot 1$ & THYY,YTV & داخل المجموعات & \\
\hline & & & YIE & MqTI,qA1 & الكلي & \\
\hline \multirow{3}{*}{$\cdot, \cdot 1$} & \multirow{3}{*}{$r, A T$} & $\Lambda 7,097$ & 7 & 019, orr & بيز المجموعات & \multirow{3}{*}{$\begin{array}{l}\text { استخدام المدونات } \\
\text { (Blogs }\end{array}$} \\
\hline & & $r r, T \cdot r$ & $r \cdot 1$ & $\xi \gamma \cdot 1, Y q$. & داخل المجموعات & \\
\hline & & & rIE & Orr.,ATr & الكلي & \\
\hline \multirow{3}{*}{ غير دالة } & \multirow{3}{*}{ 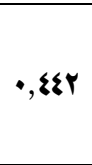 } & $\Lambda,\{\wedge$ Q & 7 & $0 \cdot 940$ & بين المجموعات & \multirow{3}{*}{$\begin{array}{c}\text { الاجتماعية الشباه الشبكات } \\
\text { (Social } \\
\text { Networks) }\end{array}$} \\
\hline & & $19, \mathrm{rIr}$ & $r \cdot 1$ & T990,990 & داخل المجموعات & \\
\hline & & & YIE & $\xi \bullet \$ 7, q 4 \cdot$ & الكلي & \\
\hline \multirow{3}{*}{$\cdot, \cdot 1$} & \multirow{3}{*}{ T,AY\& } & $r a r, \wedge \varepsilon$ & 7 & IVOA, 0.0 & بين المجموعات & \multirow{3}{*}{ ستخدام أدوات الويب 2.0} \\
\hline & & $v 9,70$. & $r \cdot A$ & 109\&T, Y\&\& & داخل المجموعات & \\
\hline & & & YI\& & $1 v v \cdot 1, v \leqslant q$ & الكلي & \\
\hline
\end{tabular}


و اقع استخدام أدوات الويبك في التعليممن وجهة نظر الطالب المعلد في ضوء بعض المتغير ات

\section{يتضح من الجدول السابق أنه:}

" توجد فروق دالة إحصائياً عند مستوى ل... في استجابات الطلاب عينة الدراسة الحالية حول واقع استخدام المحررات النتاركية (Wikis) في العملية التعليمية ترجع لاختلاف التخصص.

" توجد فروق دالة إحصائياً عند مستوى ل... في استجابات الطلاب عينة الدراسة الحالية حول واقع استخدام المدونات (Blogs)في العملية التعليمية ترجع لاختلاف التخصص. لا توجد فروق دالة إحصائباً في استجابات الطلاب عينة الدراسة الحالية حول واقع استخدام الثبكات الاجتماعية Nocial Networks) في العملية التعليمية نرجع لاختلاف التخصص. • توجد فروق دالة إحصائياً عند مستوى ا... في استجابات الطلاب عينة الدراسة الحالية حول واقع استخدام أدوات الويب 2.0 (الدرجة الكلية) في العملية التعليمية ترجع لاختلاف التخصص.

وللتعرف على الفروق ذات الدلالة في استجابات الطلاب بالتخصصات المختلفة حول

LSD واقع استخدام ادوات الويب 2.0 في العطلية التعليمية نم استخدام اختبار أقل فرق دال كاختبار للمقارنات البعدية في حالة دلالة تحليل التباين أحادي الاتجاه فكانت النتائج كما هو موضح بالجدول النالي: 


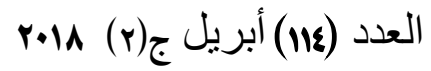

مجلة كلية التربية ببنها

جدول (\&) ) : دلالة الفروق بيز الطلاب بالتخصصات المختلفة في استجاباتهه

حول واقع استخدام ادوات الويب 2.0 في العملية التعليمية

\begin{tabular}{|c|c|c|c|c|c|c|c|}
\hline 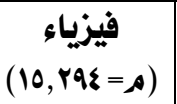 & 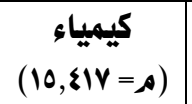 & 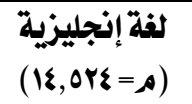 & 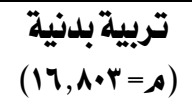 & 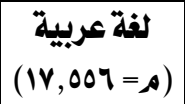 & 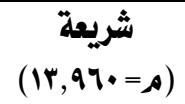 & التخصص & المتفيرات \\
\hline & & & & & $* * Y, 097$ & لفة عربية (ر= IV,007) & \multirow{6}{*}{ 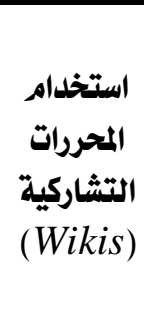 } \\
\hline & & & & •, Yor & $* * Y, \wedge \leqslant r$ & تربية بلدنية (مر= (17,A) & \\
\hline & & & $* * Y$, YYq & $* * r, \cdot r r$ & $\cdot, 07 \xi$ & لفة إنجليزية م= = 1\&,OY\& & \\
\hline & & $\cdot$ •,А9 & 1, rA9 & $r, 1 r q$ & 1, §०V & كيمياء (مر= (10,Z) & \\
\hline & $\cdot, I r r$ & $\cdot, \mathrm{VW}$. & $1,0.9$ & r,YAr & 1, TrE & 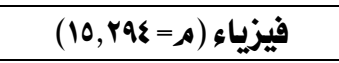 & \\
\hline$\cdot, \sum A Y$ & $\cdot, 7 \cdot 0$ & $\cdot, r \wedge \wedge$ & 1,991 & $* Y, Y \leqslant \varepsilon$ & $\cdot$, AOr & حاسب آلي ر= = & \\
\hline \multirow[t]{6}{*}{ 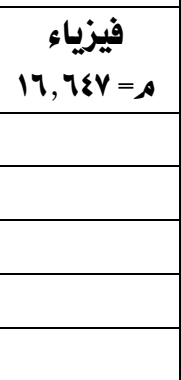 } & 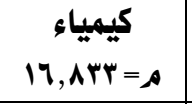 & لفة إنجليزية & (م=ربية بلدئية & 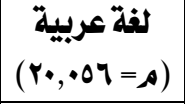 & Aر=•ش شريعة & التخصص & \multirow{7}{*}{ المدتخداه } \\
\hline & & & & & r, raq & لفة عربية (مر= 07•, •r) & \\
\hline & & & & $\cdot, 7 \leqslant V$ & $1,7 \leqslant 9$ & تربية بدنية (ر= 9-\$, 19) & \\
\hline & & & $* * Y, \wedge \mid \xi$ & $* * 4,\{7\}$ & 1,170 & لغة إنجليزية (هر= 17,090) & \\
\hline & & •, rrA & $* * Y$, OVY & $* * \&, Y Y Y$ & 1,9rV & كيمياء (ري= (17,ATr & \\
\hline & $\cdot, 119$ & $\cdot, \cdot \Delta r$ & *Y,VYY & $* \Psi,\{* 9$ & 1,114 & فيزياء (هر= 1\&Y, TY & \\
\hline •, TIV & $\cdot, 17 \mathrm{~V}$ & $\cdot, 090$ & $* * Y, \& \cdot q$ & $* *\{, \cdot 07$ & $1, \mathrm{Vq}$ & حاسب آلي (مر= ••, 17) & \\
\hline \multirow[t]{6}{*}{$\begin{array}{c}\text { فيزياء } \\
=(\Delta, \wedge \wedge r \\
(\Delta \wedge, \wedge\end{array}$} & $\begin{array}{c}\text { كيمياء } \\
(07,711=9 \text { (1) }\end{array}$ & 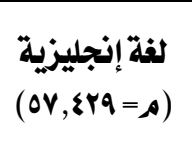 & 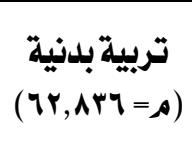 & 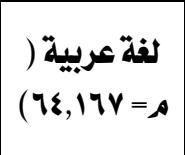 & 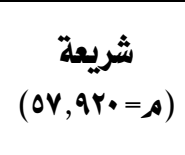 & التخصص & \multirow{7}{*}{ أدوات الويب } \\
\hline & & & & & $* \eta, Y \leqslant Y$ & لغة عربية (مر= Y\&,1 YV) & \\
\hline & & & & $1, r r I$ & $* \varepsilon, 917$ & تربية بلنية (م= IrLAFY) & \\
\hline & & & $* * 0, \xi \bullet Y$ & $* * 4, \vee \vee \wedge$ & $\cdot,\{91$ & لغة إنجليزية (مر= ov,_rq) & \\
\hline & & $\cdot$, AlY & $* * 7$, rYO & $* * \mathrm{~V}, 007$ & $1, r \cdot 9$ & كيمياء (مر= & \\
\hline & $r, r Y$ & $1,\{0\}$ & $r, 90 \xi$ & 0, YAI & $\cdot, 994$ & فيزياء (هر= & \\
\hline r, rIq & $\cdot, \cdot \& 9$ & $\cdot, 177$ & $* Y, Y Y \varepsilon$ & $* Y, Y \cdot \xi$ & 1, rov & حاسب آلي (مر= 07,07r) & \\
\hline
\end{tabular}

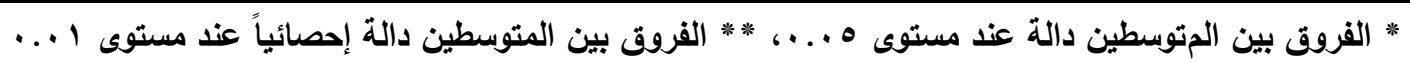

يتضح من الجدول السابق أنه:

بالنسبة لاستخدام المحررات التشاركية(Wikis): كانت هناك فروق دالثة دالة إحصائياً عند مستوى

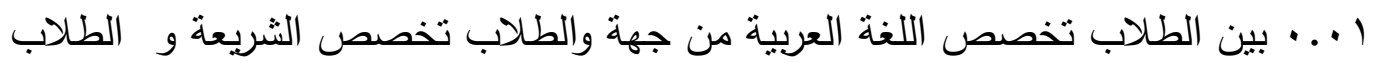
تخصص اللغة الإنجليزية والفروق لصالح طلاب تخصص اللغة العربية، كذلك كانت هناك

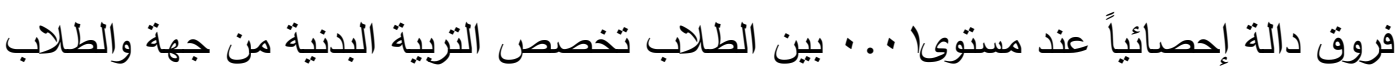

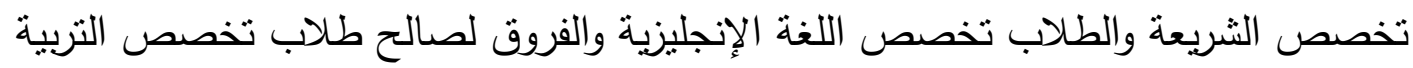
البدنية، وهو ما يؤكد أن أعلى الطلاب في تقييم واقع استخدام الموسوعات الحرة في العملية 


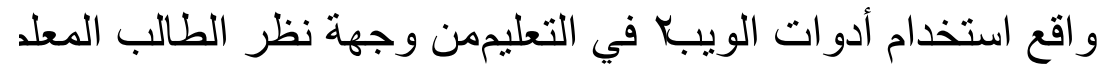
في ضو ضوء بعض المتغير الب المط

التعليمية هم الطلاب تخصص اللغة العربية وتخصص التربية البدنية بينما أقل الطلاب هم طلاب تخصص الثريعة وتخصص اللغة الإنجليزية، ويحنل طلاب تخصص الكيمياء

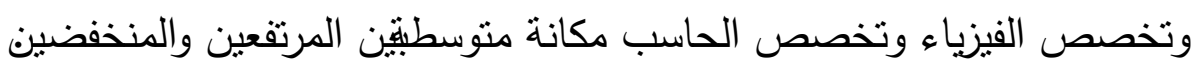

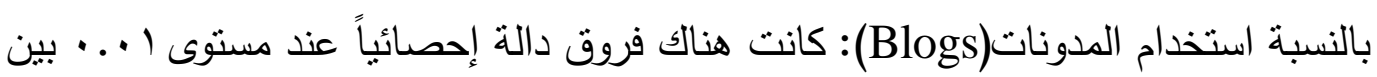

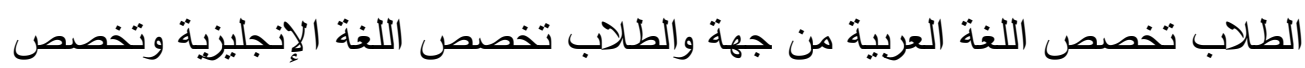

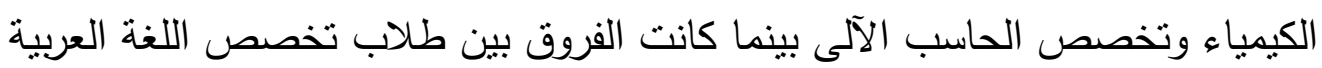

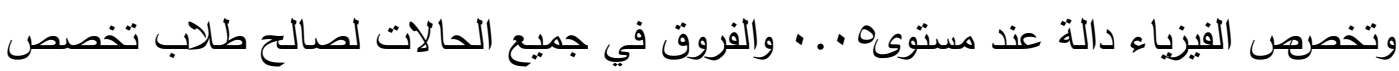

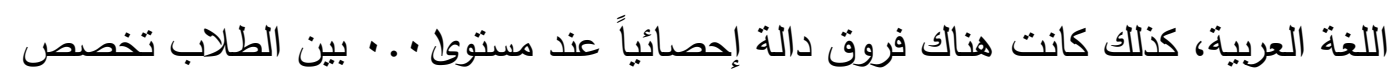

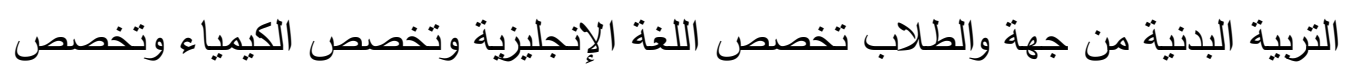

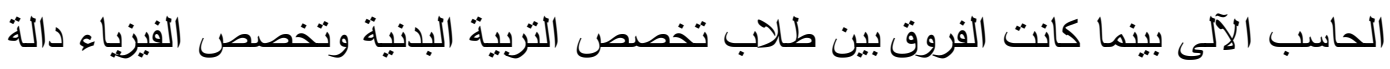

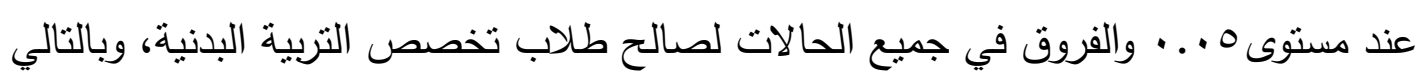
يتأكد أن أعلى الطلاب في تقييم واقع استخدام المدونات في العملية التعليمية هم الطلاب

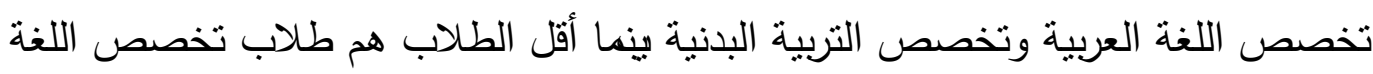
الإنجليزية وتخصص الكيمياء وتخصص الحاسب الآلى وتخصص الفيزياء، ويحتل الطلاب تخصص الثريعة مكانة منوسطة بين المرتفعين والمنخفضين الكيني

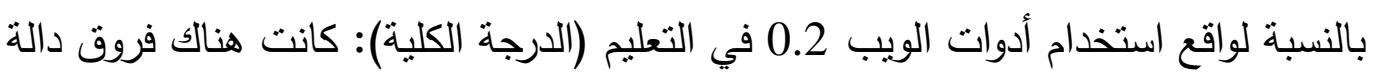

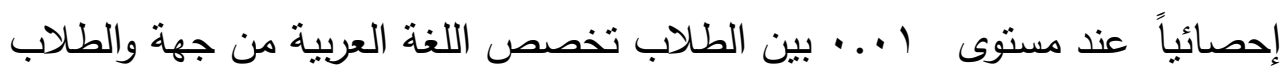

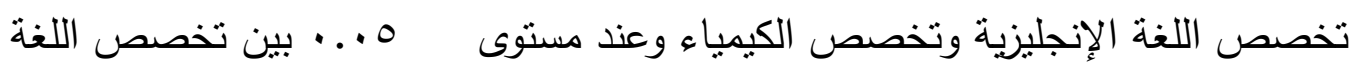

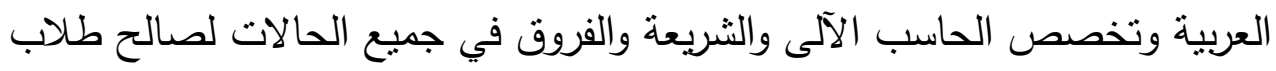

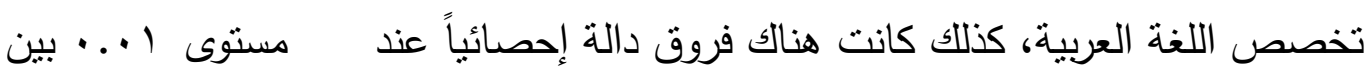
الطلاب تخصص التربية البدنية من جهة والطلاب تخصص اللغة الإنجليزية وتخصص فئه

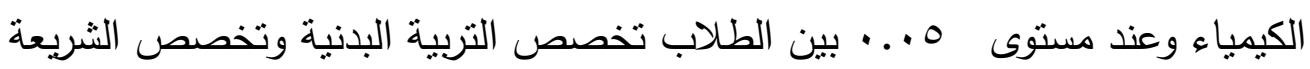
والحاسب الآلي والفروق في جميع الحالات لصالح طلاب تخصص الكص التربية البدنية، وبالتالي

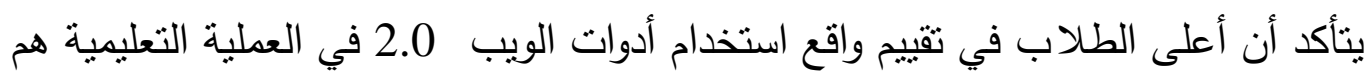

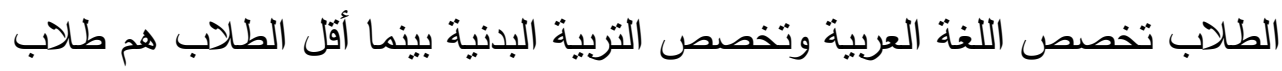




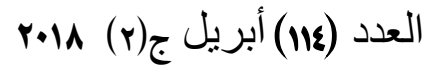

مجلة كلية التربية ببنها

تخصص اللغة الإنجليزية وتخصص الكيمياء وتخصص الثريعة والحاسب الآلى ويحتل طلاب الفيزياء مكانة متوسطة بين المرتفعين والمنخفضين.

\section{(H) بالنسبة لمتغير الدورات التدريبية في مجال الهاسب الآلي:}

تم استخدام تحليل التباين أحادي الاتجاه One Way ANOVA في الكثف عن دلالة

الفروق في استجابات الطلاب عينة الدراسة حول واقع استخدام أدوات الويب 2.0 في العملية

التعليمية والتي ترجع لاختلاف الدورات التدريبية في مجال الحاسب الآلي لا يوجد دورات، من

دورة إلى ثناث دورات، أكثر من ثلاث دورات)، فكانت النتائج كما هي موضحة فئه في التات التالي:

جدول (10) : التتوسطات الحسابية والانحرافات المعيارية لاستجابات الطلاب حول واقع استخدام

أدوات الويب 2.0 في العملية التعليمية في ضوء عدد الدورات التدريبية

\begin{tabular}{|c|c|c|c|c|c|c|c|c|c|}
\hline \multicolumn{2}{|c|}{ استخدام أدوات الويب } & \multicolumn{2}{|c|}{$\begin{array}{c}\text { الاجتماعية (Social } \\
\text { (Setworks) } \\
\text { (الشبكات }\end{array}$} & \multicolumn{2}{|c|}{$\begin{array}{c}\text { استخدام الملدونات } \\
\text { (Blogs })\end{array}$} & \multicolumn{2}{|c|}{ التشاركية (Wikis المتخدرات } & \multirow[t]{2}{*}{ العلد } & \multirow{2}{*}{ التدريبية } \\
\hline انجراف & متوسط & انحراف & متوسط & المعياري & متوسط & المياري & متوسط & & \\
\hline 9,159 & 01,707 & $\{, \xi \mid \xi$ & ro,qYz & $0, \bullet 1$. & $\mid v, \varepsilon=0$ & $\xi, r \|$ & $10, \mathrm{HYA}$ & |F| & لايوجل \\
\hline $9, \cdot v 9$ & $7 \cdot, 197$ & $\xi$, YAA & YY,YAT & $\xi, \wedge 91$ & 18,797 & $r, 9 \Lambda$. & $10, V \mid \varepsilon$ & 07 & $r-1$ \\
\hline A, TEV & $7 r, \bullet r 7$ & $\{, 101$ & ry, Yo. & $\xi, Y Y I$ & $|A, V| \xi$ & $r, \wedge 91$ & $17,0 \mathrm{VI}$ & rA & أكثر من r \\
\hline $9, \cdot 90$ & $09, ₹ 91$ & 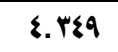 & YY, YOY & $\xi, q 4 q$ & $\mid v, 701$ & $\xi, 11 \xi$ & 10,091 & rio & العينة الكلية \\
\hline
\end{tabular}

جلول (17) : دلالة الفروق في استجابات الطلاب حول واقع استخلام أدوات الويب 2.0 في العملية

التعليمية في ضوء الدورات التدريبية في الحاسب الآلى

\begin{tabular}{|c|c|c|c|c|c|c|}
\hline مستوى & قيمة ف & متوسط & الحرية & مجموع المربعات & مصلدر التباين & واقع استخلام أدوات الويب 2.0 في العملية التعليمية \\
\hline \multirow{3}{*}{ غير دالة } & \multirow{3}{*}{$1, \cdot 11$} & $1 A, \varepsilon \cdot 0$ & r & rq,Al. & بين المجموعات & \multirow{3}{*}{ استخداه المحررات التشاركية } \\
\hline & & 17,911 & rir & rono, IVI & داخل المجموعات & \\
\hline & & & r|\& & rqrI,9AI & الكلي & \\
\hline \multirow{3}{*}{ غير دالة } & \multirow{3}{*}{ •,Alr } & $19, \wedge 7 r$ & r & rq, Vrq & بين المجموعات & \multirow{3}{*}{ ستخداه المدونات (Blogs) } \\
\hline & & r\&,ฉTq & rir & 0111,111 & داخل المجهوعات & \\
\hline & & & TIE & Orr.,Arr & الكلي & \\
\hline \multirow{3}{*}{ غير دالة } & \multirow{3}{*}{$\cdot, 9 Y \wedge$} & $11,0 \cdot 1$ & $r$ & $r v, \cdot 10$ & بين المجموعات & \multirow{3}{*}{$\begin{array}{c}\text { الاجتماعية الخداه الشبكات } \\
\text { (Social } \\
\text { Networks }\end{array}$} \\
\hline & & 11,910 & rir & $\{\cdots 99,910$ & داخل المجموعات & \\
\hline & & & YI\& & 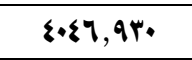 & الكلي & \\
\hline
\end{tabular}

119 


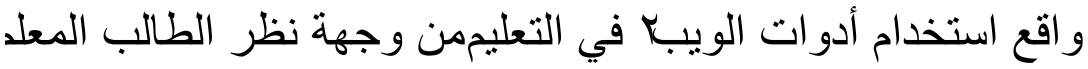
في ضوء بعض نطر المتغيرات

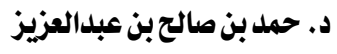

\begin{tabular}{|c|c|c|c|c|c|c|}
\hline مستوى & قيمة ف & متوسط & الحرية & مجموع المربعات & مصدر التباين & واقع استخدام أدوات الويب 2.0 في العملية التعليمية \\
\hline \multirow{3}{*}{ غير دالة } & \multirow{3}{*}{$1, A T \cdot$} & $10 \cdot, r \cdot r$ & r & $\Gamma \cdot \cdot, \xi \cdot \Gamma$ & بين المجموعات & \multirow{3}{*}{ استخدام أدوات الويب 2.0} \\
\hline & & $\Delta r, \bullet A r$ & rir & $\mid V \xi \cdot 1, r \leqslant q$ & داخل المجموعات & \\
\hline & & & YI₹ & $1 v v \cdot 1, v \leqslant q$ & الكلي & \\
\hline
\end{tabular}

يتضح من الجدول السابق أنه:

لا نوجد فروق دالة إحصائياً في استجابات الطلاب عينة الدراسة حول واقع استخدام الموسوعات الحرة Wikis) في العملية التعليمية ترجع لاختلاف الد ورات التنريبية في

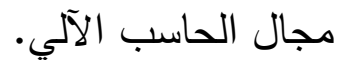
" لا توجد فروق دالة إحصائياً في استجابات الطلاب عينة الدراسة حول واقع اتخذام الددونات (Blogs) في العطلية التعليمية ترجع لاختلاف الدورات التدريبية في مجال

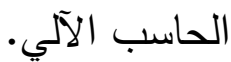
" لا توجد فروق دالة إحصائياً في استجابات الطلاب عينة ال لدراسة حول واقع استخدام الثبكات الاجتماعية (Social Networks) في العملية التعليمية ترجع لاختلاف الدورات

$$
\text { التدريبية في مجال الحاسب الآلي. }
$$

" لا توجد فروق دالة إحصائياً في استجابات الطلاب عينة الدراسة حول واقع استخدام أدوات الويب 2.0 (الدرجة الكلية) في العطلية التعليمية ترجع لاختلاف الدورات التريبية في مجال

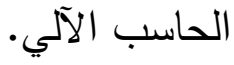

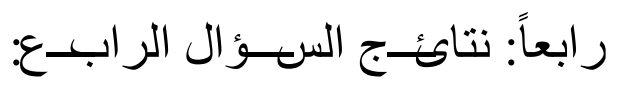

ينص السؤال الرابع للبحث الحالي على "هل تختلف استجابات الطلاب عينة الدراسة حول معوقات استخدام أدوات الويب 2.0 في العملية التعليمية باختلاف متغيرات (التخصص، الدورات التدريبية في مجال الحاسب الآلي)؟" 
تم استخدام تحليل التباين أحادي الاتجاه One Way ANOVA في الكثف عن دلالة الفروق في استجابات الطلاب عينة الدراسة حول معوقات استخدام أدوات الويب العملية التعليمية والتي ترجع لاختلاف التخصص (شريعة، لغة عربية، تربية بدنية، لغة إنجليزية، كيمياء، فيزياء، حاسب آلى)، فكانت النتائج كما هي موضحة في التالي: جدول (IV) : المتوسطات الحسابية والانحرافات المعيارية لاستجابات الطلاب حول معوقات استخدام أدوات الويب 2.0 في العملية التعليمية في ضوء التخصص

\begin{tabular}{|c|c|c|c|}
\hline \multicolumn{2}{|c|}{ معوقات استخداه أدوات الويب 2.0 في العملية التعليمية } & \multirow{2}{*}{ 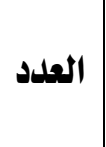 } & \multirow{2}{*}{ 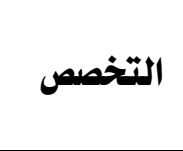 } \\
\hline انحر اف معياري & 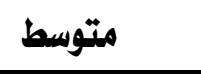 & & \\
\hline T,TrY & $r q, \wedge \xi \bullet$ & ro & 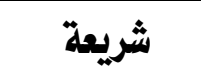 \\
\hline $7,\{T \wedge$ & $\{1,17 \mathrm{~V}$ & 11 & لفة عربية \\
\hline 7,0广1 & $\varepsilon \cdot, r \varphi$ & 71 & تربية بلدنية \\
\hline 0, rov & $r \wedge, \cdot r \xi$ & $\{r$ & لفة إنجليزية \\
\hline 0,100 & $r q, \cdots$ & rq & 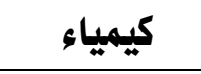 \\
\hline $7, \mathrm{Y99}$ & $\xi 1$, Ү१६ & iv & 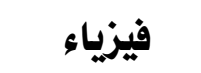 \\
\hline $7,\{7$. & ra $6 .$. & 17 & 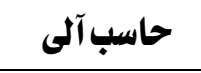 \\
\hline $9, \cdot 1 \cdot$ & $r 9,0 \wedge 1$ & rio & العينة ككل \\
\hline
\end{tabular}

جدول (1) : : دلالة الفروق في استجابات الطلاب حول معوقات استخداه أدوات

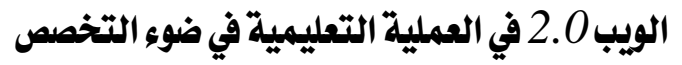

\begin{tabular}{|c|c|c|c|c|c|}
\hline مستوى & قيمةف & متوسط & الحرية & مجموع المربعات & مصلر التباين \\
\hline \multirow{3}{*}{ غير دالة } & \multirow{3}{*}{1,107} & \&r,orq & 7 & roo, IVr & بين المجموعات \\
\hline & & $r M, \lambda \cdot \xi$ & $r \cdot \Lambda$ & ryoo, 10r & المجموعات \\
\hline & & & YIE & V91.,rTq & الكلي \\
\hline
\end{tabular}


و اقع استخدام أدوات الويبك في التعليممن وجهة نظر الطالب المعلد في ضوء بعض المتنغير ات التطل

$$
\text { يتضح من الجدول السابق أنه: }
$$

• • ل الوجد فروق دالة إحصائيًا في استجابات الطلاب عينة الدراسة الحالية حول معوقات استخدام أدوات الويب 2.0 في العملية التعليمية ترجع لاختلاف التخصص.

$$
\text { r- بالنسبة لمتفير الدورات التدريبية في مجال الحاسب الآلي: }
$$

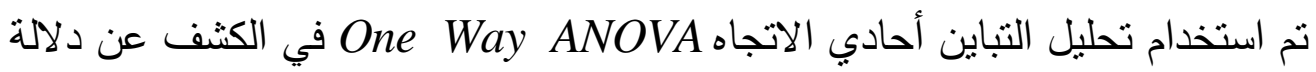
الفروق في استجابات الطلاب عينة الدراسة حول معوقات استخدام أدوات الويب2.0 في العملية

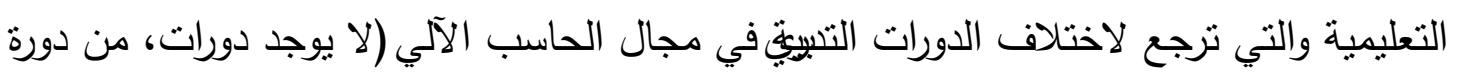

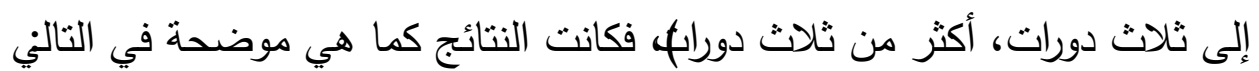
جدول (19) : المتوسطات الحسابية والانحرافات المعيارية لاستجابات الطلاب حول معوقات

\begin{tabular}{|c|c|c|c|}
\hline \multicolumn{2}{|c|}{ معوقات استخدام أدوات الويب 2.0 في العملية التعليمية } & \multirow{2}{*}{ 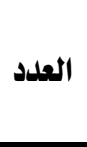 } & \multirow{2}{*}{ الدورات التدريبية } \\
\hline انحراف معياري & متوسط & & \\
\hline $0, \wedge \leqslant V$ & $r q,\{r 0$ & $|r|$ & 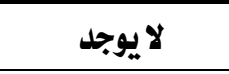 \\
\hline 7,790 & $\xi \cdot, \Gamma \xi$ & 04 & $r-1$ \\
\hline 9,899 & $r q, \cdots$ & is & 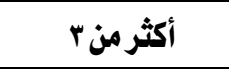 \\
\hline $7, \bullet \cdot$ & $r 9, \Delta \wedge 1$ & M10 & 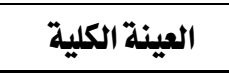 \\
\hline
\end{tabular}
استخلام أدوات الويب 2.0 في العملية التعليمية في ضوء عدد الدورات التلدريبية

جدول (•r) : دلالة الفروق في استجابات الطلاب حول معوقات استخداه أدوات الويب 2.0 في العملية

\begin{tabular}{|c|c|c|c|c|c|}
\hline الدلالة مستوى & قيمة ف & متوسط المربعات & الحرية & مجموع المربعات & مصدر التباين \\
\hline \multirow{3}{*}{ غير دالة } & \multirow{3}{*}{ 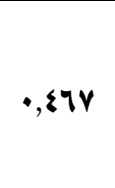 } & $\mid v, r \leq q$ & $r$ & $r \&, 799$ & بين المجموعات \\
\hline & & $r v, 1 \leqslant q$ & rIr & rAVO, TrV & داخل المجموعات \\
\hline & & & YIE & V91., rYq & الكلي \\
\hline
\end{tabular}

$$
\text { التعليمية في ضوء الدورات التلدريبية في الحاسب الآلى لفواتل }
$$

يتضح من الجدول السابق أنه: 


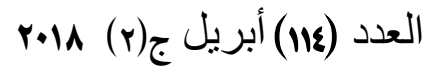

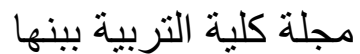

لا توجد فروق دالة إحصائياً في استجابات الطلاب عينة الدراسة الحالية حول معوقات

استخدام أدوات الويب 2.0 (الدرجة الكلية ) في العملية التعليمية ترجع لاختلاف الدورات التابه

$$
\begin{aligned}
& \text { التدريية في مجال الحاسب الآلي. }
\end{aligned}
$$

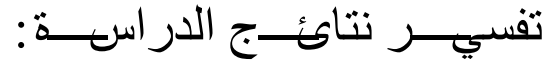

- كثفت نتائج الاجابة عن السؤال الاول: أن واقع استخدام أدوات الويب 2.0 في العملية

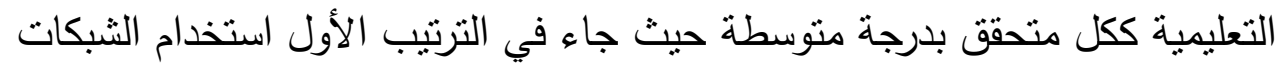

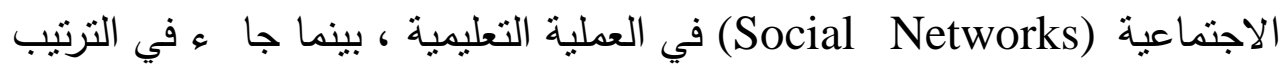

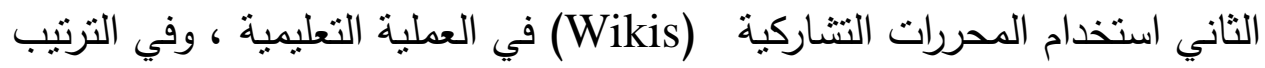

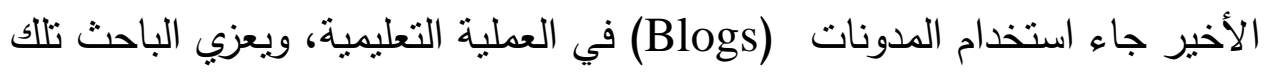

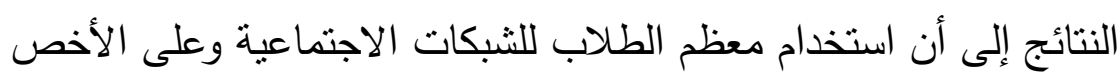
Facebook

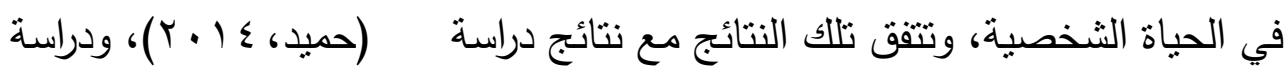

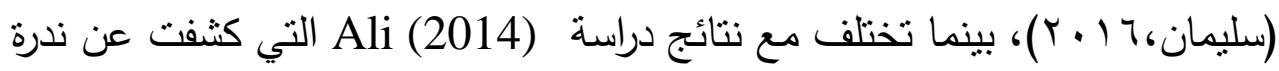

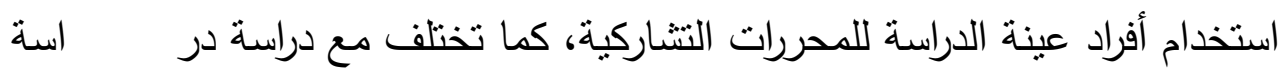

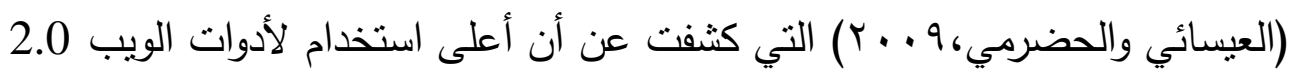

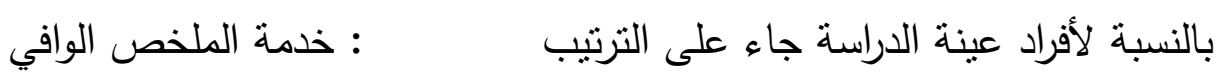

$$
\text { ( الثبكات الاجتماعية - التأليف الحر (Blogs ) - (RSS) }
$$

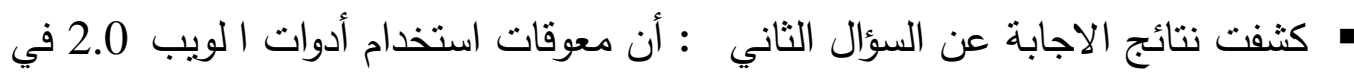

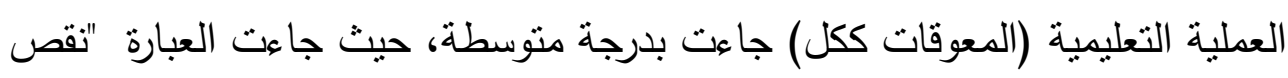

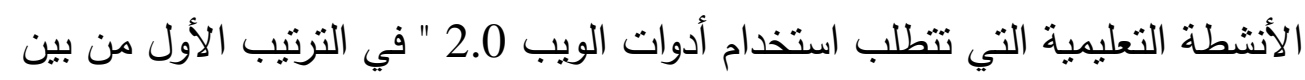

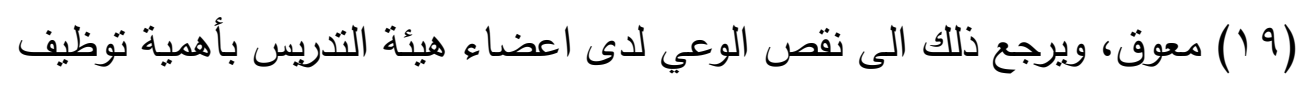

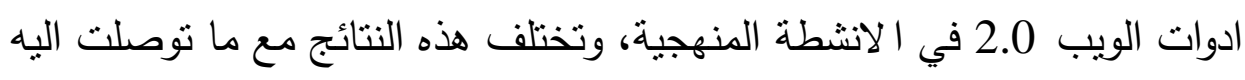

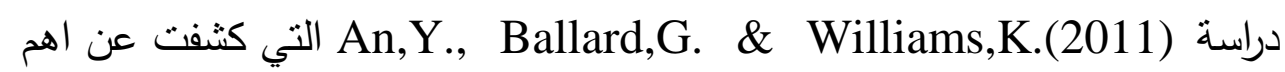
معوقات استخدام أدوات الويب 2.0 هو المشاكل التكنولوجية المتعلقة بالاستخدام ،

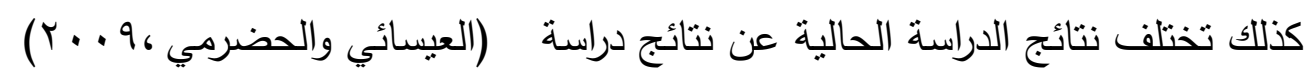




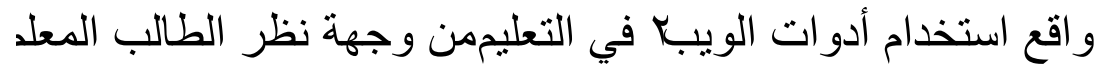
في ضوء بعض المتغير ات

التي كثفت عن أن أهم معوقات استخدام أدوات الويب 2.0 هو النقص في الأدلة

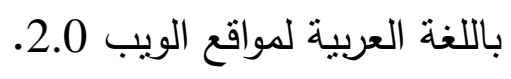

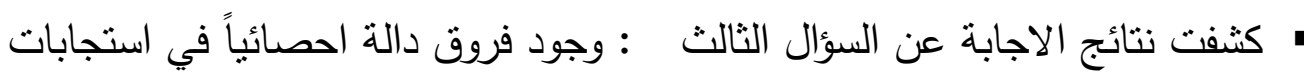

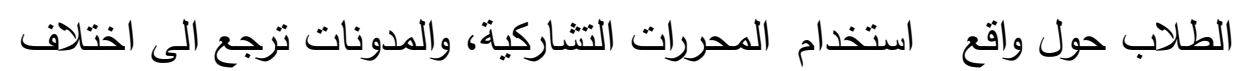

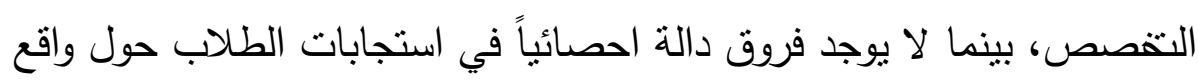

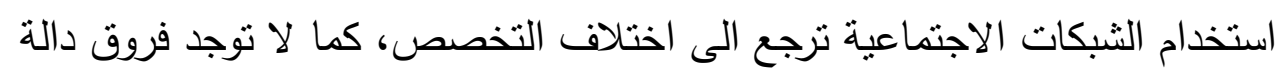

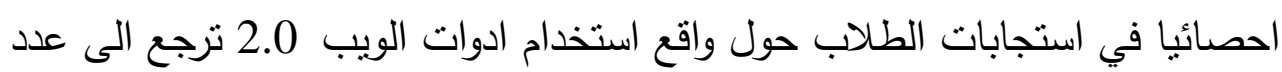

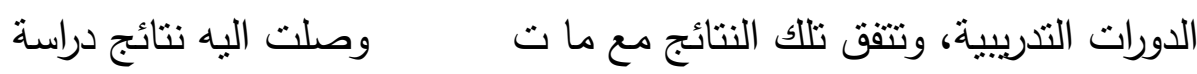

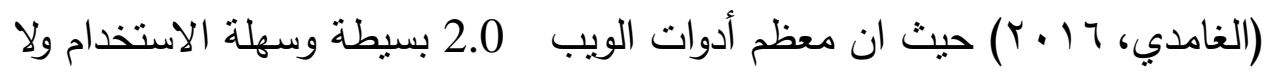
تحتاج الى تدريب. • أن أعلى الطلاب في تقييم واقع استخدام أدوات الويب 2.0 في العطلية التعليمية هم الطلاب تخصص اللغة العربية وتخصص التربية البدنية بينما أقل الطلاب هم طلاب

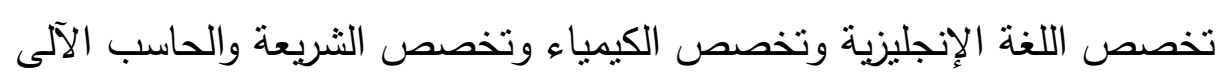
ويحتل طلاب الفيزياء مكانة منوسطة بين المرتفعين والمنخفضين. • أن أعلى الطلاب في تقييم واقع استخدام المحررات التثاركية في العطلية التعليمية هم الطلاب تخصص اللغة العربية وتخصص التربية البننية بينما أقل الطلاب هم طلاب تخصص الثريعة وتخصص اللغة الإنجليزية، ويحتل طلاب تخصص الكيمياء

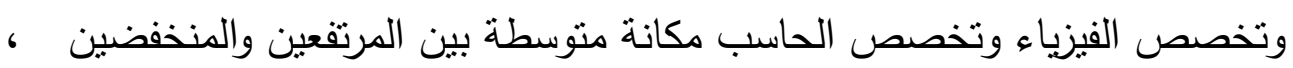
ويرجع ذلك الى أن طلاب اللغة العربية والتربية البدنية لديهم وعي أكبر بأهمية

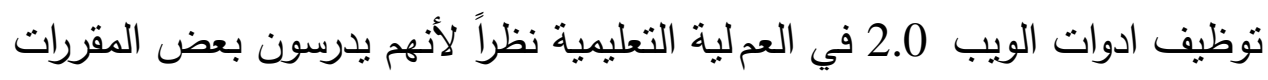
الكترونياً من خلال برمجية البلاك بورد التي نوفرها جامعة القصيم.

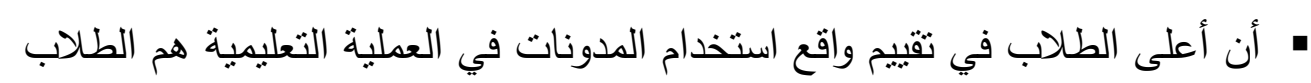
تخصص اللغة العربية وتخصص التربية البدنية بينما أقل الطلاب هم طلاب تخصص اللغة الإنجليزية وتخصص الكيمياء وتخصص الحاسب الآلى وتخصص 
الفيزياء، ويحتل الطلاب تخصص الثريعة مكانة منوسطة بين المرتفعين

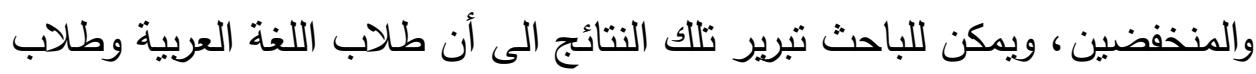
التربية البدنية يدرسون مقررات تعتمد انشطتها على استخدام بعض أدوات الويب 2.0.

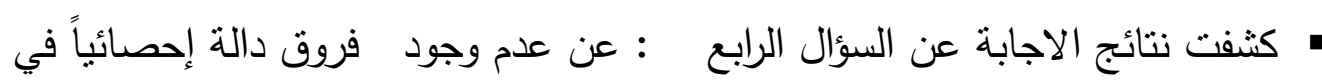
استجابات الطلاب عينة الدراسة الحالية حول معوقات استخدام أدوات الويب 2.0 في العملية التعليمية ترجع لاختلاف التخصص ويتفق ذلك مع نتائج دراسة (الغامدي، 1 ( ب) وترجع نلك النتائج الى طبيعة معوقات استخدام ادوات الويب 2.0 تخاطب الطالب بشكل عام دون تخصيص حيث ان معظمها تمس الطالب الجامعي دون الاعتبار لنوعية تخصصه العلمي. توصيات الدر اسة و الدر اسات المقترحة من خلال النتائج الني توصلت اليها الدراسة يوصي الباحث بما يلي:

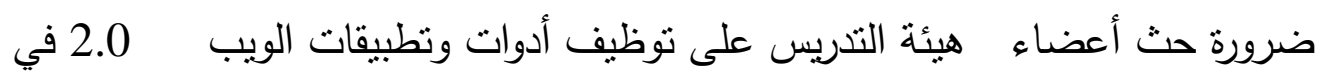
الأنشطة المنهجية واللادنهجية، والتي تحفز الطلاب على استخدام تلك النطبيقات في العملية التعليمية.

$$
\text { ضرورة دمج أدوات التعليم الالكتروني في المناهج الدراسية. }
$$

عقد دورات تدريبية تخصصية في مجال الويب 2.0 لتنمية الجوانب المعرفية والمهارية للطالب والمعلم على حداً سواء.

ومن الدراسات المقترحة: - مئ

واقع استخدام أدوات وتطبيقات الويب 2.0 وفقاً لمتغير المنطقة الجغرافية ونوع الجنس. " اتجاهات المعلمون والطلاب نحو استخدام أدوات وتطبيقات الويب 2.0 في العطلية التعليمية.

"تصور مقترح لنظظيف أدوات الويب 2.0 في الانشطة التعليمية. " أثر اختلاف استخدام بعض أدوات الويب 2.0 على تتمية الجوانب المعرفية والمهارية. 


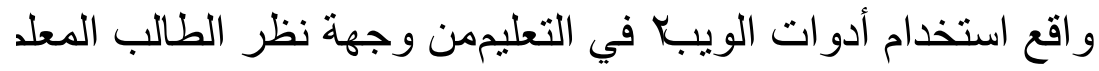
في ضوء بعض المتغير الطالب المطات

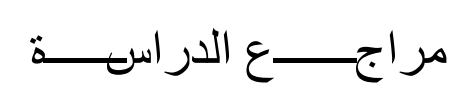

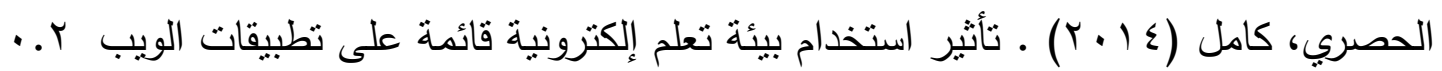

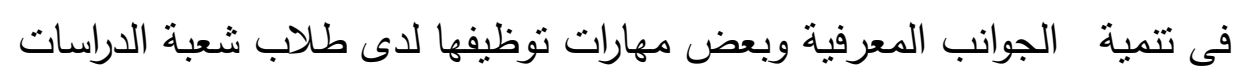

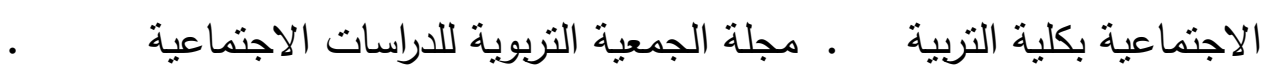

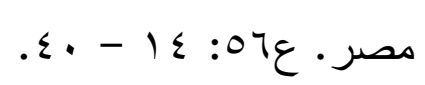

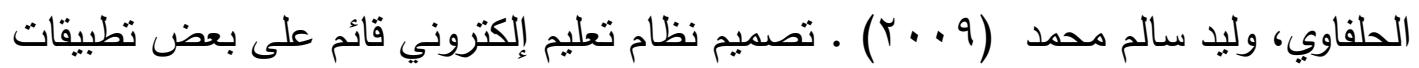

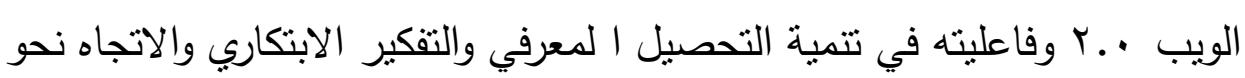

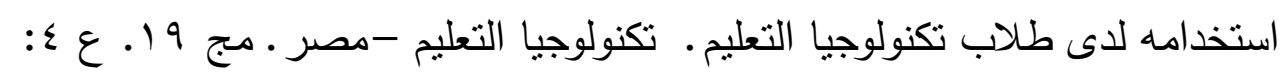

$$
.101-74
$$

حمادة، أمل إبراهيم ، وآية طلعت إسماعيل (ع ( ب). أثر تصميم بيئة للتعلم الإلكتروني

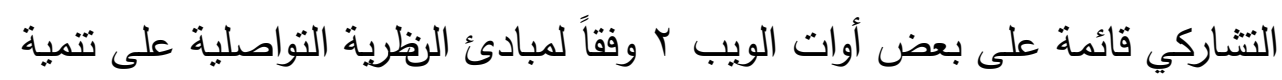

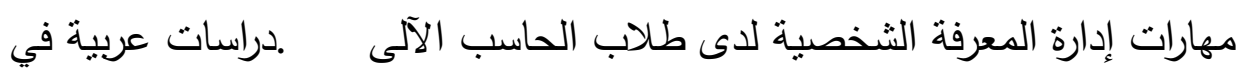

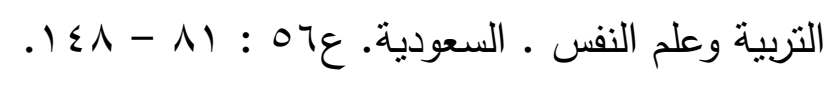

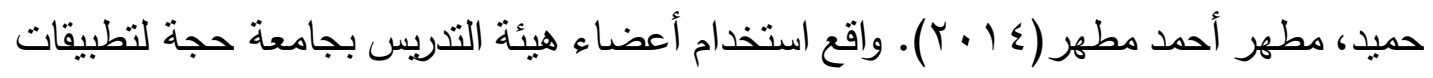

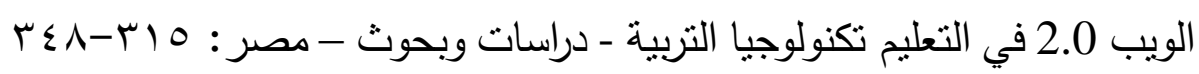

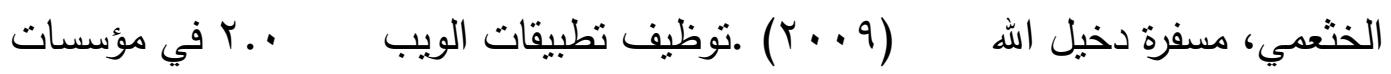

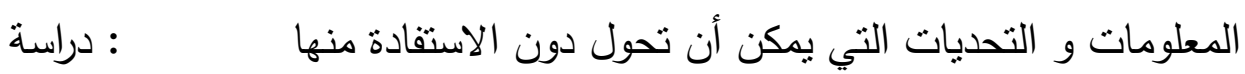

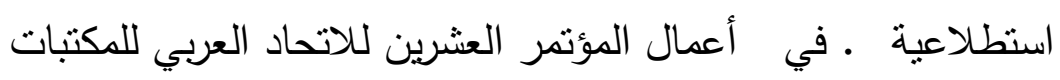

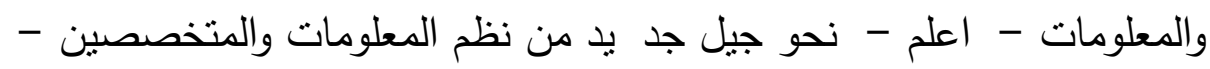

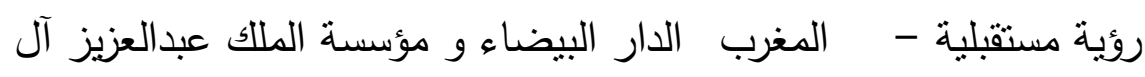

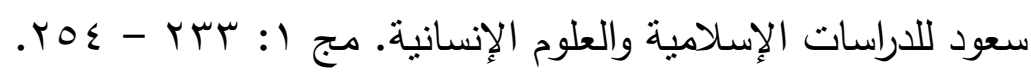

الرحيلي، تغريد عبدالفتاح محمد (؟ ( ب) .اتجاهات طالبات جامعة طيبة نحو استخدام

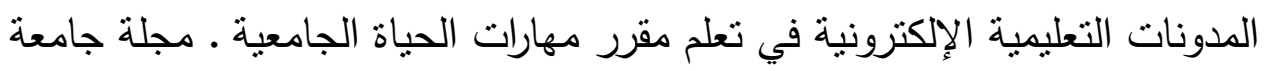

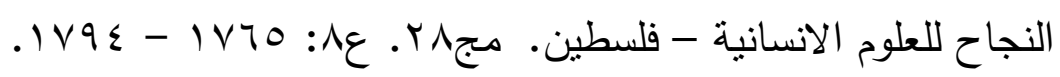




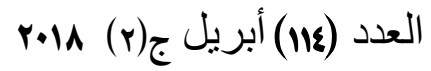

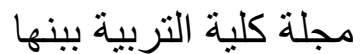

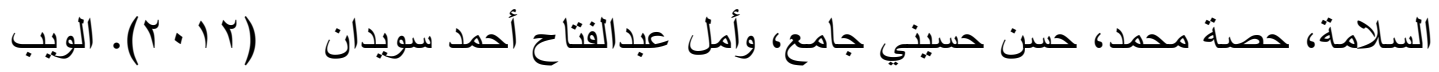

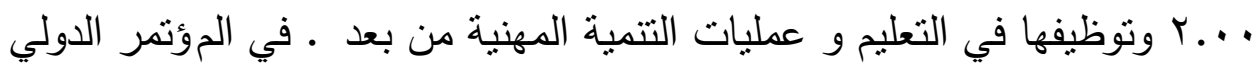

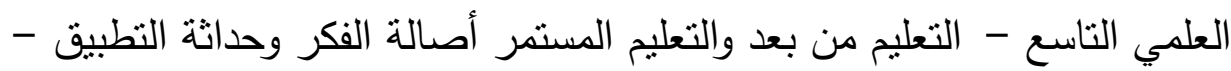

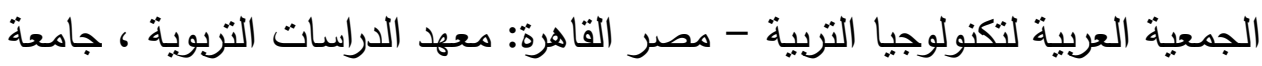

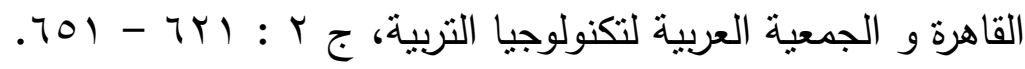

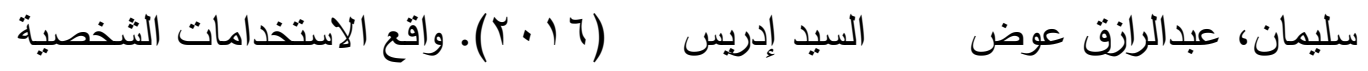

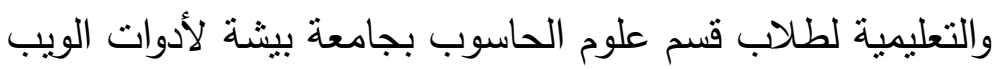

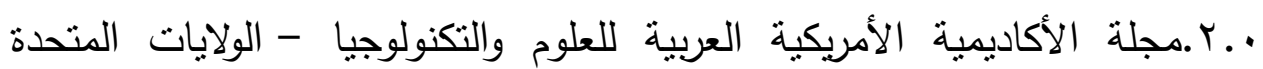

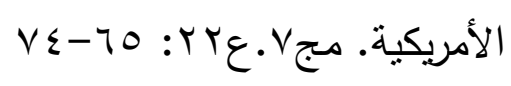

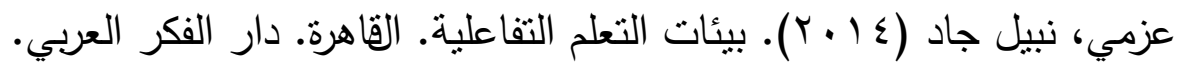

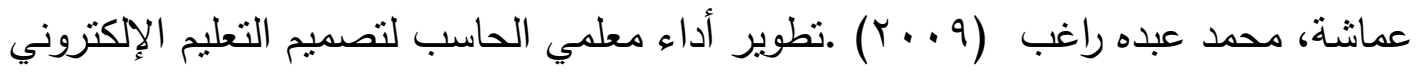

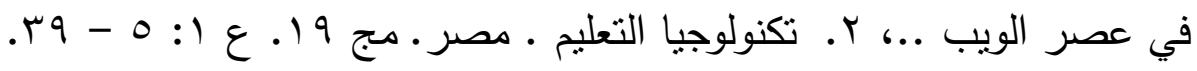

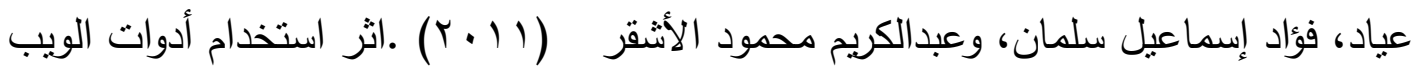

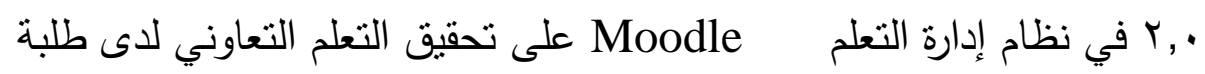

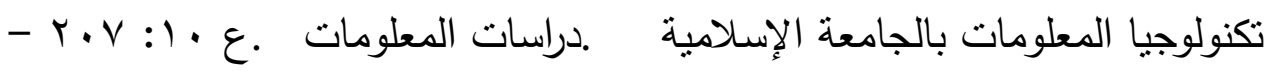
$. r \leqslant$

العيسائي، هدى سالم سعيد، و بشرى سيف محمد الحضرمي (9 . . ب) .واقع استخدام تطبيقات

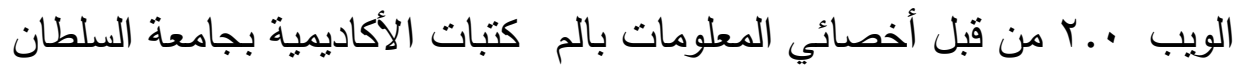

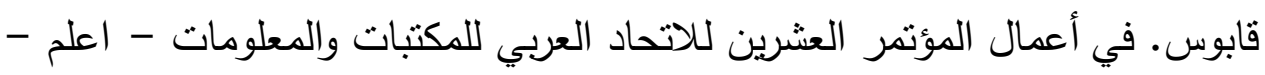

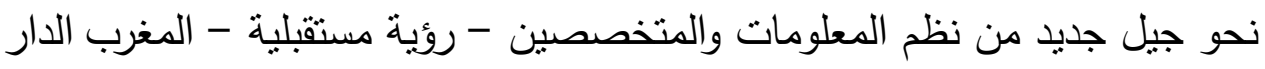
البيضاء: الاتحاد العربي للمكتبات والمعلومات " اعلم " و وزارة الثقافة ، المغرب و

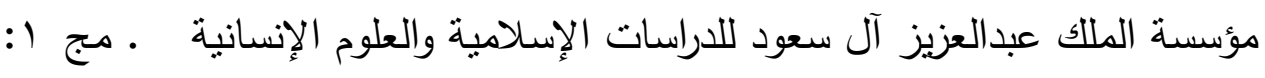
.rVq - roo

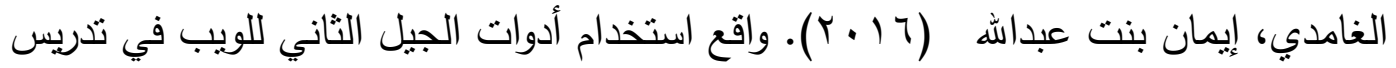

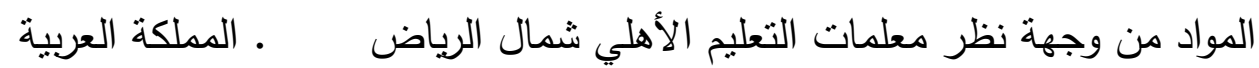




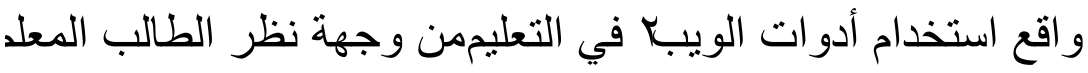
في ضو ضوء بعض المتغير الب المط

السعودية. المجلة العربية للعلوم ونشر الأبحاث .مؤسسة المجلة العربية للعلوم

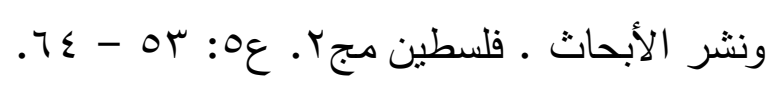

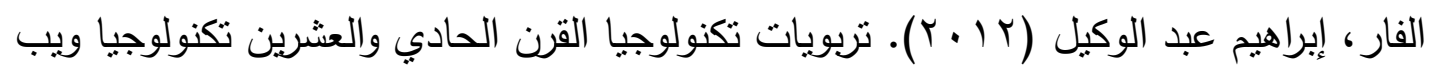

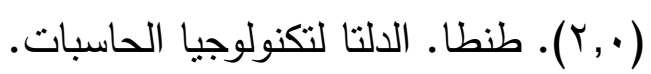

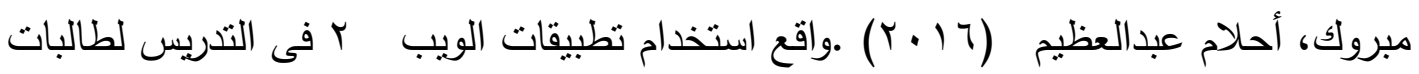

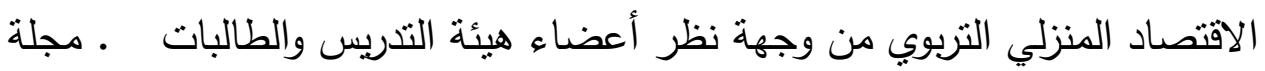

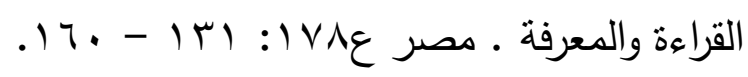

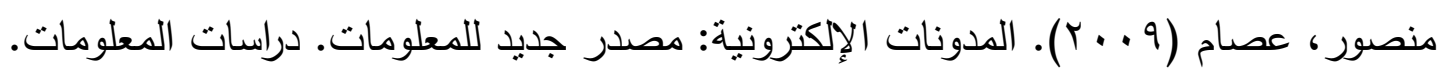

$$
91-90:(0)
$$

المنهراوي، داليا محمد نبيل نوفيق السيد (10 • ب) .اتجاهات طالبات دبلوم إدارة مصادر التعلم

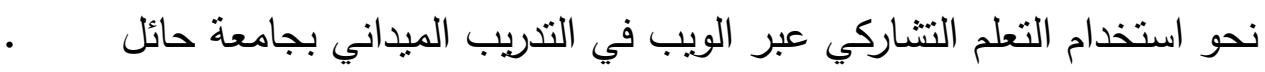

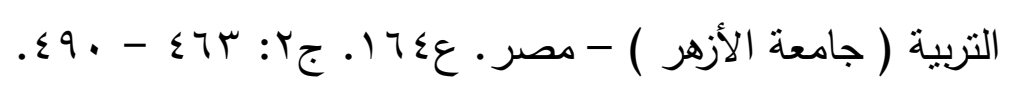

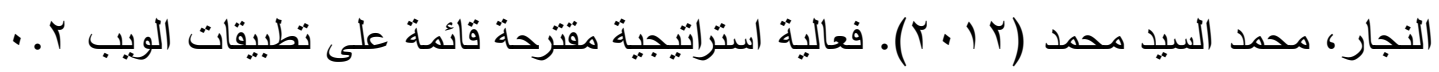

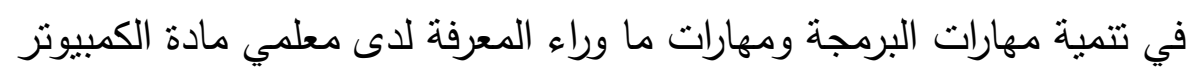

بالحلقة الإعدادية. رسالة دكتوراه، معهد البحوث والدراسات التهاء التربوية. جامعة القاهرة.

Alhayek, H. (2007). New Social Network on Web 2.0. Retrieved Juley 16, 2014, from http://informatics.gov.sa/old/details.php?id=176

Ali ،Maha Mohamed Uqail Sayed, Fayiz Munsher Al Dhafeeri. (2014).

Web 2.0 Technologeies Usage in Kuwaiti Academic Liberaies. http://search.mandumah.com/Record/812749

An,Y., Ballard,G. \& Williams,K.(2011). Teaching with Web 2.0 Technologies: Benefits, Barriers and Best Practices. http://www.aect.org/pdf/proceedings09/2009/09_1.pdf

Chiang,T., Liu,E.,Chen,S., Shih,R.(2011) Using Web 2.0 Social Networking to Enhance Collaborative Learning in Preparing Graduation Events. International Conference on Technologies for E-Learning and Digital Entertainment.6th International 


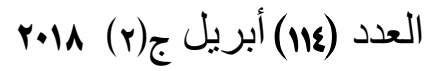

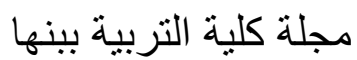

Conference on E-learning and Games, Edutainment, Taipei, Taiwan.

Crook,C., Harrison,C.(2010). Web 2.0 Technologies for Learning at Key Stages 3 and 4. http://www.becta.org.uk

Darwish,A. (2011). The Impact of the New Web 2.0 Technologies in Communication, Development, and Revolutions of Societies JOURNAL OF ADVANCES IN INFORMATION TECHNOLOGY, VOL. 2, NO. 4

Downes,S., (2005) .Feature: E-learning 2.0 . E learn magazine, http://elearnmag.acm.org/featured.cfm?aid=1104968

Eecke ,P., Truyens, M. (2010).Privacy and social networks, Elsevier, computer law \&securityreview 26, 53e546.

Ellison, N .2007) :Social network sites Definition, history , and scholarship .of comuter-Mediated Communication , 13( 1),210-230.

James B \& .Yowell, c. (2009). Leadership for Web 2.0 in EducationPromise \& Reality. Retrieved From: http://www.cosn.org/Portals/7/docs/Web\%202.0/

Light,D.(2011). Integrating Web 2.0 tools into the classroom: Changing the culture of learning. EDC Center for Children and Technology New York,NY

Nagy,J.,Bigum,C.(2007) Bounded and unbounded knowledge: teaching and learning in a web 2.00 world. Journal of distance education. Vol.8.No.3.pp76-86

Sayed, O. H. (2011). Web 2.0 Technology-Based Differentiated Instruction: Are EFL University Teachers Implementing it. http://search.mandumah.com/Record/680476

Zorko, V. (2009).Factors affecting the way students collaborate in a Wikis for English language learning. Australasian Journal of Educational Technology , 25(5), 645-665. 


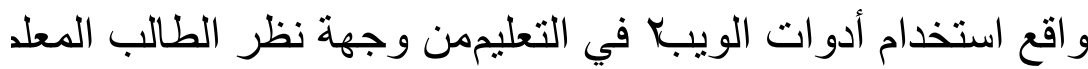

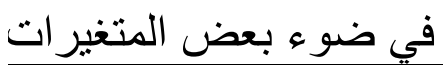

\section{Abstract}

The study aimed to identify the reality of the use of Web 2.0 tools in the educational process from the point of view of the student teacher at Qassim University in light of the variables; specialization and the number of training courses in computer field. The study sample consisted of (215) students. All of which are Educational school students enrolled in course; Introduction to Computers, Education Communication and Technology, and Production and use of teaching aids, in the first semester of the academic year 1438/1439 AH.

To reveal the reality of Web 2.0 tools use in education, a (49) phrases questionnaire was prepared. The (49) phrases were distributed on four topics; the use of Wikis, the use of blogs, the use of social networks, and obstacles to the use of Web 2.0 tools in the educational process. The statistical efficiency of the questionnaire was confirmed through; the Pearson Correlation Coefficient to ensure internal consistency and the Cronbach's alpha stability factor to ensure stability. To analyze the results of the study, Mean and Standard Deviations were used to identify the reality and constraints of the use of Web 2.0 tools in the educational process. One way ANOVA analysis was used to detect the significance of differences in students' responses to the reality and constraints of the use of Web 2.0 tools in the educational process due to variables in specialization and number of courses. In addition, the LSD test for multiple comparisons was used in the case of the significance of the One way ANOVA analysis.

The results of the study showed that the reality of the use of Web 2.0 tools in the educational process as a whole was achieved at a medium degree. The obstacles to the use of Web 2.0 tools in the educational process (the obstacles as a whole) were medium. The study also revealed that there were statistically significant differences in students' responses on the use of Wikis and blogs due to differences in specialization and the number of training courses. In addition, there were no statistically significant differences in students' responses on the reality of the use of Web 2.0 tools due differences in specialization and the number of training courses. Moreover, there were no statistically significant differences in students' responses on the obstacles to using Web 2.0 tools in the educational process due differences in specialization and the number of training courses.

Key words: (Web 2.0, Web 2.0 tools). 